San Jose State University

SJSU ScholarWorks

Master's Theses

Master's Theses and Graduate Research

Spring 2015

\title{
Longitudinal Distribution and Summer Diurnal Microhabitat Use of California Red-Legged Frogs (Rana draytonii) in Coastal Waddell Creek
}

Neil Keung

San Jose State University

Follow this and additional works at: https://scholarworks.sjsu.edu/etd_theses

\section{Recommended Citation}

Keung, Neil, "Longitudinal Distribution and Summer Diurnal Microhabitat Use of California Red-Legged Frogs (Rana draytonii) in Coastal Waddell Creek" (2015). Master's Theses. 4547.

DOI: https://doi.org/10.31979/etd.e7g8-uwah

https://scholarworks.sjsu.edu/etd_theses/4547

This Thesis is brought to you for free and open access by the Master's Theses and Graduate Research at SJSU ScholarWorks. It has been accepted for inclusion in Master's Theses by an authorized administrator of SJSU ScholarWorks. For more information, please contact scholarworks@sjsu.edu. 


\title{
LONGITUDINAL DISTRIBUTION AND SUMMER DIURNAL MICROHABITAT USE OF CALIFORNIA RED-LEGGED FROGS (Rana draytonii) IN COASTAL WADDELL CREEK
}

\author{
A Thesis \\ Presented to \\ The Faculty of the Department of Biological Sciences \\ San José State University \\ In Partial Fulfillment \\ of the Requirements for the Degree \\ Master of Science
}

by

Neil C. Keung

May 2015 
(C) 2015

Neil C. Keung

ALL RIGHTS RESERVED 
The Designated Thesis Committee Approves the Thesis Titled

\section{LONGITUDINAL DISTRIBUTION AND SUMMER DIURNAL MICROHABITAT USE OF CALIFORNIA RED-LEGGED FROGS (Rana draytonii) IN COASTAL WADDELL CREEK}

by

Neil C. Keung

APPROVED FOR THE DEPARTMENT OF BIOLOGICAL SCIENCES

SAN JOSÉ STATE UNIVERSITY

May 2015

Dr. Jerry J. Smith

Department of Biological Sciences

Dr. Paula Messina

Geology Department

Stephanie Trewhitt

Department of Biological Sciences 


\begin{abstract}
LONGITUDINAL DISTRIBUTION AND SUMMER DIURNAL MICROHABITAT USE OF CALIFORNIA RED-LEGGED FROGS (Rana draytonii) IN COASTAL WADDELL CREEK
\end{abstract}

\author{
by Neil C. Keung
}

Habitat use by federally threatened California Red-Legged Frogs (CRLF; Rana draytonii) is incompletely understood. I captured, PIT-tagged, and radio-tracked CRLFs $(n=20)$ at Waddell Creek, Santa Cruz County, from July-December 2012. Limited tracking for movements was also conducted in 2013. Frogs were clumped in deep, complex habitats along the stream within $2 \mathrm{~km}$ of breeding ponds near the stream mouth, but most adults were concentrated in the lagoon. Marked and tracked frogs had very small summer home ranges, and most returned to the same home range after breeding. Frogs tended to use good aquatic (e.g., wood, undercut banks, dense willows) and bank cover (e.g., ground vegetation, wood) at all times but used open habitats more at night than during the day. Visual night surveys were biased against cryptic frogs compared to radio-tracking results. Early fall rains increased upland habitat use, but later heavy winter rains were needed to trigger migration to breeding sites and subsequent breeding. Site-specific studies using radio-tracking are needed to design protections for breeding, migration, and nonbreeding habitats. 


\section{ACKNOWLEDGEMENTS}

This work is dedicated to my family and their unwavering support, but especially to my mother, Carol, who intimately understands what it's like to have a son who spends most of his time dreaming. Even during my own brief moments of self-doubt, she never once doubted that I would complete my thesis. She is living proof that one woman, through her joyful love of life and family, and the calm grace of strength devoid of hate, can inspire all who know her with the nobility of the human spirit.

Regrettably, I am uncertain in my ability to truly convey just how appreciative I am of Jerry Smith, a man of inspirational intellect, integrity, wit, and generosity... and a friend who is always there for me. Much of the biologist I am today is largely a direct result of his careful instruction and boundless patience.

I transferred to San José State University in 2008, and I will always think fondly of my time as a student. I thank all the talented professors for unabashedly fueling my curiosity of the natural world, and for answering all my questions, no matter how silly, in this pursuit. I especially thank Stephanie Trewhitt, Paula Messina, Luis Bonachea, and Carole Ann Foster for their guidance and assistance throughout this project, but especially for their continued support, friendship, and mentorship.

The notion of clambering over logjams waist-deep in water at the darkest of hours is enough to deter most, but I thank Joie de Leon, Dan Corral, Steve Davison, Justin Morgan, Melissa Ainsworth, Michael Na Huynh, Jared Taylor, Sarah Harris, Stephen Anderson, Adam Remmel, Brian Liu, Clayton Leal, Brittany Sanchez, Timothy Walker, Rohaum Raji, and Kenny Mann for risking life and limb in the name of science. 
Finally, I thank Anne Briggs, State Parks, as well as the Waddell Creek Association, for allowing me to trespass at odd hours late into the night. This project would not have been possible without their understanding.

The research was graciously supported by the Marianna Pisano Scholarship, the Arthur and Karin Nelson Scholarship, and the Michael Lee Environmental Foundation Scholarship for Biodiversity Conservation.

Additional research on California Red-Legged Frogs is needed in order to successfully recover this sensitive species in decline. My hope is that the findings from this thesis will aid conservation land managers and all future researchers of Rana draytonii.

"A civilization which destroys what little remains of the wild, the spare, the original, is cutting itself off from its origins and betraying the principles of civilization itself."

-Edward Abbey 


\section{Table of Contents}

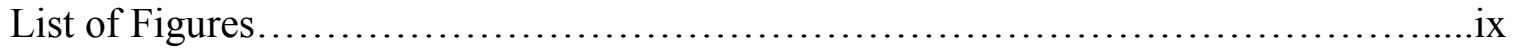

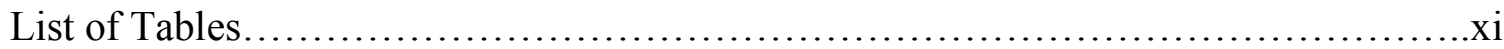

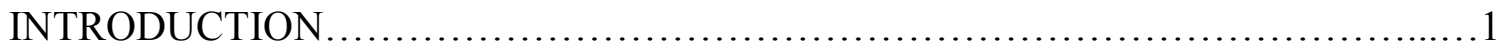

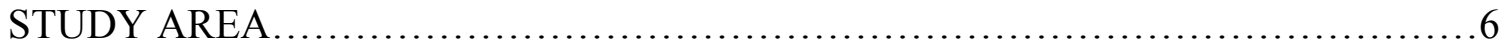

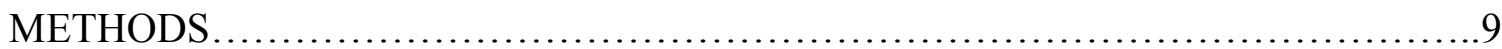

Temperature and Weather.........................................9

Longitudinal Distribution............................................. 10

Stream Surveys for Frogs............................................ 10

Lagoon Surveys.................................................. 12

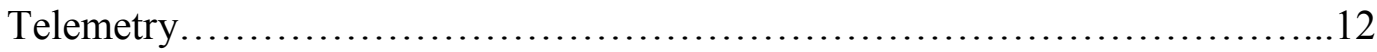

Habitat Characterization.................................................. 16

Data Analysis..................................................... 18

RESULTS.............................................................. 18

Air and Water Temperature.............................................. 18

Longitudinal Frog Distribution Pattern...................................20

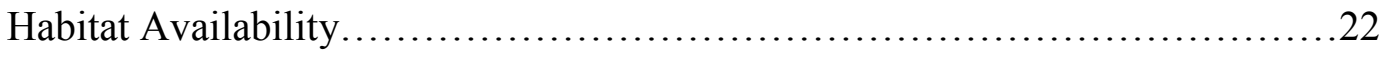

Instream Movements.................................................25

Habitat Use...................................................... 26

Daytime versus nighttime habitat use by transmittered frogs.............26

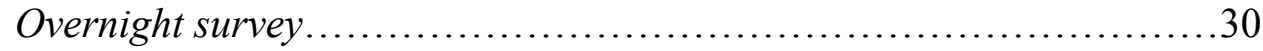

Habitat use by non-transmittered frogs........................... 31

Early upland forays in response to rain................................. 32

Breeding Migration................................................... 34

Year-to-Year Site Fidelity Along the Stream............................. 37

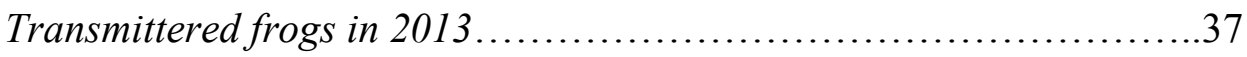

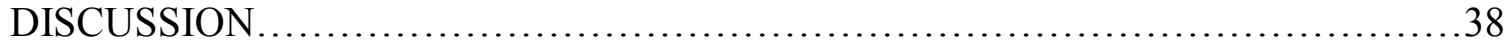

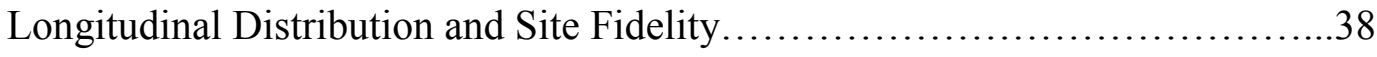

Habitat Use........................................................ 40 
Daytime habitat use.........................................40

Nighttime habitat use ...........................................41

Terrestrial habitat use during rain ..................................42

Breeding Movements.............................................43

Management Implications..............................................45

REFERENCES..............................................................47

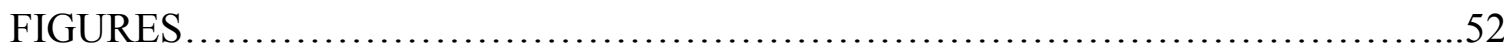

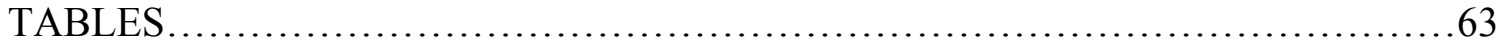




\section{List of Figures}

FIGURE 1. Study site of California Red-Legged Frogs (Rana draytonii) at Waddell Creek in and adjacent to Big Basin Redwoods State Park, Santa Cruz County, California. The two park bridges are shown, as well as the park footbridge located at stream marker 46 along The Marsh Trail. Shown above are the major $(30.5 \mathrm{~m})$ markers between reaches, represented by ( $)$. Also shown is the location of Alder Camp (top right), relative to the main study site..............53

FIGURE 2. Waddell Creek air temperatures near the (a) first park bridge (stream marker 61) and (b) second park bridge (stream marker 96) from July-December 2012. The two temperature drops in November were associated with heavy rain events

FIGURE 3. Waddell Creek air temperatures in afternoon and evening (14:00-21:00) near the (a) first park bridge (stream marker 61) and (b) second park bridge (stream

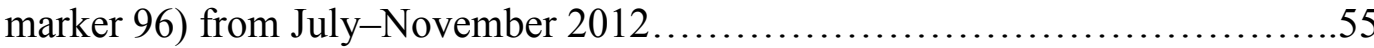

FIGURE 4. Waddell Creek water temperature from July-December 2012 from near the first park bridge (stream marker 61). The temperature drops in November and December were associated with rain events.................................56

FIGURE 5. Individual captures showing longitudinal distribution of California RedLegged Frogs at first capture along Waddell Creek and lagoon from July-early November $2012(n=64)$ and $2013(n=64)$. Reaches are separated by lines, and locations of major logjams and bridges are shown. Distance between each stream marker was 30.5 meters. F represents females; M represents males; f or $\mathrm{m}$ represents frogs with unknown sex at first capture but sexed in late summer or fall; U represents frogs of unknown sex. Frogs that received radio-transmitters in 2012 and 2013 are underlined and italicized; transmittered frogs from 2012 that were recaptured in 2013 are bolded

FIGURE 6. Range, mean, and standard deviations for snout-vent lengths ( $\mathrm{mm}$ ) of initial captured male, female, and undetermined yearling California Red-Legged Frogs in the lagoon (dark dotted bars) and stream (white bars) at Waddell Creek from July-November (a) 2012 and (b) 2013 
FIGURE 7. Instream home range sizes of transmittered California Red-Legged Frogs $(\mathrm{n}=20)$ throughout Waddell Creek from July-November 2012 (prior to breeding movements). Black bars represent frogs with shallow habitats at upper extent of home ranges; white bars represent frogs that moved through shallow habitat within their summer range and used more than one home range during the tracking period......................................................5

FIGURE 8. Instream daily movements of transmittered California Red-Legged Frogs $(\mathrm{n}=16)$ along Waddell Creek from July-November 2012. Black bars represent daily movements from July through August; white bars represent daily movements from September through November. Frog 073 had a summertime movement of $24.8 \mathrm{~m}$. Frogs are arranged from downstream (left) to upstream (right)

FIGURE 9. Daytime (white bars) and nighttime (black bars) positions of (a) transmittered and (b) non-transmittered visually-located frogs during the non-rainy season from July-early November 2012. Aquatic out of water refers to frogs perched on structures within the stream.

FIGURE 10. Cover-types of nighttime aquatic and bank locations of all non-transmittered California Red-Legged Frogs (including repeat encounters and non-captures; $\mathrm{n}=204$ ) along Waddell Creek and lagoon from July-November 2012. No aquatic frogs were located in open water away from cover.

FIGURE 11. Breeding migration timing of transmittered frogs along Waddell Creek during precipitation events (bars; NOAA Record of Climatological Observations 2013) in November and December 2012. Triangles with frog identifier indicate dates of breeding migration initiation..................................61

FIGURE 12. Distance differences of (a) transmittered and (b) non-transmittered California Red-Legged Frogs to precise locations along Waddell Creek between 2012 and 2013, confirmed by subsequent recaptures of individuals in summer of 2013. Black bars represent frogs captured in 2013 downstream of 2012 locations; white bars represent frogs captured upstream. Five non-transmittered frogs were captured in 2013 over $100 \mathrm{~m}$ downstream (199, 567, 701, 866, $1759 \mathrm{~m}$; black bar) of their 2012 locations and one frog was captured upstream (236 m; white bar) 


\section{List of Tables}

TABLE 1. Percent available bank ( $\leq 0.8 \mathrm{~m}$ from shore) and aquatic cover from the transect along Waddell Creek upstream of the lagoon. Values were used to compare frog habitat use in 2012. Eleven frogs were captured downstream of stream marker 46

TABLE 2. Percent available upland cover (at and beyond the top of the bank) from the transect along Waddell Creek...........................................665

TABLE 3. Additional habitat characteristics available in (a) aquatic and bank (to the top of the bank) and (b) upland (at and beyond the top of the bank) habitat throughout Waddell Creek. Shown below are means with standard deviations in parentheses. Cover Quality and Basking Quality $(1=$ very poor; $2=$ poor; $3=$ fair; $4=$ good; $5=$ very good $)$, and Basking Potential $(1=15-30 \mathrm{~min} ; 2=30 \mathrm{~min}-2 \mathrm{~h} ; 3=4+\mathrm{h})$ are ratings based on field observations. Escape Water Depth is the depth of water $0.6 \mathrm{~m}$ out from shore, the distance a frog can cover when jumping from an inclined position. Boxes indicate habitat values substantially different from entire stream

TABLE 4. Summary of percent use during daytime of aquatic and bank (to the top of the bank) cover-types within $0.8 \mathrm{~m}$ radius of each transmittered frog between Julyearly November 2012. For each frog, the most used microhabitat feature is bolded and boxed; the second most used microhabitat feature is bolded and underlined; the third most used microhabitat feature is underlined. Cover Quality and Basking Quality ( 1 = very poor; 2 = poor; 3 = fair; 4 = good; $5=$ very good) are ratings based on field observations. Standard deviations for Cover and Basking Ratings are shown in parentheses. One frog with fewer than five observations was excluded from the table....

TABLE 5. Summary of percent use during nighttime of aquatic and bank (to the top of the bank) cover-types within $0.8 \mathrm{~m}$ radius of each transmittered frog between July-early November 2012. For each frog, the most used microhabitat feature is bolded and boxed; the second most used microhabitat feature is bolded and underlined; the third most used microhabitat feature is underlined. Cover Quality $(1=$ very poor; 2 = poor; $3=$ fair; $4=$ good; $5=$ very good $)$ are ratings based on field observations. Standard deviation for Cover Rating is shown in parentheses. Two frogs with fewer than five observations were excluded from the table......68 
TABLE 6. Summary of use during daytime of additional habitat characteristics of each transmittered frog between July-early November 2012. Means and medians are shown with standard deviations and interquartile ranges in parentheses. Two frogs with fewer than five observations were excluded from the table

TABLE 7. Summary of use during nighttime of additional habitat characteristics of each transmittered frog and totals for all non-transmittered frogs (bottom) between July-early November 2012. Means and medians are shown with standard deviations and interquartile ranges in parentheses. Two frogs with fewer than five observations were excluded from the table.

TABLE 8. Summary of percent use during daytime of upland (beyond the top of the bank), farther than $4.5 \mathrm{~m}$ from stream, cover-types within $0.8 \mathrm{~m}$ radius of each transmittered frog during rain events in late October to mid-December 2012. For each frog, the most used microhabitat feature is bolded and boxed; the second most used microhabitat feature is bolded and underlined; the third most used microhabitat feature is underlined....................................... 71

TABLE 9. Summary of percent use during nighttime of upland (beyond the top of the bank), farther than $4.5 \mathrm{~m}$ from stream, cover-types within $0.8 \mathrm{~m}$ radius of each transmittered frog during rain events in late October to mid-December 2012. For each frog, the most used microhabitat feature is bolded and boxed; the second most used microhabitat feature is bolded and underlined; the third most used microhabitat feature is underlined..............................................72 


\section{INTRODUCTION}

Once abundant throughout much of California, the California Red-Legged Frog (Rana draytonii; CRLF) has been reduced by an estimated $70 \%$ of its former range throughout the state (USFWS 1996). It is now restricted primarily to portions of the Coast Range, from Mendocino County to northwestern Baja California (Jennings and Hayes 1985), and has been federally listed as a threatened species since 24 June 1996 (USFWS 1996). The species, once thought of as one of two subspecies: the CRLF and the Northern Red-Legged Frog (NRLF; Rana aurora aurora), is now considered a distinct species (Shaffer et al. 2004). The NRLF ranges from British Columbia to Northern California (Shaffer et al. 2004) and calls primarily underwater during breeding (Hayes and Miyamoto 1984). In ranges where both taxa overlap, such as in Mendocino County, the two do not interbreed (Shaffer et al. 2004). Habitat alterations (Hayes and Jennings 1986; Allen and Tennant 2000), removal of emergent aquatic vegetation (Hayes and Jennings 1986), change in hydrology from seasonal to permanent ponds (Hayes and Jennings 1986; Adams 2000; Allen and Tennant 2000; Doubledee et al. 2003), invasive fish and amphibian species (Moyle 1973; Hayes and Jennings 1986; USFWS 1996; Lawler et al. 1999; Adams 2000; Allen and Tennant 2000; Doubledee et al. 2003; EBRPD 2007), urban and agricultural development (Allen and Tennant 2000; USFWS 2002) and combinations of these (USFWS 1996; Allen and Tennant 2000; USFWS 2002) have all contributed to the decline of CRLFs.

For populations along the central coast of California, breeding occurs in marshes, ponds, or slower waters of streams from late November to early April (Jennings and 
Hayes 1985; Jennings and Hayes 1994). Generally, males mature in two years and females in three years (Jennings and Hayes 1985), with adult males (78-116 mm snoutvent length; SVL) being smaller than adult females (87-138 mm; Hayes and Miyamoto 1984). Most of the egg deposition occurs in a short period of about two weeks (Cook and Jennings 2007; Alvarez et al. 2013; Smith 2014), and egg masses are attached onto live emergent or unattached vegetation near or at the water surface (Storer 1925; Cook and Jennings 2007; Alvarez et al. 2013). Tadpoles emerge in approximately five weeks, depending on water temperature, and larvae require another four to five months to metamorphose into frogs (Altig and McDiarmid 1999). Timing can vary, but in general, egg hatching and larval development rates increase with increases in temperature (Altig and McDiarmid 1999).

Research has shown that movement (Bulger et al. 2003; EBRPD 2007; Fellers and Kleeman 2007; Tatarian 2008) and breeding activity (Alvarez et al. 2013; Smith 2014) increases with rain, and movements toward breeding sites in other studies occurred during heavy rain events in late fall and winter (Bulger et al. 2003; Fellers and Kleeman 2007). Riparian corridors can be used as migration routes, but most frogs moved overland in relatively straight paths toward breeding sites regardless of terrain or changes in topography (Bulger et al. 2003; Fellers and Kleeman 2007). During overland movements, frogs remained hidden upland in dense ground cover if available (Bulger et al. 2003), but were also capable of moving quickly overnight across exposed grasslands (Bulger et al. 2003; Fellers and Kleeman 2007) or cultivated fields (Bulger et al. 2003). 
Proximity to ponds or slow moving water year-round is important for frogs, and Hayes and Jennings (1988) reported that water with a minimum depth of $0.7 \mathrm{~m}$ was an important habitat characteristic, to allow evasion of predators. In other CRLF studies, most adult frogs did not move much, remaining residents at aquatic sites all year if water was available (Rathbun and Schneider 2001; Bulger et al 2003; EBPRD 2007; Fellers and Kleeman 2007; Tatarian 2008; D'Amore et al. 2009a). Even though frogs moved to terrestrial habitats for foraging or during storms, they always returned to the pond or stream (Rathbun et al. 1993; Bulger et al. 2003; EBRPD 2007; Tatarian 2008). Bulger et al. (2003) and Fellers and Kleeman (2007) found that frogs in ponds with suitable breeding habitats were resident, but stream frogs moved to ponds for breeding. Following breeding, frogs moved to the nearest suitable aquatic nonbreeding habitat, and Bulger et al. (2003) and Fellers and Kleeman (2007) observed that frogs were concentrated along the creek sections nearest the breeding sites; however, they did not track them after they reached an aquatic nonbreeding habitat. Therefore, a better understanding of the use of nonbreeding habitats is needed in order to ensure suitable CRLF habitat throughout the year.

There are few reports of CRLF site fidelity between years, and they discussed site fidelity in a pond environment (Rathbun and Schneider 2001; Tatarian 2008). However, site fidelity on streams, especially between years, has not been examined. When a pond was scheduled for demolition in the Guadalupe Dunes study area along the central coast of California, Rathbun and Schneider (2001) translocated several CRLFs to other nearby ponds. Subsequent recaptures and relocations of the same individuals showed over and 
over that CRLFs, in all age groups, possessed a strong inclination to return to their source pond, even when they were relocated to several different ponds (Rathbun and Schneider 2001). Tatarian (2008) also detected a high degree of site and position fidelity by CRLFs within a pond habitat. In the largest pond with the most frogs with radio-transmitters ("transmittered"), 24 of 49 frogs were observed to use the same positions along the pond edge in almost every daytime telemetry survey, and most frogs that moved away from this source pond always returned (Tatarian 2008).

When not breeding, CRLFs can occupy a wide range of habitats, including grassland (Fellers and Kleeman 2007), riparian woodland and scrubland (Hayes and Jennings 1988; Rathbun et al. 1993; Bulger et al. 2003; EBRPD 2007; Fellers and Kleeman 2007), marshes (Hayes and Jennings 1988; Bulger et al. 2003; Rathbun et al. 2003; EBRPD 2007; Cook and Jennings 2007), and man-made ponds (EBRPD 2007; Fellers and Kleeman 2007; D'Amore et al. 2009a), as well as upland habitats with burrows (EBPRD 2007; Tatarian 2008) or moist understory vegetation (Hayes and Jennings 1988; Rathbun et al. 1993; Bulger et al. 2003; Cook and Jennings 2007; Fellers and Kleeman 2007; Tatarian 2008). Research to investigate nonbreeding habitat use with radio-transmitters is limited and focused mainly on CRLFs in San Luis Obispo County (Rathbun et al. 1993), Santa Cruz County (Bulger et al. 2003), Marin County (Fellers and Kleeman 2007), and Contra Costa County (Tatarian 2008). Although non-vegetated ponds and streams have been used (EBRPD 2007; Fellers and Kleeman 2007), vegetative cover, and deep, calm water, have been identified as two range-wide habitat features highly associated with CRLF presence (Hayes and Jennings 1988). CRLFs occupying 
stream habitats during the nonbreeding season preferred sunny stream reaches (EBRPD 2007; Fellers and Kleeman 2007) with object cover versus exposed sites (Bulger et al. 2003; Fellers and Kleeman 2007; Tatarian 2008). Vegetative cover was reported to be used most often (Rathbun et al. 1993; Bulger et al. 2003; Fellers and Kleeman 2007; Tatarian 2008; D'Amore et al. 2009a), followed by wood and other object cover (e.g., stones, roots, leaf litter, anthropogenic structures, ground-squirrel burrows). While these studies were extensive, analyses of habitat use were during daytime telemetry and in relation to seasonal habitat changes. Nighttime visual sampling surveys of nocturnal habitat use have been reported (Rathbun et al. 1993; EBRPD 2007; Fellers and Kleeman 2007; D'Amore et al. 2009a); however nighttime telemetry was not involved.

Additional research to gain a better understanding of CRLF ecology, including habitat use and habitat requirements at all times of the year, is needed to develop sitespecific management strategies and ultimately aid in the recovery of the species under the US Endangered Species Act of 1973 (USFWS 2002).

In study areas where the invasive American Bullfrog (Rana catesbeiana) cooccurs, CRLFs are negatively affected at all life stages (Hayes and Jennings 1986; Kiesecker and Blaustein 1997; Doubledee et al. 2003; Pearl et al. 2005; EBRPD 2007; D'Amore et al. 2009a; D'Amore et al. 2009b). The Bullfrog's high rates of reproduction and large body size have allowed this species to be the dominant frog in many lowelevation habitats, especially those altered by human disturbance (Moyle 1973). Besides predation, Bullfrogs can also interfere with CRLF breeding since many CRLF males were unable to differentiate between female CRLF adults and sub-adult Bullfrogs due to 
a similarity in body sizes (Storm 1952; Pearl et al. 2005; D’Amore et al. 2009b). Cook and Jennings (2007) reported some overlap between CRLFs and Bullfrogs in habitat use within an ephemeral marsh during spring and summer, but other studies have found that habitat partitioning was common between the two species, with CRLFs using denser hiding cover in the presence of Bullfrogs (D'Amore et al. 2009a). After Bullfrog removal efforts, D’Amore et al. (2009a) detected a shift in pond microhabitat use by CRLFs from dense cover of tules and willows to sparser tules and bare shore.

In this study, I examined the longitudinal summer distribution of CRLFs in a central coast watershed that lacks Bullfrogs and has available, but less intensive, data for CRLFs for the last 14 years (Smith 2014). I tracked summer movement of radiotransmittered frogs and summer site fidelity between the two years (2012-2013). I also looked at daytime versus nighttime microhabitat use of radio-transmittered frogs and habitat shifts in response to fall rains. When early fall rains in 2012 triggered movement toward breeding ponds, I also followed those movements to determine whether all mature frogs migrated, their speed of individual frog movement, and to which of two possible breeding sites they moved.

\section{STUDY AREA}

The study was conducted in the Waddell Creek watershed located in Santa Cruz County, California, approximately $76 \mathrm{~km}$ south of San Francisco (Figure 1). Much of the watershed is within Big Basin Redwoods State Park, but portions, including the east bank of the stream within the study area, are privately owned. The climate is Mediterranean, with a mean annual precipitation of $108 \mathrm{~cm}$, mostly occurring in December, January, and 
February (NOAA Watershed Characterization 2008). Air temperatures range from $11.6^{\circ} \mathrm{C}$ to $40.0^{\circ} \mathrm{C}$ in summertime and $7.8^{\circ} \mathrm{C}$ to $18.9^{\circ} \mathrm{C}$ in wintertime (Big Creek Road weather station, Davenport, CA). Coastal fog rolls inland and cloaks the lagoon and lowermost Waddell Creek on many mornings and nights throughout spring and summer.

From its source in the Santa Cruz Mountains, small tributaries combine to form the east and west branches, which join to form the mainstem of Waddell Creek. There is approximately $19 \mathrm{~km}$ of stream length from source to mouth. The mainstem consists of the lower $7 \mathrm{~km}$. The Waddell Creek Watershed occupies approximately 6,215 hectares (NOAA Watershed Characterization 2008). The upper watershed is steep and intercepts Pacific storms, so stream levels and flows rise dramatically during large rain events that last more than a few days, with the potential to significantly alter stream habitat and riparian landscape yearly. During the course of this study, increases in stream stages of up to $1.5 \mathrm{~m}$ were observed during telemetry surveys two to three days following significant rains events. Summertime flows were less than $0.03 \mathrm{~m}^{3} / \mathrm{s}\left(1 \mathrm{ft}^{3} / \mathrm{s}\right)$. In late spring through fall, Waddell Creek downstream of the forks is essentially a series of long, calm pools separated by short riffles or longer shallow runs.

Waddell Creek is a perennial stream that terminates in a small estuary. As with many of Central California's coastal streams, a full or partial sandbar forms at the mouth in late spring through summer when runoff from winter rains begin to decline, but timing can vary greatly depending on stream flow and tidal deposition of sediment. Once formed, the lagoon behind the sandbar can increase $1 \mathrm{~m}$ in depth and water levels increase to more than $2 \mathrm{~m}$. Highway 1 passes directly over the lagoon where Waddell 
Beach begins, and the impounded lagoon extends upstream approximately 0.8 to $1.2 \mathrm{~km}$, depending upon whether the sandbar is partially or fully closed.

Two breeding ponds are utilized by CRLFs near the Waddell Creek lagoon. The seasonal breeding pond is located approximately $170 \mathrm{~m}$ west of the lagoon. It is a dry depression in the marsh for four to eight months, and is filled by winter rains, depending on rainfall amount and timing. Cattails (Typha spp.) are abundant in the pond, and the shallow edges are dominated by salt rush (Juncus lesuerii). The seasonal pond can reach approximately $0.6-0.9 \mathrm{~m}$ deep, but because of wide year to year differences in the timing of filling and duration of water retention, frogs do not successfully breed here every year (Smith 2014). The permanent breeding pond is $100 \mathrm{~m}$ east of the lagoon. It is nearly filled by a shoreline ring of California bulrush (Schoenoplectus californicus) and a dense ( $0.25 \mathrm{~m}$ thick) floating mat of California bulrush over water up to $1.3 \mathrm{~m}$ deep. Although CRLFs breed at the permanent pond, the floating tule mat prevents significant sampling for frogs and frog breeding success.

Lower Waddell Creek was logged for redwoods from the 1860s to the 1950s, and several residences and agricultural fields are scattered throughout the lower valley within the study area. Riparian zones along the majority of mainstem Waddell Creek were welldefined with a dense canopy, and stream edges and flood plain were comprised of white alder (Alnus rhombifolia) and willows (Salix spp.) along the majority of mainstem Waddell Creek. Coast redwoods (Sequoia sempervirens), box-elder (Acer negundo), bigleaf maple (Acer macrophyllum), and black cottonwood (Populus trichocarpa) were also present. Riparian ground cover consisted largely of trailing blackberry (Rubus ursinus), 
cape ivy (Delairea odorata), poison-oak (Toxicodendron diversilobum), and stinging nettle (Urtica dioica). Patches of watercress (Nasturtium officinale) occurred in some unshaded stream sections.

The uplands along Waddell Creek that are not farmed were dominated by a mixed evergreen forest of coast redwoods, Douglas fir (Pseudotsuga menziesii), Monterey Pine (Pinus radiata), and tan-oak (Lithocarpus densiflorus), interspersed with coast live oak (Quercas agrifolia), California buckeye (Aesculus californica), Pacific madrone (Arbutus menziesii), and California bay (Umbellularia californica). Understory was mostly poison-oak and trailing blackberry. Coastal scrub species such as coyote brush (Baccharis pilularis), sticky monkey flower(Mimulus aurantiacus), and poison-oak were also found on drier slopes, including above the road west of the lagoon.

\section{METHODS}

\section{Temperature and Weather}

Temperature loggers (Onset HOBO Pro V2 Data loggers) were placed at the following locations: a water logger was placed near the first park bridge at stream marker (SM) 63; an air logger was placed in the shade near the water logger; and a second air logger was placed in dense shade near the second park bridge. The loggers were programmed to record temperatures at 15 min intervals.

In addition, stream air and water temperatures were recorded at the start of each survey, and whenever habitat data were recorded, using two identical pocket thermometers $\left(-5^{\circ} \mathrm{C}\right.$ to $50^{\circ} \mathrm{C}$ in $0.5^{\circ} \mathrm{C}$ increments $)$. Rainfall data were obtained from 
NOAA's online public database for Santa Cruz (NOAA Record of Climatological Observations 2013).

\section{Longitudinal Distribution}

To examine longitudinal summer distribution of frogs along the stream, relative positions were determined for every observed frog throughout the study. Bright orange vinyl flagging and numbered aluminum tags with reflective tape were installed every $30.5 \mathrm{~m}$ of stream channel, as determined with a hip-chain. The reflective tags were highly visible when spotlighted during night surveys. The downstream SM 24 was at the downstream limit of willows in the lagoon area. SM 124 was upstream at Alder Campgrounds, but because frogs declined upstream, most surveys stopped upstream near SM 97.

Relatively precise frog locations (within 1-2 m) were estimated by comparison with locations of the nearest upstream and downstream SMs. Left or right bank or midchannel positions of the frog were also recorded. In addition, major instream structures such as logs and logjams were used as reliable reference points to describe frog locations. Positions were estimated in units of feet and later converted to meters, because distances in feet could be estimated more precisely.

\section{Stream Surveys for Frogs}

Stream surveys were conducted beginning in July 2012 when past experience (J. Smith, pers. comm. 2011) indicated that within-stream movements were relatively small. Surveys continued through November 2012 and again in May-September 2013. With an assistant, CRLFs along the stream were located by eye-shine and captured with hands or 
a small hand-net during night surveys. To maximize spotlighting and capture efficiency, one person led and spotlighted (LED headlamp, up to 100 lumens) for frogs while the trailing person spotlighted behind and to the sides for frogs that may have been passed. Often, vegetation or stream structures obscured eye-shine for the lead person. Captured frogs were handled with wet hands, measured for snout-to-vent length, and weighed to the nearest gram with a Pesola spring-scale. Sex was determined based upon the presence of nuptial pads located on the thumbs of mature males. Frogs with SVL $\geq 75$ $\mathrm{mm}$ without nuptial pads by late summer were assigned as females, while frogs with SVL $<75 \mathrm{~mm}$ could not be sexed accurately. Passive Integrated Transponder (PIT) tags (12.5 $\mathrm{mm}, 125$ or $134 \mathrm{kHz}$ ) were inserted through a small incision made with toe-nail clippers in the skin of the back with a plunger-in-needle syringe (Biomark MK7 Implanter). The PIT-tag was then gently repositioned with fingers above the urostyle as a stable position. Lastly, the unwebbed portion of the longest toe on the right hind-leg was removed with scissors to indicate that the frog had been previously caught and PIT-tagged. All equipment and tools were disinfected with 70\% isopropyl alcohol between each use to minimize risk of infection (upon subsequent captures, all frogs were healing or had healed). Frogs were released at the location of capture.

Stream surveys were conducted with alternating upstream and downstream starting and ending locations to minimize sampling bias, as frog activity declined with decreasing air temperatures after dark. Repeated surveys were conducted one to four times per week, including telemetry surveys. Few unmarked frogs were captured late in 
summer 2012, most stream frogs had been captured, and many frogs had been captured multiple times.

\section{Lagoon Surveys}

Night surveys in the impounded lagoon (lower $850 \mathrm{~m}$ of the sample area) were conducted four times in 2012 between September to early November, and required a boat once rising water depth precluded wading. One person maneuvered the boat and scanned one bank for eye-shine while the other person scanned the opposite bank. Detected frogs were directly approached and caught with hands or a small hand-net. Captured frogs were processed as previously described. Lagoon surveys began and ended approximately $50 \mathrm{~m}$ upstream of the Highway 1 bridge. A staff gage on the bridge abutment was inspected before every survey to track changes in lagoon extent and depth.

\section{Telemetry}

To examine summer movements and to compare daytime versus nighttime habitat use, 18 transmitters were attached to 20 individual CRLFs (13 females, 4 males, and 3 unknowns) in 2012. To minimize injury, radio-transmitters were attached in July, when frogs were presumed to be in good condition after having regained weight lost during breeding. The frogs were tracked from July 2012 to February 2013 or until the batteries on the transmitters were exhausted.

Transmitters were installed on shore adjacent to capture site and immediately following capture. Transmitter attachment followed Rathbun and Murphey (1996). Custom-sized waist belts of aluminum ball chain (size \#3 beads), spray-painted black, were used. Waterproof epoxy was used to connect the radio-transmitter (Holohil Systems 
$L t d$.) to a stainless steel chain connector. Sample belts of different sizes were fitted onto the frog, to check for the proper sizing. A good fit was when the belt was snug over the thighs but not constricting around the waist. Once the proper belt size was determined, a new belt of 30 beads was trimmed down to the desired number of beads. Transmitters were attached with the serial number facing up, allowing a frog to be identified if the serial number was visible, without handling the frog. All frogs were released back at the exact site of capture. The entire process took less than five minutes per frog. Frogs with $\mathrm{SVL} \geq 104 \mathrm{~mm}$ received larger transmitters (model PD-2, whip antenna, $3.2 \mathrm{~g}$ without attachment and with battery life of approximately 26 weeks); smaller frogs received small transmitters (model BD-2, whip antenna, $1.8 \mathrm{~g}$ without attachment and with battery life of approximately 17 weeks).

Belts were checked when frogs were periodically recaptured in order to avoid frog injury or transmitter shedding. A poorly fitting belt was adjusted by removing beads or replacing the chain with a longer one. Even so, some frogs shed belts in summer 2012 and transmitters were installed on two replacement frogs.

In June 2013, five frogs received transmitters; three individuals in this group were frogs previously captured at a more upstream location in 2012. The remaining two frogs were new captures in spring 2013. These five frogs were tracked from June-September 2013. Telemetry work in 2013 was only conducted to investigate summertime locations along the stream for a consecutive year, not for habitat use.

Telemetry work occurred two to four times a week, depending on weather, with a portable radio-receiver (TRX-1000S, Wildlife Materials, Inc.) and a folding 3-element 
Yagi directional antenna. Beginning and ending survey times, air temperatures, water temperatures, direction of travel (upstream or downstream) were noted, as well as other environmental data. When telemetry surveys during heavy rains were conducted, double freezer bags were used to encase the receiver (without the cover), and a small hole was cut to allow attachment of the antenna cable.

Night surveys to acquire positions and habitat of transmittered frogs began at dark and required two people for efficiency and safety: one person performed the telemetry, spotlighted, and captured non-transmittered frogs, while the other person recorded data and carried the field vest with equipment. The survey continued until all transmittered frogs were located, and on one occasion, work continued all night to determine overnight movements of seven frogs, chosen from different segments of the stream. Nighttime telemetry surveys were usually followed up with a daytime survey the next day, to detect night to day movements of frogs.

Daytime telemetry surveys were often conducted alone, and surveys started at approximately 13:00 hours in summer and 12:00 hours in winter to give frogs time to maneuver into their daytime positions as ambient air temperatures warmed. On average, night and day telemetry surveys lasted $4-5 \mathrm{~h}$ each.

Positions of transmittered frogs along the stream and upland were acquired through triangulation and visual sightings. The antenna was oriented vertically for better signal detection, and horizontally for better directionality. The attenuator setting on the receiver was used for short-distance directional tracking when the target frog was within approximately $25 \mathrm{~m}$. Target frogs were not initially approached directly. Instead, usually 
a minimum of three different straight-line bearings were obtained to triangulate a frog's suspected location. For precise locations, a coaxial cable with one end stripped off to reveal internal cable threads was threaded through a sealed PVC pipe and used as a probe (Fellers and Kleeman 2003). This was also useful within dense cover (e.g., logjams) or in poison-oak.

Transmitter radio-signals were acquired from elevated positions whenever possible. This became especially important as transmitter batteries began to weaken in November 2012 when frogs were migrating to their breeding sites. With weak batteries, the receiver often did not pick up any signals from ground-level, but faint signals indicating general directions could be picked up from a raised position. For frogs moving toward the two breeding ponds, signal directions from the access roads west and east of the lagoon, Highway 1 (south), and the elevated Ranger Station (north) were combined to determine general frog locations.

If the signal was fixed at the exact same location for 1 week, an effort was made to locate the frog or the shed transmitter. Shed transmitters in water were recovered with an underwater viewer and the PVC coaxial probe with a magnet attachment. Stopping of the signal indicated that the magnet picked up the transmitter successfully. Five of the transmitters were recovered this way.

The original plan was to remove transmitters in November 2012 prior to battery failure, but early heavy rains triggered movements toward the breeding ponds. A decision was made to leave radio-transmitters on frogs to track breeding movements despite the risk of battery failure. If frogs approached the ponds, or signal irregularity or 
weakness indicated approaching battery failure, a dedicated attempt was made to capture the frog at the breeding pond. Several failed transmitters were removed from frogs captured at the breeding pond through chance encounter between January to March 2013. Otherwise, the waist-belts were likely to be shed on their own as frogs lost weight during breeding.

\section{Habitat Characterization}

All habitat features within a $0.8 \mathrm{~m}$ radius of all observed, captured, or tracked frogs were recorded in three different zones: upland, bank, and aquatic. Bank was defined as the portion of the channel below the bank crest. This was associated with a change in slope and generally was associated with the bankfull height of channel-forming flow (Leopold and Maddock 1953). For upland frogs, defined as frogs at or beyond the bank crest, cover features recorded included percent cover of blackberry, nettle, grass, cape ivy, other low ground cover less than $0.25 \mathrm{~m}$ tall, young trees (willow, elderberry, alder saplings less than $1 \mathrm{~m}$ tall), small woody debris, and large woody debris. For the stream bank, the same cover features were recorded. Aquatic features included logjams, large woody debris, small woody debris, aquatic vegetation, flotsam, undercut bank, roots, live branches, and overhanging vegetation. I also noted whether the frog was in or out of water (i.e., perched on logjam, wood, or tree branches). For bank and upland frogs, bare areas or exposed habitats used by frogs, and additional environmental factors such as slope, distance from water, and water depth $0.6 \mathrm{~m}$ out from the bank were also recorded. The $0.6 \mathrm{~m}$ distance was the approximate distance a frog would reach if jumping into the stream from an inclined bank. 
Daytime surveys included information on canopy directly above target frogs and estimation of how much sunlight a particular location received throughout the day based on observed sun movement patterns for the frog position. Finally, subjective quality ratings from $1-5(5=$ very good; $4=$ good; $3=$ fair; $2=$ poor; $1=$ very poor $)$ were assigned to each frog's site based upon habitat choice for concealment cover (night and day) and basking opportunity (daytime only).

Frog habitat preference was determined by comparing the observed habitats used with all available habitats. Habitat availability transects were conducted along the study area from SM 46 to SM 124 in Waddell Creek. Summertime transects were conducted with data taken at three randomly selected points every $30.5 \mathrm{~m}$. A random number generator (stattrek.com/statistics/random-number-generator.aspx) was used to determine the distance in feet upstream of the nearest downstream marker. Distances in the field were determined by using a measuring tape with units in feet, later converted to meters. At each data location, a habitat profile of upland, bank, and aquatic elements, including slope, canopy cover, and water depth $0.6 \mathrm{~m}$ from the bank, was conducted perpendicular to the stream. Hiding cover within the aquatic and bank zones was assigned percent cover values based upon all available cover within a $0.8 \mathrm{~m}$ radius plot in mid-channel, at left stream edge and right stream edge for aquatic cover, and on the left bank and right bank for bank cover. A $1.2 \times 9 \mathrm{~m}$ wide band was used for assigning available upland cover. Comparable to recording frog habitat use data, ratings from 1 to 5 were also determined at every transect data location for assessing potential daytime basking quality and hiding cover quality for frogs. 


\section{Data Analysis}

IBM SPSS 20 was used to evaluate statistical significance. After dividing the entire stream into continuous reaches, Chi-square goodness of fit was used to compare the habitat features of each reach with those of the entire stream. Significantly $(\alpha=0.05)$ different reaches were then further examined for microhabitat features that differed from microhabitat features available throughout Waddell Creek. Significant values were a result of either one large difference or the combination of multiple small differences between the target reach and habitat availability throughout Waddell. Chi-square tests become less reliable with very small values, so observed microhabitat values 0.04 or smaller were excluded. The results of the habitat availability transects were also compared to the observed habitat features used by transmittered frogs with Chi-square goodness of fit tests. Paired samples t-tests were used to compare lower Waddell air temperatures with upper Waddell, differences in movement rates between summer and fall, and shifts in habitat feature choices between day and night.

\section{RESULTS}

\section{Air and Water Temperature}

Air temperatures were generally similar from July through October with alternating periods of warmer versus cooler, foggy weather (Figure 2). Cooldowns in November and December were associated with significant early rains. Diurnal air temperatures did not differ significantly between the two temperature stations. However, air temperatures at the second park bridge $2 \mathrm{~km}$ inland between 14:00-21:00 (mean = $16.7 \pm 3.8^{\circ} \mathrm{C}$ ) were significantly higher in summer/fall than air temperatures at first park 
bridge $\left(\right.$ mean $=15.5 \pm 3.2^{\circ} \mathrm{C} ;$ Wilcoxon-signed rank test: $\mathrm{z}=-38.234, \mathrm{df}=2293, \mathrm{p}<$ 0.001; Figure 3). A Wilcoxon-signed rank test was performed because the temperature differences between the first and second park bridge violated assumptions of normality (Shapiro-Wilk: 0.986 [df=2293], $\mathrm{p}<0.001$ ). Maximum and minimum air temperatures upstream were also higher in summer/fall $\left(\right.$ maximum $=29.6$, minimum $\left.=6.4^{\circ} \mathrm{C}\right)$ between 14:00-21:00 versus air temperatures downstream at SM 61 (maximum $=27.1$, minimum $=5.9^{\circ} \mathrm{C}$; Figure 3 ). However, lower Waddell had a slightly narrower diurnal temperature range $\left(26.8^{\circ} \mathrm{C}\right)$ than the upper station $\left(29.7^{\circ} \mathrm{C}\right)$. I observed morning fog to rarely reach the upstream temperature station, and evening breezes started early and were stronger at the downstream station resulting in lower maximums and faster initial cooling of the downstream site. However, minimum temperatures were somewhat cooler at the upstream site.

Unlike the relatively similar July-October afternoon/evening air temperature pattern, stream water temperature gradually decreased from August to November (Figure 4), with the decline in day length. Daily fluctuations of $0.5-2^{\circ} \mathrm{C}$ were substantially less than air temperatures. Nighttime minimum water temperatures were usually warmer than those in air by 23:00-01:00.

No temperature loggers were placed in the lagoon, but starting and ending water temperatures were recorded for each lagoon survey $(n=4)$ from July-November 2012. Lagoon surface water temperatures during surveys were about $3^{\circ} \mathrm{C}$ degrees warmer than the stream at sunset, and declined $1.5-2^{\circ} \mathrm{C}$ by survey end, still warmer than the stream. 


\section{Longitudinal Frog Distribution Pattern}

Sixty-four individual CRLFs were captured along the lagoon and stream during night surveys between July-November 2012 (Figure 5). Nineteen of the 64 captured frogs $(30 \%)$ were yearlings, some of which could not be sexed until late summer or fall. All but four of the yearling frogs were captured upstream of the first park bridge, with nine of them concentrated near a major logjam at SM 65 and 66 (Figure 5). Females were more numerous and larger than males, and yearlings and males varied substantially in size compared to females in 2012 (Figure 6). However, in 2013 females varied in size more than males, due to the presence of smaller, immature 2-year old females.

Frogs were abundant, but very difficult to spot and catch in the lagoon. Most frogs in the lagoon were obscured by dense overhanging willows just above the water surface. Banks were judged to be only 5-10\% visible from the boat from SM 33 to SM 46. The habitat characterization transect did not extend to the lagoon downstream of SM 46. Capture rates were relatively high $(>80 \%)$ if frogs were accessible, but captured individuals averaged only $25 \%$ (17 of 69 ) of sighted individuals, because even the small percentage of visible frogs used well-protected positions.

Relative to the stream habitat, frogs were abundant along the portion of the lagoon with overhanging willows. I observed $18.3 \pm 6.9$ frogs in $670 \mathrm{~m}$ of lagoon during each night survey, even though less than $10-20 \%$ of the frogs were likely visible because of shoreline willows. The number of frogs in the lagoon likely exceeded 100, while only 53 other frogs were captured during repeated sampling of more than $1.6 \mathrm{~km}$ of stream habitat in 2012 . 
A similar longitudinal distribution pattern of frogs was observed in 2013 with the exception that fewer yearlings were caught (Figure 5). Twelve of the 64 captured frogs (19\%) were yearlings, most of which remained unsexed. As in 2012, all but one of the yearling frogs were captured upstream of the first park bridge in 2013 , with seven of them concentrated near the major logjam at SM 65 to 66 and the newly formed logjam at SM 69 (Figure 5).

The reach of stream from SM 46-SM 54 was a transition zone between lagoon and stream. Prior to sandbar closure, most habitat conditions were shallow; willows and other cover were far up the banks at the lagoon inundation line. However, after full sandbar closure, depth increased by at least $1 \mathrm{~m}$, and overhanging willows provided good cover for frogs, similar to that in the lower lagoon. Seven individuals were caught in approximately $244 \mathrm{~m}$ of stream in this reach during summer surveys in both 2012 and 2013 (Figure 5).

The two night surveys conducted in late September and early October 2012 between SM 97 and SM 124 located only two frogs, only one of which was caught (at SM 106; Figure 5).

The majority of survey effort was focused on the length of stream from SM 54 to SM 96 (second park bridge), which was sampled 1-3 nights per week until fall in 2012. Unlike the lagoon, habitat availability and frog distribution along the stream were much more variable. Frogs were observed to use a variety of habitats along Waddell Creek, but seemingly clumped around certain habitat resources. Reach separation and characterization were determined based upon the distribution of individuals along the 
stream (Figure 5). Eleven frogs were captured in Stream Reach 2, from SM 54 to SM 60. Eleven frogs were captured in Reach 4, from SM 64 to SM 67, near a logjam. Only a single frog was captured in the shallow and simple habitat between the two reaches. Similarly, only a single frog was captured in Reach 5, from SM 67 to SM 78, but 21 frogs were captured in Reach 6, from SM 78 to SM 97.

In 2013, the stream distribution was generally similar to 2012 (Figure 5). Twelve frogs were captured between SM 54 and SM 60 (Reach 2), eight frogs, mostly immatures, were captured near the major logjam between SM 64 and SM 67 (Reach 4), and only a single frog was captured between SM 60 and SM 64 (Reach 3). However, eight frogs were captured between SM 79 and SM 97 (Reach 6), and eight frogs were captured between SM 67 and SM 78 (Reach 5), in a reach that had only one frog in 2012. In Reach 5, two were at the reach boundaries and four were at a new major logjam (Figure 5).

\section{Habitat Availability}

Two-hundred and thirty-eight transect habitat characterization stations were sampled for aquatic and bank (Table 1) and upland (Table 2) habitat availability. From SM 46 to SM 124, exposed banks (26.6\%) were the most abundant bank cover microhabitat feature, followed by blackberry $(7.7 \%)$ and small woody debris $(4.7 \%$; Table 1). The most abundant aquatic cover features within the stream channel were aquatic vegetation (14.3\%) and overhanging vegetation (14.1\%), followed by small woody debris $(8.0 \%)$. Undercut banks $(4.0 \%)$ and roots $(4.0 \%)$ were also relatively 
common habitat features. Flotsam $(0.2 \%)$ was scarce during summer prior to leaf drop in fall (Table 1) and is usually associated with logjams.

Observed available aquatic and bank cover microhabitat features in Reach 1 $\left(X^{2}[14, \mathrm{n}=146]=32.509, \mathrm{p}=0.003\right)$, Reach $2\left(X^{2}[14, \mathrm{n}=135]=87.555, \mathrm{p}<0.05\right)$, and Reach $4\left(X^{2}[16, \mathrm{n}=131]=75.375, \mathrm{p}<0.001\right)$ differed significantly from cover available throughout the entire stream ("expected"; Table 1). Reaches 1 and 2 had more than expected amounts of large woody debris as aquatic cover (expected $=3.5 \%$, Reach 1 $=9.4 \%$, Reach $2=6.2 \%)$, overhanging vegetation $($ expected $=14.1 \%$, Reach $1=14.8 \%$, Reach $2=22.8 \%$ ), and submerged branches (expected $=1.9 \%$, Reach $1=4.2 \%$, Reach 2 $=5.9 \%$ ). In addition, the transition zone (Reach 1 ) had almost double the amount of bank cover of blackberry (expected $=7.7 \%$, Reach $1=12.9 \%)$ and aquatic vegetation $($ expected $=14.3 \%$, Reach $1=25.1 \%)$ than what was expected, and bare areas on the bank were scarce $($ expected $=26.6 \%$, Reach $1=11.1 \%)$. Cape ivy was substantial on the banks along Reach 2 (expected $=2.3 \%$, Reach $2=8.1 \%)$ and Reach $4(6.2 \%)$, but was absent in Reach 7. Reach 4 was the only stream segment with abundant logjam cover (expected $=0.3 \%$, Reach $4=4.0 \%$ ) and small woody debris within the stream (expected $=8.0 \%$, Reach $4=21.2 \%$; Table 1). Large logs in the aquatic habitat within Reach 4 were mostly associated with other large logs to form a complex jam, and these concentrated structures provided some of the best habitats for frogs. In 2012 and 2013, frogs were observed to be concentrated around logjams along the stream.

The uplands (at and beyond the top of the bank) surrounding Waddell Creek had many bare ground areas (23.8\%) but were often dominated by blackberry $(30.8 \%$; Table 
2). Cape ivy (17.6\%) was the other abundant ground cover, but it generally declined upstream and was absent in the uppermost reach. Other low vegetative ground cover (6.9\%) and young trees smaller than $1 \mathrm{~m}$ off of the ground (4.9\%) occurred much less frequently (Table 2). Observed upland cover frequencies in Reach $1\left(X^{2}[6, \mathrm{n}=101]=\right.$ $60.634, \mathrm{p}<0.001)$, Reach $2\left(X^{2}[8, \mathrm{n}=101]=15.775, \mathrm{p}=0.046\right)$, Reach $3\left(X^{2}[6, \mathrm{n}=\right.$ $100]=16.270, \mathrm{p}=0.012)$, and Reach $4\left(X^{2}[9, \mathrm{n}=99]=18.068, \mathrm{p}=0.034\right)$ differed significantly from upland cover expected throughout the entire stream. In the transition zone, cape ivy (expected $=17.6 \%$, Reach $1=38.4 \%)$ and blackberry $($ expected $=30.8 \%$, Reach $1=54.7 \%$ ) were especially abundant, and bare areas along this reach were unusually scarce $($ expected $=23.8 \%$, Reach $1=1.8 \%$; Table 2$)$.

Waddell Creek (SM 46-SM 124) water depth near the bank for escape averaged $0.8 \pm 0.5 \mathrm{~m}$ throughout, with the deepest segments in the Reach 1 transition zone after lagoon inundation (mean: $1.5 \pm 0.5 \mathrm{~m}$ ) and the shallowest segments in Reach 3 (mean: $0.4 \pm 0.1 \mathrm{~m} ;$ Table 3$)$.

Aquatic cover quality rating averaged $2.4 \pm 1.5$ throughout Waddell Creek from SM 46 to SM 124 (Table 3). The transition zone (Reach 1) had a high aquatic cover quality rating (mean: $3.0 \pm 1.6$ ) with deep water (mean: $1.5 \pm 0.5 \mathrm{~m}$ ). Cover quality rating was even higher in Reach 2 (mean: $3.3 \pm 1.7$ ), and although water depth near the banks was less than in Reach 1 (mean: $1.0 \pm 0.6 \mathrm{~m}$ ), it was still significantly higher than in upstream reaches. Along with being the shallowest reach (mean: $0.4 \pm 0.1 \mathrm{~m}$ ), Reach 3 also had the lowest aquatic cover quality rating (mean: $2.1 \pm 1.4$ ). 
Throughout Waddell Creek, the bank slope averaged $33.1 \pm 7.5^{\circ}$ and percent canopy coverage averaged $84.8 \pm 33.2 \%$ (Table 3 ). Slope was greater (mean: $40.5 \pm$ $\left.4.5^{\circ}\right)$, and canopy less $(60.6 \pm 38.3 \%)$ in Reach 1 , but these results can vary with degree of lagoon inundation. The densest bank canopies were in Reaches 5 (mean: $97.7 \pm$ $23.6 \%$ ) and 6 (mean: $91.3 \pm 28.2 \%$; Table 3 ). Because of the dense canopy in most reaches, basking quality ratings (mean: $1.6 \pm 0.9$ ) and potential to bask in direct sun (mean: $1.4 \pm 0.6$ ) were similarly low. Streamside bank cover quality ratings were generally also similar throughout the stream (means: $2.7 \pm 1.3$ to $3.6 \pm 1.7$ ) except for Reach 1 (mean: $4.3 \pm 1.0$; Table 3 ), where shoreline aquatic vegetation was particularly dense (Table 1).

Upland slope (at and beyond the top of the bank; mean: $26.7 \pm 13.5^{\circ}$ ) was more level than the bank. Upland percent canopy cover (mean: $81.3 \pm 30.8 \%$ ) was generally similar to that near the channel, except in the transition zone (Reach 1) where the canopy was more open at the bank because of a wider channel. Only Reach 4, with a more level upland terrain (mean: $14.0 \pm 15.0^{\circ}$ ) and a slightly more open upland canopy (mean: 62.6 $\pm 28.2 \%)$, differed much from other reaches.

\section{Instream Movements}

During July to early November 2012, when no heavy rains occurred, most transmittered frogs made only small daily movements within the stream channel and had relatively small home range sizes. Fifteen of twenty frogs had home range sizes of $60 \mathrm{~m}$ or less, and home range sizes averaged $47.1 \pm 36.1 \mathrm{~m}$ with minimum home range of 10.7 $\mathrm{m}$ and a maximum of $131.4 \mathrm{~m}$ (Figure 7). Home ranges were limited mostly by the 
length of the on-channel pools, and frogs seldom crossed riffles or stretches of shallow water with poor cover quality. Only one frog was captured between SM 60-SM 62 (Figure 5) after an increase in stream water level near the end of October, otherwise this reach was shallow from July-September. Downstream of this shallow reach, frogs were abundant in an extensive pool up to $1.4 \mathrm{~m}$ max depth. Three frogs had home ranges greater than $90 \mathrm{~m}$ (Figure 7), but for those three frogs, at the upper portion of the study area, there was sequential use of two separate areas. There was no relationship between frog size (SVL $\mathrm{mm}$ ) or sex and size of home ranges.

Transmittered frogs tracked in both summer and fall $(\mathrm{n}=16)$ made significantly larger daily instream movements between July and August (mean: $5.0 \pm 5.8 \mathrm{~m}$ ) than September to November (mean: $2.1 \pm 1.3 \mathrm{~m}$; Wilcoxon-signed rank test: $\mathrm{z}=3.206, \mathrm{p}=$ 0.001; Figure 8). A Wilcoxon-signed rank test was performed because the data violated the assumptions of normality between the samples (Shapiro-Wilk: 0.629, $\mathrm{df}=16, \mathrm{p}<$ 0.001). There was no relationship between frog size (SVL mm) or sex and the amount of frog movement.

\section{Habitat Use}

Daytime versus nighttime habitat use by transmittered frogs.-The movements of 20 frogs were tracked with 18 different transmitters (two transmitter belts that slipped off primary recipients, and were reattached on new frogs) from July 2012 to February 2013 or until the batteries on the transmitters were exhausted. The range of SV lengths of these frogs ranged from 74-113 mm (three frogs in the 70-79 $\mathrm{mm}$ size class, one in the 80-89 $\mathrm{mm}$ size class, three in the $90-99 \mathrm{~mm}$ size class, nine frogs in the $100-109 \mathrm{~mm}$ 
size class, and four in the 110-119 mm size class). The frogs were scattered from SM 55 through SM 97 (Figure 5).

From July-early November 2012, prior to breeding migration, transmittered frogs during both night and day preferred aquatic positions in or out of water (day $=61 \%$, night $=69 \%)$ over bank $($ day $=34 \%$, night $=27 \%)$ and upland $($ day $=5 \%$, night $=4 \%)$, but frogs moved out of the water more frequently during the daytime versus at night (Figure 9). Frogs in the stream were frequently observed out of water on stream structures such as logs or branches, and this occurred more often during the day versus at night (day $=$ $15 \%$, night $=8 \%$; Figure 9).

Transmittered frogs used sites associated with pools and high cover quality both day and night from July-early November 2012, but cover quality of daytime sites (mean: $4.7 \pm 0.7$; Table 4 ) was significantly higher than nighttime sites (mean: $4.5 \pm 1.0$; Table 5; paired samples t-test: $\mathrm{t}=2.513, \mathrm{df}=253, \mathrm{p}=0.013$ ). During the daytime, most frogs used aquatic and bank sites with good or very good cover quality, and usually remained completely hidden in or out of water rather than favoring open basking opportunities. Daytime sites used by frogs had poor basking quality (mean: $2.5 \pm 1.2$; Table 4 ) and dense canopy (mean: $83.7 \pm 36.9 \%$; Table 6 ). A few instances of daytime basking were observed if direct sunlight reached their location; however, no apparent movements with the intention to seek out sunlight were observed.

Average daytime (mean: $52.0 \pm 26.6^{\circ}$; Table 6) and nighttime (mean: $50.2 \pm$ $24.3^{\circ}$; Table 7) slopes used were similar and steeper than expected (mean: $33.1 \pm 7.5^{\circ}$ ), and bank positions used were relatively close to the water's edge both day (mean: $1.3 \pm$ 
$3.4 \mathrm{~m}$; median: $0.03 \mathrm{~m}$; Table 6) and night (mean: $1.1 \pm 3.3 \mathrm{~m}$; median: $0.03 \mathrm{~m}$; Table 7). In either case only short movements were required by frogs to move between the two habitats. Bare and exposed banks were not preferred, but were used if adequate water depth for escape was present, which seemed to be more important to frogs during the day. Escape water depths of daytime sites (mean: $0.6 \pm 0.3 \mathrm{~m}$; Table 6 ) was significantly greater than those of nighttime sites (mean: $0.4 \pm 0.3 \mathrm{~m}$; Table 7; paired samples t-test: $\mathrm{t}$ $=6.173, \mathrm{df}=231, \mathrm{p}<0.001)$. While in aquatic habitats, frogs were positioned farther away from the shore during the day (mean: $0.6 \pm 0.8 \mathrm{~m}$; median: $0.06 \mathrm{~m}$ Table 6 ), and moved significantly closer to shoreline cover at night (mean: $0.2 \pm 0.4 \mathrm{~m}$; Table 7; median: $0.03 \mathrm{~m}$; paired samples t-test: $\mathrm{t}=3.841, \mathrm{df}=80, \mathrm{p}<0.001$ ).

Observed daytime (Chi-square goodness of fit: $X^{2}[15, \mathrm{n}=100]=106.497, \mathrm{p}<$ 0.001; Table 4) and nighttime (Chi-square goodness of fit: $X^{2}[15, \mathrm{n}=103]=74.747, \mathrm{p}<$ 0.001; Table 5) microhabitat use of all transmittered frogs from July-early November 2012 differed significantly from microhabitat types available throughout Waddell Creek. Microhabitat use varied among individuals, but generally, transmittered frogs used denser, more complex aquatic and bank microhabitats during the day than at night. Overhanging vegetation was the most used microhabitat during the day $(12.0 \%$; Table 4$)$, and use of this particular habitat increased at night (17.5\%; Table 5), exceeding the expected amount (14.1\%). At night, frogs concentrated in lower Waddell $(<$ SM 60$)$ clumped under overhanging willows $19-51 \%$ of the time (Table 5), indicating a preference to use dense willows just above the water surface. Similar shifts in habitat use were observed for aquatic small wood and undercut banks, and frogs showed preferential 
uses of these microhabitats during the daytime $($ small $\operatorname{wood}=10.2 \%$, undercut bank $=$ 9.3\%; Table 4) versus nighttime ( small wood $=8.3 \%$, undercut bank $=3.9 \%$; Table 5$)$. Telemetry surveys showed that frogs used blackberry and cape ivy bank cover more than what was available almost equally both day (blackberry $=10.0 \%$, cape ivy $=7.8 \%$; Table 4) and night (blackberry $=10.4 \%$, cape ivy $=6.5 \%$; Table 5). For aquatic cover, small woody debris, roots, and branches were used more often than what was expected both day $($ small $\operatorname{wood}=10.2 \%$, roots $=7.8 \%$, branches $=2.1 \%$; Table 4$)$ and night $($ small wood $=8.3 \%$, roots $=7.9 \%$, branches $=2.7 \%$; Table 5). Logjams were uncommon $(0.3 \%)$ and concentrated along a few portions of the stream, but were used relatively often both day (1.5\%; Table 4) and night (1.8\%; Table 5), along with flotsam (day = $8.2 \%$, night $=11.4 \%$; Table 4 and 5 ). Bare areas on the banks were the most common microhabitat of all (26.6\%), but not preferred by transmittered frogs day (10.4\%; Table 4) or night (11.6\%; Table 5).

Individual transmittered frogs displayed predictable day and night movements and high site fidelity, often using the exact spot night after night. Although a variety of microhabitats were used, one transmittered female (F363) used the major logjam heavily at SM 65 throughout the study. During the day, she was observed many times on the bank basking in direct sunlight while hidden within the logjam (15.3\%) and associated large (15.3\%) and small woody debris (20.7\%; Table 4$)$. She moved into the deep pool with flotsam (18.7\%) and aquatic vegetation (21.1\%) within or downstream of the logjam (17.6\%; Table 5) at night. 
Watercress along Waddell Creek occurred in dense bunches at several locations where direct sunlight was available for a few hours each day; it was used as an effective basking platform and aquatic cover. Frogs used dense shoreline watercress by climbing onto it to get out of the water during daytime and climbing into it at the waterline as cover habitat during nighttime. One transmittered frog (f437) used dense watercress patches day (31.0\%; Table 4) and night (32.2\%; Table 5) in this manner. During one night survey, a non-transmittered frog was observed to dive into the water and head directly to the nearest clump of watercress for cover, where it remained hidden at waterline for the remainder of the night survey.

A female (F795) between SM 81B-SM 82 used blackberry on the bank or sat in a very specific spot in the fork of a multi-trunk alder while looking out toward the stream during nighttime. Aquatic habitats under overhanging blackberry near the left bank or nearby small woody debris over a deep pool were also used by F795 at night, but less often. During the day, she hid within the surrounding blackberry, but also in a very specific area. Further upstream at SM 85, another female (F904) used almost exclusively the same bunch of waterline watercress in the stream night after night, while moving into the undercut bank, roots, or aquatic vegetation during the day. This open site had high basking potential, while willows at the bank crest protected the frog from above.

Overnight survey.-An overnight survey was conducted on the night of 07 September 2012 until sunrise the following morning. Some frogs remained stationary all night, and other frogs actively moved between different habitats throughout the night. Two of the seven frogs observed, one using a large log on the bank, the other within 
grass, did not move at all during the night. The remaining five frogs were already in their nighttime positions at the time of survey start (20:40), and each made two to three small movements of 0.3 to $3.4 \mathrm{~m}$ to different habitats within their respective pools throughout the night. All five frogs retired for the night between 04:50 and 07:15. Of the five frogs, two retreated into a major logjam, two retreated into aquatic cover as watercress and rootwad, and one moved from aquatic habitat to a bank position within blackberry.

Habitat use by non-transmittered frogs.- During the daytime, non-transmittered frogs were nearly undetectable, and only two were seen during radio-tracking surveys. One frog was basking on the bank, and the other was at waterline against the bank. Both frogs were in good cover and dove underwater when they were disturbed.

Sightings of non-transmittered frogs at night $(\mathrm{n}=204)$ from July-early November 2012 were almost exclusively in aquatic habitats. Eighty-one percent of frogs were in the water using aquatic habitats, including $13 \%$ of the frogs perched on top of aquatic habitat structures out of water (Figure 9). Nineteen percent were on the banks, and no frogs were seen upland (at or beyond the top of the bank). While in bank positions, frogs were $0.6 \pm$ $0.8 \mathrm{~m}$ (median: $0.3 \mathrm{~m}$ ) away from the stream on $57.7 \pm 20.6^{\circ}$ slopes adjacent to pools with water depths of $0.5 \pm 0.3 \mathrm{~m}$ (Table 7). While in aquatic positions, frogs were $0.8 \pm$ $1.0 \mathrm{~m}$ (median: $0.6 \mathrm{~m}$ ) away from the nearest shore. Cover quality of sites used was good (mean: $4.3 \pm 0.9)$. Overhanging vegetation $(32.9 \%)$ was used most often, followed by flotsam (14.6\%), roots (13.1\%), aquatic small wood (11.2\%), large woody debris $(6.2 \%)$, and aquatic vegetation (5.7\%; Figure 10). Frogs were rarely observed on exposed bare banks $(5.4 \%)$ and other microhabitats. 
Logjams were uncommon along the stream, but were attractive habitat features for frogs, especially small frogs. In addition, logjams were often accompanied by abundant small wood and flotsam, and often associated with the deep pool created by scouring. From July-November 2012, 11 frogs consisting of 9 sub-adults and 2 large (> $100 \mathrm{SVL} \mathrm{mm}$ ) females, were captured at night in $92 \mathrm{~m}$ of stream (SM 64-SM 67; Figure 5). Frogs in this area were all clumped around the large logjam near SM 65, and used the associated habitats created from the jam. This logjam was the first of three major logjams present upstream of the lagoon along the stream in 2012 and has been in place since prior to 2011. The jam extended approximately $6 \mathrm{~m}$ up the flood plain on the left bank, and created many opportunities for frogs to remain well hidden during the day, and to move from upland sites within the jam to the water.

Aside from logjams, associations of small woody debris and overhanging willows were areas with the heaviest frog use. Scouring usually occurred directly under logs or mounds of small woody debris with willows, resulting in deep pools beneficial to frogs for escape. In particular, from July-November 2012, seven individuals (six adults, one yearling) were initially captured at night in $61 \mathrm{~m}$ of stream (SM 58-60; Figure 5). Most frogs were clumped around large overhanging willow structures and over pools $1 \mathrm{~m}$ or greater in depth.

Early upland forays in response to rain.-Transmittered frogs moved farther into terrestrial habitats ( $\geq 4.5 \mathrm{~m}$ from stream) during light rain in October within days of the start of the rain, but breeding migration movements downstream did not occur until November. Frogs moved farther upland during the light rains in October than they did in 
response to the much larger storm events which occurred in November. In 2012 only 4 $\mathrm{mm}$ of rain fell between 10 October and 12 October, followed by a slightly larger rain event that dropped $10 \mathrm{~mm}$ of rain between 22 October and 24 October (Big Creek Road weather station, Davenport, CA). Twelve frogs were $13.1 \pm 11.2 \mathrm{~m}$ away from the stream during and immediately following the first light rainfall, and the maximum distance away from the stream was $25.9 \mathrm{~m}$. Eight of the 20 frogs did not respond and remained within the channel. Over the next week, the 12 frogs that went upland gradually made their way back toward the stream and were confirmed through telemetry to be within the channel by 19 October. A similar response was observed following the second light rainfall event, during which only seven frogs made upland exploratory forays. Frogs were $16.2 \pm 24.3 \mathrm{~m}$ away from the stream, and the maximum distance away from the stream was $26.2 \mathrm{~m}$; most of the frogs were back to the stream within two to three days. Nine other frogs did not move upland farther than $3 \mathrm{~m}$ but displayed increased activity within the stream channel. Similar patterns were observed following the two additional light rainfall events at the beginning of November.

The first large storm in November was over six times greater in rainfall than the first October event, and dropped $7.4 \mathrm{~cm}$ of rain from 16 November to 21 November (Figure 11). However, transmittered frogs that had not started migrating $(n=8)$ responded by only moving half as far away from the stream (mean: $8.7 \pm 6.0 \mathrm{~m}$ ) as they did during October. Following the storm, five frogs were confirmed to be back at the stream within four days, compared to seven days following the much smaller October events. 
Transmittered frogs used significantly different upland habitats at night during rain events than those available throughout Waddell Creek $\left(X^{2}[8, \mathrm{n}=100]=27.871, \mathrm{p}<\right.$ 0.001). Compared to observations during the non-rainy season, transmittered frogs used more cover during nighttime and more open areas during daytime in rain or immediately following rain. During rain, no significant difference was detected between daytime habitat use and habitat available (expected) throughout the entire stream; however, the use of open areas was almost double in day versus night. During the day, blackberry $(32.8 \%)$, bare areas $(23.4 \%)$, and cape ivy $(21.8 \%)$ were used most often (Table 8$)$. At night, there was increased use of blackberry (37.8\%) and cape ivy (32.2\%), and bare areas (12.4\%) were used half as often versus daytime (Table 9).

\section{Breeding Migration}

Twelve transmittered frogs started their breeding migration with significant large rainfall events in November 2012 (Figure 11). When $7.4 \mathrm{~cm}$ of rain fell between 16 November and 21 November (Big Creek Road weather station, Davenport, CA), four frogs began their movements to the breeding area. An additional frog started migrating two days later. The second large storm from 28 November to 03 December brought on $9.6 \mathrm{~cm}$ over five days (Big Creek Road weather station, Davenport, CA), during which an additional seven frogs began their migrations to the breeding area (Figure 11). Five transmittered frogs are not included: contact was lost with two frogs during November storms, two frogs were immature females that did not move to the breeding area, and a fifth mature frog moved over $100 \mathrm{~m}$ westward away from the stream toward agricultural fields. 
A third storm event occurred between 21 December and 26 December, totaling $11.0 \mathrm{~cm}$ of rain (Big Creek Road weather station, Davenport, CA; Figure 11), but all frogs most likely had arrived at or near the breeding ponds by then. Males $(n=3)$, apparently arrived at or adjacent to the seasonal or permanent breeding pond in 1-8 days; females $(n=9)$ arrived in 5-28 days. There was no relationship between the distance frogs traveled and the number of days until frogs arrived in the breeding area. Based upon migration path or tracking to a pond, twelve frogs moved toward the seasonal breeding pond. One of them, a female frog (F844), which had shed its transmitter, was killed on the road near the seasonal breeding pond. One male (m590), initially caught as an immature frog, moved into the permanent breeding pond.

Large overland movements occurred during heavy rain events; otherwise, frogs moved relatively little between storms and remained in upland cover. Frogs became increasingly difficult to locate accurately during this time due to weak signals from failing transmitter batteries, but overland movements were observed for two females (320B and 073) between 18 November and 28 November. During heavy rainfall on 17 November, F320B moved approximately 140 m downstream, and was found on 18 November approximately $238 \mathrm{~m}$ from the stream within a dense mound of pine needles. In the dry period between storms in November, she moved roughly $16 \mathrm{~m}$ per day, staying in good cover until the onset of the next large storm event. After 03 December, she was within the breeding area, having moved an approximate straight-line distance of $570 \mathrm{~m}$ over five days of substantial rain. A similar pattern was observed for F073. After traveling an approximate straight-line distance of $430 \mathrm{~m}$ during the first November storm, 
she remained in good upland cover, moving approximately $18 \mathrm{~m}$ per day until the second November storm, during which she moved approximately $650 \mathrm{~m}$ over five days to reach the breeding area. In addition to longer migration movements with rain, frogs already positioned in the marsh area demonstrated increased movement activity during light rain events.

Unfortunately, all transmitters failed so activity could not be followed during the unusual breeding season. No rain occurred after early January and breeding was apparently extremely limited at the seasonal pond, despite suitable depths and water chemistry. Only one egg mass was found.

One transmittered frog (F255B/820) moved overland immediately following the light rain events of November and was tracked near and in the agricultural field approximately $270 \mathrm{~m}$ west of the stream. Its weakened transmitter was swapped for a recovered transmitter with more battery life in order to investigate the movement patterns of this particular frog. Instead of migrating to the breeding area, she made small daily movements of 1-9 $\mathrm{m}$ and continued to use a well-vegetated drainage of dense blackberry thickets outside the farmed field. The frog was tracked under a cover crop within the field, and its transmitter was removed on 21 January 2013, so it was not known if she eventually made a breeding migration or failed to migrate because of the lack of rain after early January. The same frog was encountered along the stream during night surveys conducted in August 2013 near the same stream section she used in 2012. 


\section{Year-to-Year Site Fidelity Along the Stream}

Site fidelity of frogs to precise locations along Waddell Creek from 2012 to 2013 was confirmed by subsequent recaptures of individuals during spring and summer surveys in 2013. Nine frogs that carried transmitters in 2012 were recaptured in 2013, and all were within $50 \mathrm{~m}$ of their 2012 locations (Figure 12). Five $(\mathrm{n}=5)$ were within 5 $\mathrm{m}$ of their 2012 locations along the stream. Two of the nine were immature females that did not migrate to the breeding pond but migrated substantially upland in winter. Two were within $1.5 \mathrm{~m}$ and $18.3 \mathrm{~m}$ of their 2012 stream locations by April 2013. The remaining five frogs were captured in the lagoon during spring, and did not arrive at their final destinations until July 2013.

Twelve mature non-transmittered frogs with well-established 2012 home locations were recaptured in 2013. One was within 10-20 m of its 2012 stream location by April and another was within $10 \mathrm{~m}$ by July (Figure 12). Five frogs were recaptured in spring at locations $199,567,701,866$, and 1759 m downstream of their 2012 locations, and one frog was recaptured $236 \mathrm{~m}$ upstream (Figure 12). Those non-transmittered frogs $(n=7)$ from 2012 that settled in more downstream locations in 2013 all did so within good habitat (i.e., deep pools with abundant cover).

Transmittered frogs in 2013.- Of the five frogs that received radio-transmitters in 2013, three were recaptures from 2012, one (F255B/820) of which never migrated to the breeding area. She ultimately settled within $50 \mathrm{~m}$ of her 2012 location along the stream (Figure 12). The other two recaptures from 2012 were included in the analysis of non transmittered frogs. By the end of summer 2013, both of these frogs settled within good 
aquatic habitat, one settled $29 \mathrm{~m}$ upstream, and the other settled $199 \mathrm{~m}$ downstream of their 2012 locations (Figure 12). Since the remaining two out of five transmittered frogs were new captures in spring 2013, site fidelity could not be determined. However, one frog settled in good backwater habitat near SM 56 and the other frog settled upstream near SM 74.

\section{DISCUSSION}

\section{Longitudinal Distribution and Site Fidelity}

Along Waddell Creek, CRLF abundance was highest in the lagoon, which is close to the breeding site and has abundant optimal habitat in the form of deep water and overhanging willows. Farther upstream, CRLF abundance declined, and the distribution was clumped, with local concentrations scattered along the stream at pools with bank access and good habitat cover. Transmittered frogs had small summer home ranges bounded by riffles or other shallow or simple habitats. A clumped distribution of CRLFs was also observed by Rathbun et al. (1993) in Pico and San Simeon creeks, San Luis Obispo County, with CRLFs primarily present along stream reaches and at pools with both deep water and vegetative cover.

CRLFs were very scarce farther upstream than $2 \mathrm{~km}$ upstream of the lagoon in 2012, but in 1998 to 2000 Smith (2014) captured CRLFs as far as $3 \mathrm{~km}$ upstream of the lagoon, and frogs were more than twice as abundant upstream of the lagoon as in 2012. Compared to the shady conditions observed during this study, in 1998 to 2000, Waddell Creek had a much more open canopy because floods in 1998 thinned the riparian zone (Smith 2014). The cause of the decline in CRLFs along the stream is unknown, but 
stream habitat suitability may have declined as riparian canopy increased and aquatic insect production decreased by shading (Foster 2014). In addition, density and intraspecific competition in the lagoon apparently decreased, so distribution of frogs generally contracted downstream toward the lagoon (Smith 2014).

After breeding, marked frogs moved to the lagoon as the nearest suitable aquatic site. Similar movements to nearest stream habitat were observed by Bulger et al. (2003) and Fellers and Kleeman (2007), but they did not track frogs to their ultimate destinations. In Waddell Creek in 2013, 13 of 21 former transmittered and marked frogs recaptured upstream, moved from the lagoon to reach other high quality habitats (e.g., deep water, vegetation, logjams) near (within $30 \mathrm{~m}$ ) the locations from the previous summer. Some were back in their home sites by mid-spring 2013, indicating they moved upstream from the lagoon rapidly. In 2013, several (5 of 12) recaptured marked frogs from 2012 in Waddell Creek settled in more downstream locations closer to the lagoon, but within good or better habitat. Site fidelity of adult CRLFs along Waddell Creek was also observed in 2000 by Smith (2014). Even as frog distribution was contracting downstream, Smith (2014) reported that many upstream outliers were older frogs that continued to return to their summer locations.

Most yearlings in this study were captured along the stream rather than at the lagoon. Very little is known about juvenile CRLF dispersal, but several studies have shown that CRLF metamorphs typically segregate themselves and occupy habitats on the perimeters of the adults (Rathbun et al. 1993; EBRPD 2007). This suggests that metamorphs at Waddell moved upstream in order to avoid larger frogs and overcrowded 
conditions in the lagoon. Such avoidance behavior is adaptive and may serve to reduce the risks of adult cannibalism near natal sites (EBRPD 2007). Logjams, although uncommon along the stream, were complex, high quality habitats used by both adults, and especially by small frogs. Logjams may be magnets for dispersing frogs of all sizes. One transmittered female from 2012 spent several weeks at a logjam in 2013 before she was recaptured in her original 2012 summer location $500 \mathrm{~m}$ farther upstream. Studies of toads and frogs have shown that post-metamorphic dispersal, rather than adult dispersal, is more responsible for establishing regional metapopulations (Breden 1987; Sinsch 1992; Sinsch and Seidel 1995; Sinsch 1997). This may be because adults have already selected suitable habitats, and continue to utilize them.

\section{Habitat Use}

Daytime habitat use._EBRPD (2007) and Fellers and Kleeman (2007) tracked CRLFs along streams and reported that it was common to see them basking in full sunlight next to water, but frogs not directly basking were associated with complex cover such as root-balls, logjams, undercut banks, or under dense vegetation on the stream banks (Rathbun et al. 1993; Jennings and Hayes 1994; Bulger et al. 2003; Fellers and Kleeman 2007). Similar daytime telemetry results were observed along Waddell Creek in 2012, with the exception that frogs were not often observed basking in direct sunlight because of the generally dense riparian canopy. However, Smith (2014) observed CRLFs basking on more open banks on Waddell Creek during 1998-2000 after the canopy was opened up by high flood flows in 1998. While remaining hidden in very good cover, frogs can effectively ambient bask, successfully storing body heat during the daytime for 
nocturnal foraging. Perhaps the tradeoff in higher survival rate due to lower detection by predators was enough to mitigate the benefits of direct basking.

Along Waddell Creek, dense thickets of blackberry and cape ivy provided the some of the best cover on and above stream banks, and they were often used by transmittered frogs. Blackberry was also a common choice for CRLFs in other habitat use studies along streams (Rathbun et al. 1993; Bulger et al. 2003; Fellers and Kleeman 2007). Tatarian (2008) found sites with cover, regardless of habitat type, to be preferred by CRLFs.

In aquatic microhabitats, wood, undercut banks, and overhanging vegetation provided great concealment cover during the day, and Waddell CRLFs were only observed near water depths of at least $0.5 \mathrm{~m}$, consistent with other studies along streams (Rathbun et al. 1993; Fellers and Kleeman 2007).

Nighttime habitat use. - Other nighttime habitat use studies have not used telemetry to locate frogs (Rathbun et al. 1993; Bulger et al. 2003; Cook and Jennings 2007; EBRPD 2007; Fellers and Kleeman 2007; Tatarian 2008). In this study there was a substantial difference in habitat use between telemetry and visual detection, with visual detection strongly biased toward less cryptic frogs. At Waddell Creek, some transmittered frogs remained concealed in good cover at night, but frogs more readily used open areas at night versus day. Aquatic frogs moved closer to and on the bank at night for foraging. Fellers and Kleeman (2007) suggested the increased use of open areas at night allows greater visibility of prey, a behavior which may mitigate for the somewhat 
increased exposure to predators. At Waddell, CLRFs were also often in shallower habitats at night for better foraging, despite increased predation risk.

Larger CRLFs in Waddell Creek were often observed using deep pools with aggregated woody debris and willows directly hanging over the water, but small frogs were scarce on these structures. This was also reported by Rathbun et al. (1993). Perhaps large adults were attracted to these habitat patches because they offered increased opportunities to feed on larger prey, including deer mice (Peromyscus spp.) that were seen at night $(\mathrm{n}=5)$ moving within willow branches overhanging the stream. Hayes and Tennant (1985) also observed deer mice using willow branches directly over the surface of deep pools, and also reported large CRLFs under willows to be oriented toward mice in their area. Preference for large prey items is not surprising, because larger frogs in other ranid species regularly prey on mice (Frost 1935; Raney and Ingram 1941; Jenssen and Klimstra 1966; Stewart and Sandison 1972). After examining the gut contents of 31 CRLFs, Hayes and Tennant (1985) found that vertebrates comprised the majority of prey biomass.

Terrestrial habitat use during rain.--At Waddell in 2012, similar to observations of Bulger et al. (2003) and Tatarian (2008), CRLFs made more terrestrial habitat use during initial fall rains than during later heavy winter rains. Waddell frogs remained upland for a longer period of time (1 week) during fall rains than in winter, despite the ample rainfall in early winter of 2012. Tatarian (2008) noted that terrestrial foray rates were $57 \%$ in fall and $32 \%$ in winter (and $11 \%$ during spring rains). Despite very wet conditions in winter, Bulger et al. (2003) found the frogs in Scott Creek spent 4-6 days 
(median) upland during initial sparse summer rains, yet only spent 1-4 days (median) upland during winter when rainfall was abundant.

Some frogs were observed along Waddell Creek during storm flows positioned on the banks just above waterline, most likely a response to avoid flooding. However, frogs that moved upland beyond the bank crest may have been trying to take advantage of increased feeding opportunities during rain, as suggested by Tatarian (2008). Compared to the non-rainy season, transmittered frogs in Waddell Creek used open areas significantly more during daytime upland forays in rain, which may indicate that frogs were using this period to forage actively. These foraging efforts preceded breeding and its increased energy demands. Accordingly, Tatarian (2008) observed more upland forays by female CRLFs than males in fall, just prior to the breeding season.

\section{Breeding Movements}

As with CRLFs in other telemetry studies (Bulger et al. 2003; Fellers and Kleeman 2007), all large movements by transmittered frogs in Waddell Creek coincided with large rain events in late fall/early winter. No breeding migration movements took place in October 2012 despite greater periods of rain-related upland habitat use, as also observed by Bulger et al. (2003) and Fellers and Kleeman (2007). Frogs may not have been hormonally prepared to move at that time (Bulger et al. 2003).

Some of my transmittered frogs at Waddell Creek did not use the riparian corridor to move to breeding sites, but took overland shortcuts. Similarly, Bulger et al. (2003) and Fellers and Kleeman (2007) reported that most frogs exited riparian corridors and moved in relatively direct routes overland toward the breeding area, regardless of ground cover 
or changes in elevation. If upland cover was available, as was the case in Waddell and Scott creek (Bulger et al. 2003) watersheds, frogs concealed themselves during periods between storms, sometimes remaining immobile for days, but CRLFs were also capable of moving across grasslands (Bulger et al. 2003; Fellers and Kleeman 2007) and cultivated fields (Bulger et al. 2003) rather quickly. One transmittered CRLF in the Waddell Creek study was approximately $240 \mathrm{~m}$ away from the stream, and Bulger et al. (2003) documented some frogs as far away as $500 \mathrm{~m}$ from any water.

Drought or salinity (from large ocean waves) has affected reproductive success at the Waddell seasonal pond in half of the years from 1998-2014 (Smith 2014). However, in 2012 all but one tracked frog in Waddell Creek was confirmed to have moved toward the seasonal breeding pond. Past telemetry (Smith 2014) showed more use of the permanent pond, and many males PIT-tagged in the stream failed to show at the seasonal pond, so both ponds are important breeding sites.

In 2012-2013, the seasonal breeding pond formed by the end of December, but there was little additional rain until small March and April storms. Although up to eight transmittered females were tracked to the breeding area, only one egg mass was found. Only two egg masses were found in the dry 2013-2014 season (Smith 2014). Rainfall was apparently associated with breeding activity (Alvarez et al. 2013; Smith 2014) and may be required to trigger the start of reproduction. If rain stops, breeding may stop, but at Waddell Creek breeding doesn't start at the seasonal pond until late December, even when the pond is full and suitable in November or early December (Smith 2014). 


\section{Management Implications}

To ensure viable populations of CRLFs, known breeding sites and nonbreeding aquatic sites, and corridors that connect the two need to be protected. For the Waddell Creek watershed, this includes the seasonal and permanent breeding ponds, the marsh, lagoon, stream and some upland habitat along the stream. As suggested by Bulger et al. (2003) and Tatarian (2008), object cover along the stream such as vegetation and downed trees must be present so frogs can avoid predators and desiccation. Adult frogs at Waddell had small summer home ranges with good habitat conditions and tended to use the same site between years. Relocating a frog does not necessarily mean it has been saved (Rathbun and Schneider 2001) if suitable habitat is lacking at the relocation site or if the frog is likely to attempt to return through hazardous habitat.

Current conservation strategies for CRLFs rely on buffer zones around critical habitat patches and corridors that connect suitable breeding and nonbreeding habitats, and allow dispersal of individuals (Saunders and Hobbs 1991; Hobbs 1992; Beebee 1996). However, this study and other CRLF studies (Bulger et al. 2003; Fellers and Kleeman 2007) have shown that riparian corridors may not be preferred as routes during breeding migration. Bulger et al. (2003) cautioned that any attempts at designing or creating corridors to aid in CRLF migration would be problematic because CRLFs often moved in relatively straight paths toward the breeding site. As Bulger et al. (2003) suggested, protected corridors may not be needed in relatively undisturbed landscapes without barriers or anthropogenic sources of high frog mortality. Forests and rangelands were acceptable (Bulger et al. 2003), and Fellers and Kleeman (2007) even observed CRLFs 
moving through an exposed, recently burned field during migration. Nevertheless, at Waddell Creek the stream may be essential as a dispersal corridor and nursery for juvenile frogs, in addition to providing nonbreeding habitat for adults moving away from the lagoon.

At Waddell Creek the breeding ponds near the stream mouth support a stream summer population within $2 \mathrm{~km}$ of the ponds, although Smith (2014) found frogs moved farther upstream $(2.5-3.5 \mathrm{~km})$ when densities were higher. CRLFs are present as scarce individuals even farther upstream ( $>7 \mathrm{~km}$ ), apparently due to precarious instream reproduction (Smith 2014). To support an abundant stream frog population farther upstream would require a suitable breeding site, such as a constructed off-channel pond.

Wood in Waddell Creek was responsible for creating complex habitat patches with deep pools and complex cover for frogs. Logjams, in particular, had a substantial influence in determining the clumped distribution of frogs along the stream, and appeared to aid in the overall dispersal and recruitment of new frogs to the population. Complexity of logjams also appeared to shelter small frogs from larger frogs and acted as waypoints to help disperse frogs farther upstream. In developed landscapes, low recruitment of dispersing individuals may be a primary factor in extirpation of frog populations from otherwise suitable aquatic habitats (Sjögren 1991; Sinsch 1992; Sjögren Gulve 1994; Stacey et al. 1997; Vos and Chardon 1998). Thus conservation of such habitats to aid in juvenile dispersal, in addition to protection of established and potential aquatic breeding and nonbreeding sites, may be an important goal for land managers. 


\section{REFERENCES}

Adams, M. J. 2000. Pond permanence and the effects of exotic vertebrates on anurans. Ecological Applications 10(2):559-568.

Allen, M. F., and T. Tennant. 2000. Evaluation of critical habitat for the California redlegged frog (Rana aurora draytonii). Center for Conservation Biology, University of California, Riverside.

Altig, R., and R. W. McDiarmid. 1999. Editors. Tadpoles: The biology of anuran larvae. Chicago, IL: University of Chicago Press 295-337.

Alvarez, J. A., D. G. Cook, J. L. Yee, M. G. van Hattem, D. R. Fong, and R. N. Fisher. 2013. Comparative microhabitat characteristics at oviposition sites of the California red-legged frog (Rana draytonii). Herpetological Conservation and Biology 8(3):539-551.

Beebee, T. J. C. 1996. Ecology and conservation of amphibians. Chapman \& Hall, London.

Big Creek Rd Forecast for Davenport, CA, Station KCADAVEN4 (n. d.). Available: http://www.wunderground.com/personal-weatherstation/dashboard?ID=KCADAVEN4. (December 2013).

Breden, F. 1987. The effect of post-metamorphic dispersal on the population genetic structure of Fowler's toad (Bufo woodhouseii fowleri). Copeia 386-395.

Bulger, J. B., N. J. Scott Jr., and R. B. Seymour. 2003. Terrestrial activity and conservation of adult California red-legged frogs (Rana aurora draytonii) in coastal forests and grasslands. Biological Conservation 110:85-95.

Cook, D. G., and M. R. Jennings. 2007. Microhabitat use of the California red-legged frog and introduced bullfrog in a seasonal marsh. Herpetologica 63(4):430-440.

D’Amore, A., E. Kirby, and V. Hemmingway. 2009a. Invasive species shifts ontogenetic resource partitioning and microhabitat use of a threatened native amphibian. Aquatic Conservation: Marine and Freshwater Ecosystems 19:534-541.

D'Amore, A., E. Kirby, and V. Hemmingway. 2009b. Reproductive interference by an invasive species: an evolutionary trap? Herpetological Conservation and Biology $4: 325-330$. 
Doubledee, R. A., E. B. Muller, and R. M. Nisbet. 2003. Bullfrogs, disturbance regimes, and the persistence of the California red-legged frogs. The Journal of Wildlife Management 67(2):424-438.

East Bay Regional Park District (EBRPD). 2007. The status of the California tiger salamander (Ambystoma californiense), California red-legged frog (Rana draytonii), foothill yellow-legged frog (Rana boylii), and other aquatic herpetofauna in the East Bay Regional Park District, California:20-31.

Fellers, G. M., and P. M. Kleeman. 2003. A technique for locating and recovering radiotransmitters at close range. Herpetological Review 34:123.

Fellers, G. M., and P. M. Kleeman. 2007. California red-legged frog (Rana draytonii) movement and habitat use: implications for conservation. Journal of Herpetology 41(2):276-286.

Foster, Carole A. 2014. Benthic macroinvertebrates in Uvas Creek, California, downstream of a reservoir. San Jose State University Master's Thesis.

Frost, S. W. 1935. The food of Rana catesbeiana. Copeia:15-18.

Hayes, M. P., and M. R. Jennings. 1986. Decline of ranid frog species in western North America: are bullfrogs (Rana catesbeiana) responsible? Journal of Herpetology 20:490-509.

Hayes, M. P., and M. R. Jennings. 1988. Habitat correlates of distribution of the California red-legged frog (Rana aurora draytonii) and the foothill yellow-legged frog (Rana boylii): implications for management. Management of Amphibians, Reptiles, and Small Mammals in North America:144-158.

Hayes, M. P., M. M. Miyamoto. 1984. Biochemical, behavioral and body size differences between Rana aurora aurora and $R$. a. draytonii. Copeia:1018-1022.

Hayes, M. P., and M. R. Tennant. 1985. Diet and feeding behavior of the California redlegged frog, Rana aurora draytonii (Ranidae). The Southwestern Naturalist 30:601-605.

Hobbs, R. J. 1992. The role of corridors in conservation: solution or bandwagon? Trends in Ecology and Evolution 7:389-392.

Jennings, M. R., and M. P. Hayes. 1985. Pre-1900 overharvest of California red-legged frogs (Rana aurora draytonii): the inducement for bullfrog (Rana catesbeiana) introduction. Herpetologica 41:94-103. 
Jennings, M. R., and M. P. Hayes. 1994. Amphibian and reptile species of special concern in California. California Department of Fish and Game, Sacramento, California, USA.

Jenssen, T. A., and W. D. Klimstra. 1966. Food habits of the green frog, Rana clamitans, in southern Illinois. American Midland Naturalist 76:169-182.

Kiesecker, J. M., and A. R. Blaustein. 1997. Population differences in responses of redlegged frogs (Rana aurora) to introduced bullfrogs. Ecology 78:1752-1760.

Lawler, S. P., D. Dritz, T. Strange, and M. Holyoak. 1999. Effects of introduced mosquitofish and bullfrogs on the threatened California red-legged frog. Conservation Biology 13:613-622.

Leopold, L. B., and T. Maddock Jr. 1953. The hydraulic geometry of stream channels and some physiographic implications. U. S. Geological Survey Professional Paper 252.

Moyle, P. B. 1973. Effects of introduced bullfrogs, Rana catesbeiana, on the native frogs of the San Joaquin Valley, California. Copeia 1:18-22.

National Oceanic and Atmospheric Administration (NOAA) Watershed Characterization. 2008. Waddell Watershed Stats and Maps pdf. Available: http://www.ncdc.noaa.gov. (December 2013).

National Oceanic and Atmospheric Administration (NOAA) Record of Climatological Observations. 2013. Available: http://www.ncdc.noaa.gov/data-access/landbased-station-data/data-publications. (December 2013).

Pearl, C. A., M. P. Hayes, R. Haycock, J. D. Engler, and J. Bowerman. 2005. Observations of interspecific amplexus between western North American ranid frogs and the introduced American bullfrog (Rana catesbeiana) and a hypothesis concerning breeding interference. The American Midland Naturalist 154(1):126134.

Raney, E. C., and W. M. Ingram. 1941. Growth of tagged frogs (Rana catesbeiana and Rana clamitans) under natural conditions. American Midland Naturalist 26:201206.

Rathbun, G. B., M. R. Jennings, T. G. Murphey, and N. R. Siepel. 1993. Status and ecology of sensitive aquatic vertebrates in lower San Simeon and Pico Creeks, San Luis Obispo County, California. 
Rathbun, G. B., and T. G. Murphey. 1996. Evaluation of a radio-belt for ranid frogs. Herpetological Review 27:187-189.

Rathbun, G. B., and J. Schneider. 2001. Translocation of California red-legged frogs (Rana aurora draytonii). Wildlife Society Bulletin 29(4):1300-1303.

Saunders, D. A., and R. J. Hobbs (Eds.). 1991. The role of corridors. Surrey Beatty \& Sons, Chipping Norton, NSW, Australia.

Shaffer, H. B., G. M. Fellers, S. R. Voss, J. Oliver, and G. Pauly. 2004. Species boundaries, phylogeography, and conservation genetics of the red-legged frog (Rana aurora/draytonii) complex. Molecular Ecology 13: 2667-2677.

Sinsch, U. 1992. Structure and dynamic of a natterjack toad metapopulation (Bufo calamita). Oecologia 90:489-499.

Sinsch, U. 1997. Postmetamorphic dispersal and recruitment of first breeders in a Bufo calamita metapopulation. Oecologia 112:42-47.

Sinsch, U., and D. Seidel. 1995. Dynamics of local and temporal breeding assemblages in a Bufo calamita metapopulation. Australian Journal of Ecology 20:351-361.

Sjögren, P. 1991. Extinction and isolation gradients in metapopulations: the case of the pool frog (Rana lessonae). Biological Journal of the Linnean Society 42:135-147.

Sjögren Gulve, P. 1994. Distribution and extinction patterns within a northern metapopulation of the pool frog, Rana lessonae. Ecology 75:1357-1367.

Smith, J. 2014. Summary of California red-legged frog sampling on lower Waddell Creek, Santa Cruz County. FWS (Fish and Wildlife Service) Annual Report.

Stacey, P. B., V. A. Johnson, and M. L. Taper. 1997. Migration within metapopulations: the impact upon local population dynamics. In: Hanski, I., and M. E. Gilpin (Eds.), Metapopulation Biology: Ecology, Genetics, and Evolution. Academic Press, San Diego: 267-291.

Stewart, M. M., and P. Sandison. 1972. Comparative food habits of sympatric mink frogs, bullfrogs, and green frogs. Journal of Herpetology 6:241-244.

Storer, T. I. 1925. A synopsis of the amphibia of California. University of California Publications in Zoology 27:1-342.

Storm, R. M. 1952. Interspecific mating behavior in Rana aurora and Rana catesbeiana. Herpetologica 10:161-166. 
Tatarian, P. J. 2008. Movement patterns of California red-legged frogs (Rana draytonii) in an inland California environment. Herpetological Conservation and Biology 3(2):155-169.

United States Fish and Wildlife Service. 1996. Endangered and threatened wildlife and plants: determination of threatened status for the California red-legged frog. Federal Register 61:25813-25833.

United States Fish and Wildlife Service. 2002. Recovery plan for the California redlegged frog (Rana aurora draytonii). U. S. Fish and Wildlife Service, Portland, OR.

Vos, C. C., and J. P. Chardon. 1998. Effects of habitat fragmentation and road density on the distribution pattern of the moor frog Rana arvalis. Journal of Applied Ecology $35: 44-56$. 
FIGURES 


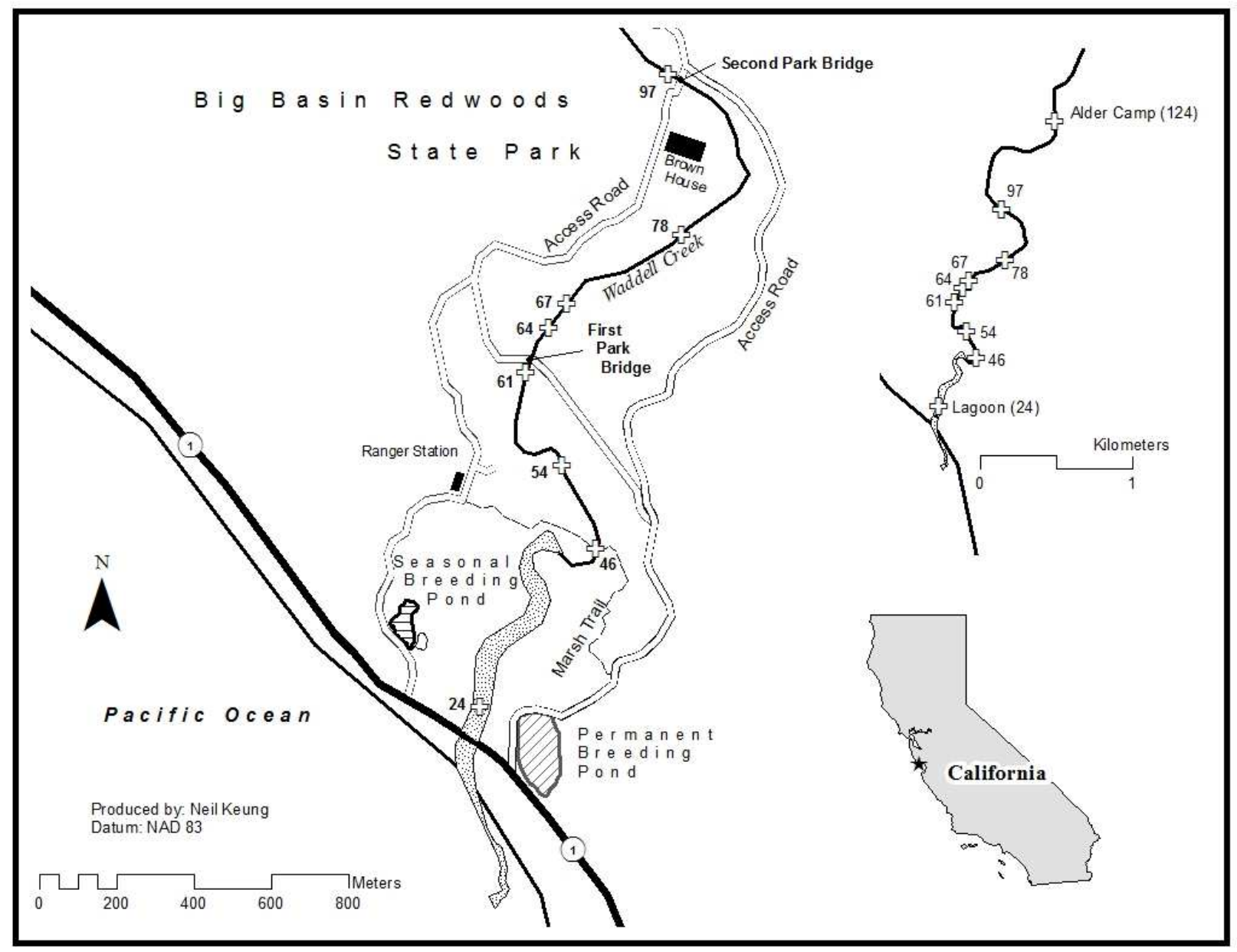

FIGURE 1. Study site of California Red-Legged Frogs (Rana draytonii) at Waddell Creek in and adjacent to Big Basin Redwoods State Park, Santa Cruz County, California. The two park bridges are shown, as well as the park footbridge located at stream marker 46 along The Marsh Trail. Shown above are the major $(30.5 \mathrm{~m}$ ) markers between reaches, represented by (ङ). Also shown is the location of Alder Camp (top right), relative to the main study site. 
a)

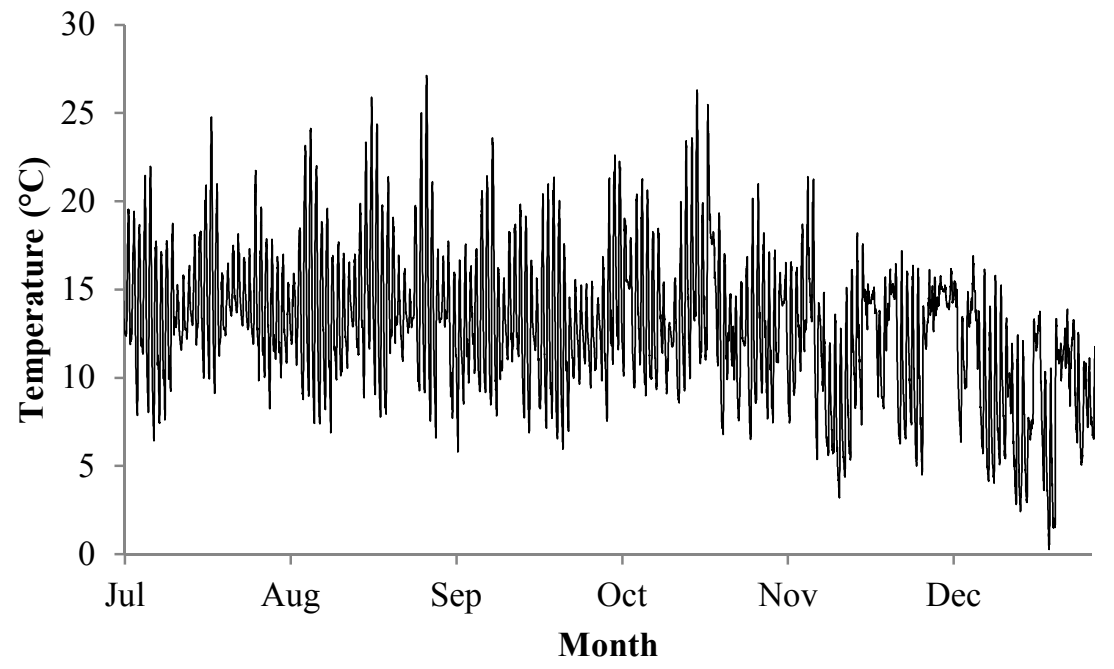

b)

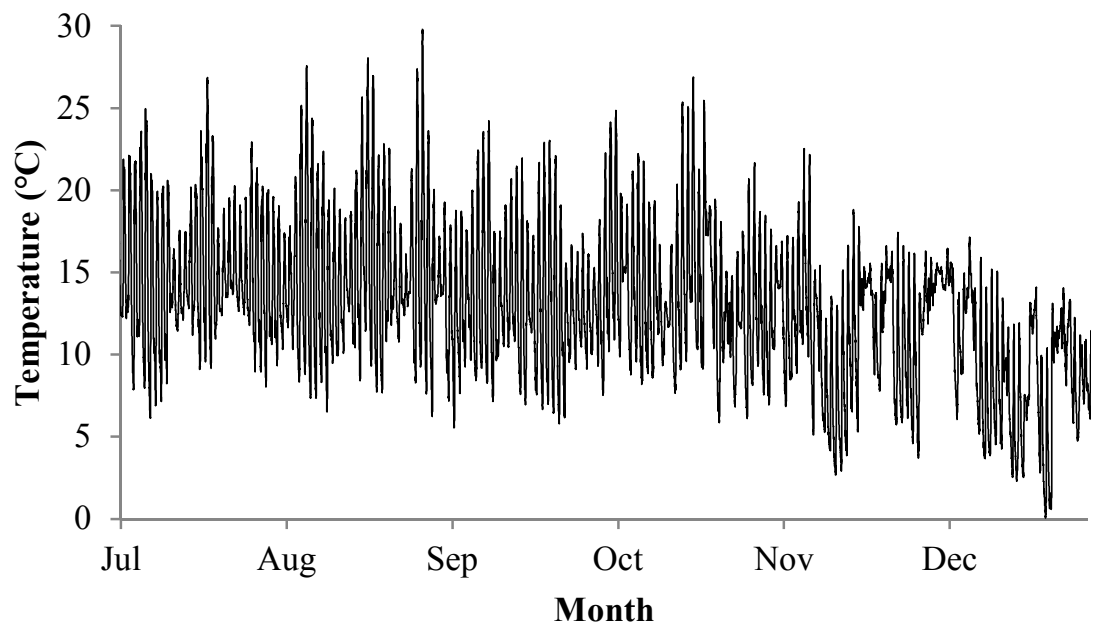

FIGURE 2. Waddell Creek air temperatures near the (a) first park bridge (stream marker 61) and (b) second park bridge (stream marker 96) from July-December 2012. The two temperature drops in November were associated with heavy rain events. 
a)

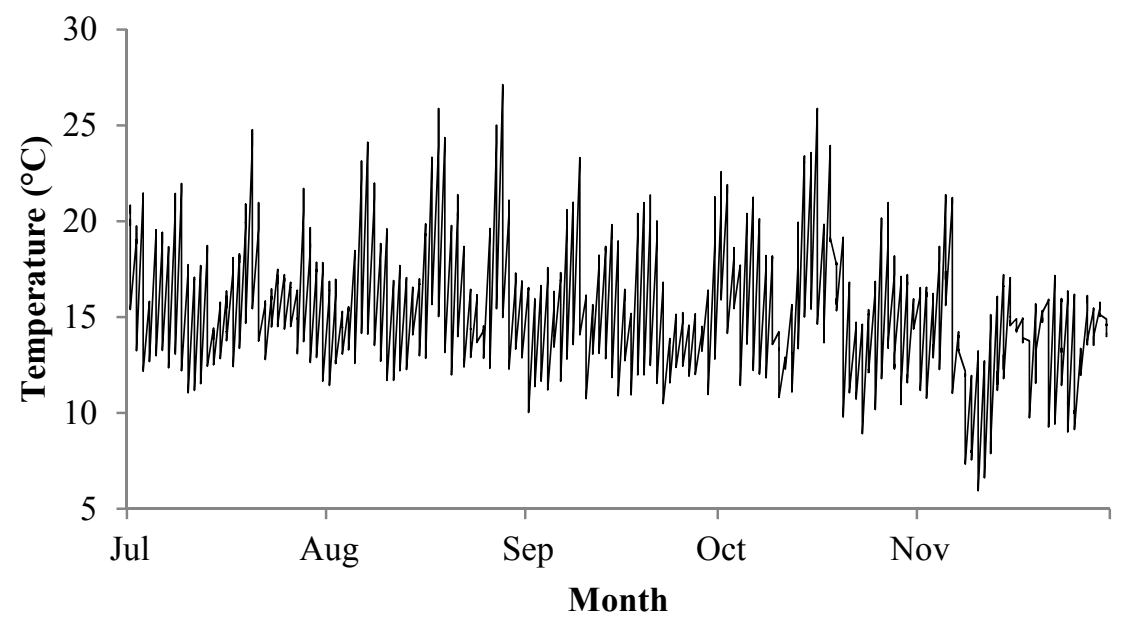

b)

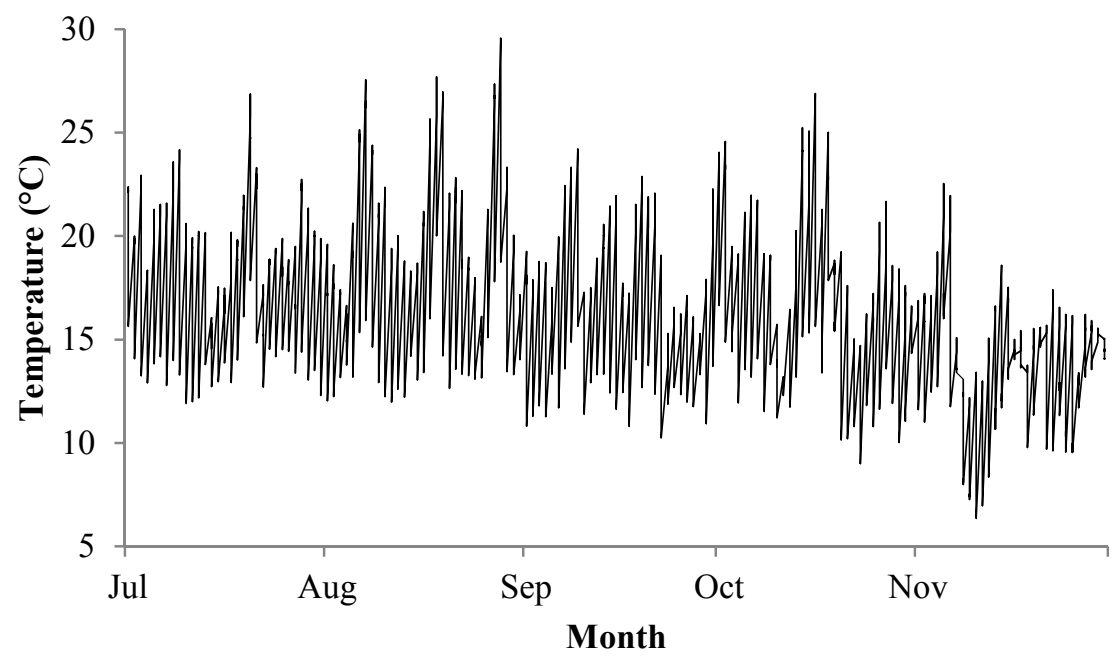

FIGURE 3. Waddell Creek air temperatures in afternoon and evening (14:00-21:00) near the (a) first park bridge (stream marker 61) and (b) second park bridge (stream marker 96) from July-November 2012. 


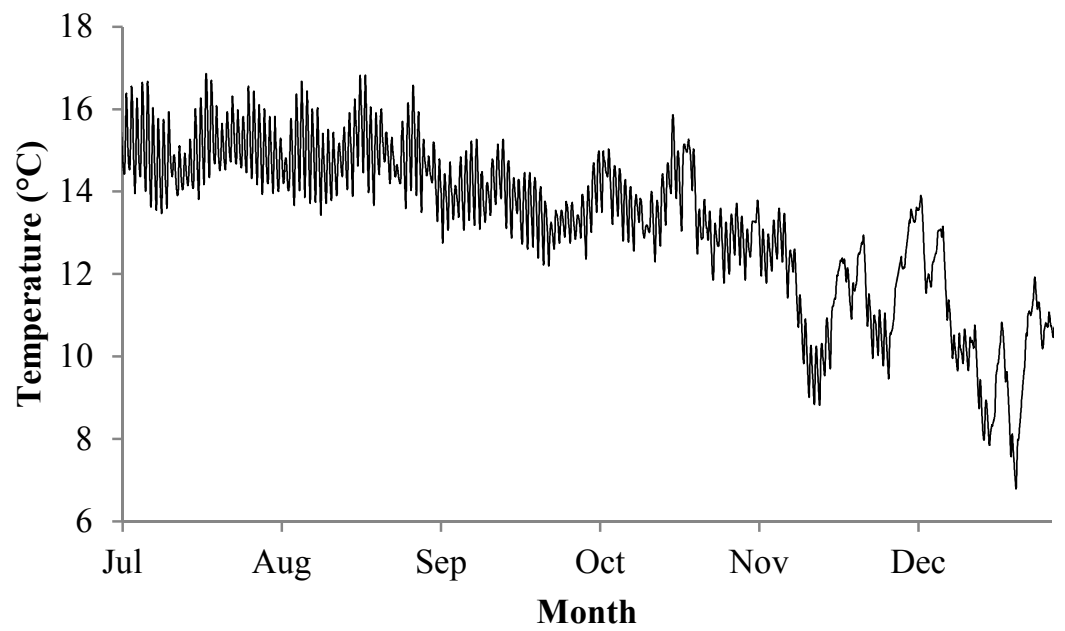

FIGURE 4. Waddell Creek water temperature from July-December 2012 from near the first park bridge (stream marker 61). The temperature drops in November and December were associated with rain events. 


\begin{tabular}{|c|c|c|c|c|c|c|c|}
\hline \multirow[t]{2}{*}{ Field Notes } & \multirow[t]{2}{*}{$\begin{array}{l}\text { Stream } \\
\text { Marker }\end{array}$} & \multicolumn{2}{|c|}{$\begin{array}{c}\text { Captured } \\
\text { Individuals }\end{array}$} & \multirow[t]{2}{*}{ Field Notes } & \multirow[t]{2}{*}{$\begin{array}{l}\text { Stream } \\
\text { Markers }\end{array}$} & \multicolumn{2}{|c|}{$\begin{array}{l}\text { Captured } \\
\text { Individuals }\end{array}$} \\
\hline & & 2012 & 2013 & & & 2012 & 2013 \\
\hline & 24 to 25 & & & & 78 to 79 & $F \mathrm{fUU}$ & \\
\hline & 25 to 26 & $\mathrm{~F}$ & $\mathrm{~F}$ & & 79 to 80 & $\bar{M} \mathrm{M} \mathrm{U}$ & \\
\hline & 26 to 27 & & & & 80 to $81 \mathrm{~A}$ & & $\mathrm{U}$ \\
\hline & 27 to 28 & & $\mathrm{~F}$ & & $81 \mathrm{~A}$ to $81 \mathrm{~B}$ & $F$ & $\mathrm{U}$ \\
\hline & 28 to 29 & & & & $81 \mathrm{~B}$ to 82 & $\bar{F}$ & $\underline{F} \mathbf{F}$ \\
\hline & 29 to 30 & $\mathrm{~F}$ & $\mathrm{~F}$ & & 82 to 83 & $\underline{F} \underline{M}$ & \\
\hline & 30 to 31 & & F F F M & & 83 to 84 & & \\
\hline & 31 to 32 & & F M & & 84 to 85 & $\underline{F}$ & $\mathrm{~F}$ \\
\hline & 32 to 33 & & $\mathrm{~F}$ & & 85 to 86 & $\overline{\mathrm{F}}$ & \\
\hline & 33 to 34 & M & F M & & 86 to 87 & & \\
\hline & 34 to 35 & & M M & & 87 to 88 & $\mathrm{U}$ & \\
\hline & 35 to 36 & M & & & 88 to 89 & $\underline{F} \mathrm{f}$ & \\
\hline & 36 to 37 & M & & & 89 to 90 & & \\
\hline & 37 to 38 & & $\mathrm{M}$ & & 90 to 91 & & \\
\hline & 38 to 39 & M & M & & 91 to 92 & & \\
\hline & 39 to 40 & & & small logjam & 92 to 93 & $\underline{F F \mathrm{~F}}$ & \\
\hline & 40 to 41 & M & & & 93 to 94 & & F U \\
\hline & 41 to 42 & & & & 94 to 95 & & \\
\hline & 42 to 43 & & & & 95 to 96 & & \\
\hline & 43 to 44 & F U & F F M & PARK BRIDGE 2 & 96 to 97 & $\underline{F} \mathrm{~F}$ & $\mathrm{~F}$ \\
\hline & 44 to 45 & M & & & 97 to 98 & & \\
\hline & 45 to 46 & $\mathrm{~F}$ & $\mathrm{~F}$ & & 98 to 99 & & \\
\hline $\begin{array}{l}\text { FOOTBRIDGE } \\
\text {. }\end{array}$ & 46 to 47 & $\mathrm{~F}$ & M & & 99 to 100 & & \\
\hline & 47 to 48 & F M & M & & 100 to 101 & & \\
\hline & 48 to 49 & $\mathrm{M}$ & $\mathrm{F}$ & & 101 to 102 & & \\
\hline & 49 to 50 & M M & $\underline{M}$ & & 102 to 103 & & \\
\hline & 50 to 51 & & $\bar{M}$ & & 103 to 104 & & \\
\hline & 51 to 52 & & & & 104 to 105 & & \\
\hline & 52 to 53 & M & F F & & 105 to 106 & & \\
\hline & 53 to 54 & & & & 106 to 107 & $\mathrm{~F}$ & \\
\hline & 54 to 55 & $f M$ & $\mathbf{F}$ & & 107 to 108 & & \\
\hline & 55 to 56 & $\underline{F} \underline{m}$ & F M & & 108 to 109 & & \\
\hline & 56 to 57 & & $\underline{M} \mathrm{M}$ & & 109 to 110 & & \\
\hline & 57 to 58 & & & & 110 to 111 & & \\
\hline & 58 to 59 & $\underline{F} \underline{M} \mathrm{M} \mathrm{U}$ & $\mathbf{M} \underline{M} \mathrm{M} \mathrm{U}$ & & 111 to 112 & & \\
\hline & 59 to 60 & $\underline{F} \underline{F}$ & F F M & & 112 to 113 & & \\
\hline PARK BRIDGE 1 & 60 to 61 & & & & 113 to 114 & & \\
\hline & 61 to 62 & M & & & 114 to 115 & & \\
\hline & 62 to 63 & & & & 115 to 116 & & \\
\hline & 63 to 64 & & $\mathrm{U}$ & & 116 to 117 & & \\
\hline & 64 to 65 & FU & $\underline{F} \mathrm{UU}$ & & 117 to 118 & & \\
\hline major logjam & 65 to 66 & $\underline{F} f f \mathrm{~m} \mathrm{U} U \mathrm{U}$ & $\overline{\mathbf{F}} \mathbf{F} \mathrm{U} U$ & & 118 to 119 & & \\
\hline & 66 to 67 & $\mathrm{~m} \mathrm{U}$ & $\mathrm{F}$ & & 119 to 120 & & \\
\hline & 67 to 68 & & $\mathrm{U}$ & & 120 to 121 & & \\
\hline & 68 to 69 & & & & 121 to 122 & & \\
\hline new logjam in 2013 & 69 to 70 & & F F f M & & 122 to 123 & & \\
\hline & 70 to 71 & & & & 123 to 124 & & \\
\hline & 71 to 72 & & M & & 124 to 125 & & \\
\hline major logjam & 72 to 73 & & & & & & \\
\hline & 73 to 74 & & & & & & \\
\hline & 74 to 75 & & $\mathbf{M}$ & & & & \\
\hline major logjam & 75 to 76 & $\underline{M}$ & & & & & \\
\hline & 76 to 77 & & & & & & \\
\hline & 77 to 78 & & $\mathrm{U}$ & & & & \\
\hline
\end{tabular}

FIGURE 5. Individual captures showing longitudinal distribution of California Red-Legged Frogs at first capture along Waddell Creek and lagoon from July-early November $2012(\mathrm{n}=64)$ and $2013(\mathrm{n}=64)$. Reaches are separated by lines, and locations of major logjams and bridges are shown. Distance between each stream marker was 30.5 meters. F represents females; M represents males; for $\mathrm{m}$ represents frogs with unknown sex at first capture but sexed in late summer or fall; $\mathrm{U}$ represents frogs of unknown sex. Frogs that received radio-transmitters in 2012 and 2013 are underlined and italicized; transmittered frogs from 2012 that were recaptured in 2013 are bolded. 
a)

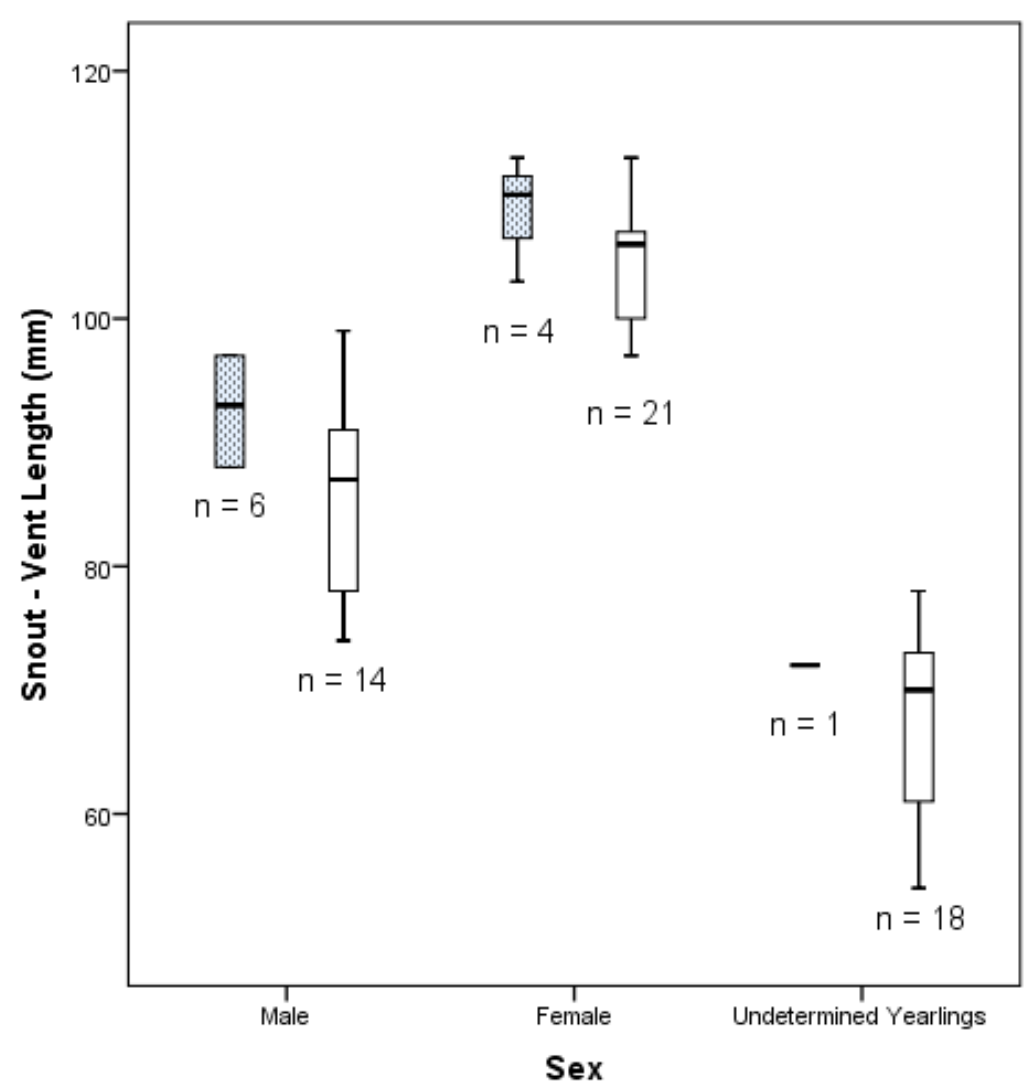

b)

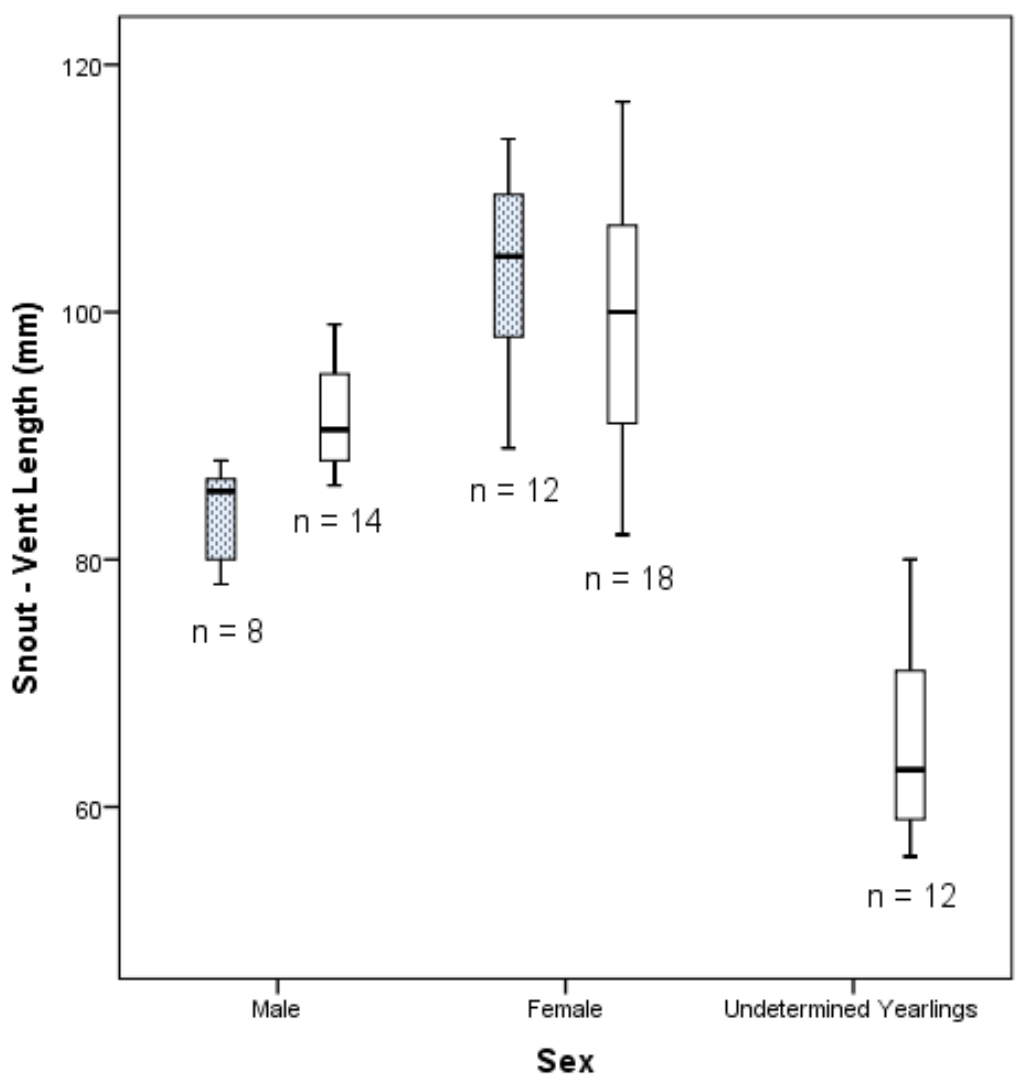

FIGURE 6. Range, mean, and standard deviations for snout-vent lengths ( $\mathrm{mm}$ ) of initial captured male, female, and undetermined yearling California Red-Legged Frogs in the lagoon (dark dotted bars) and stream (white bars) at Waddell Creek from July-November (a) 2012 and (b) 2013. 


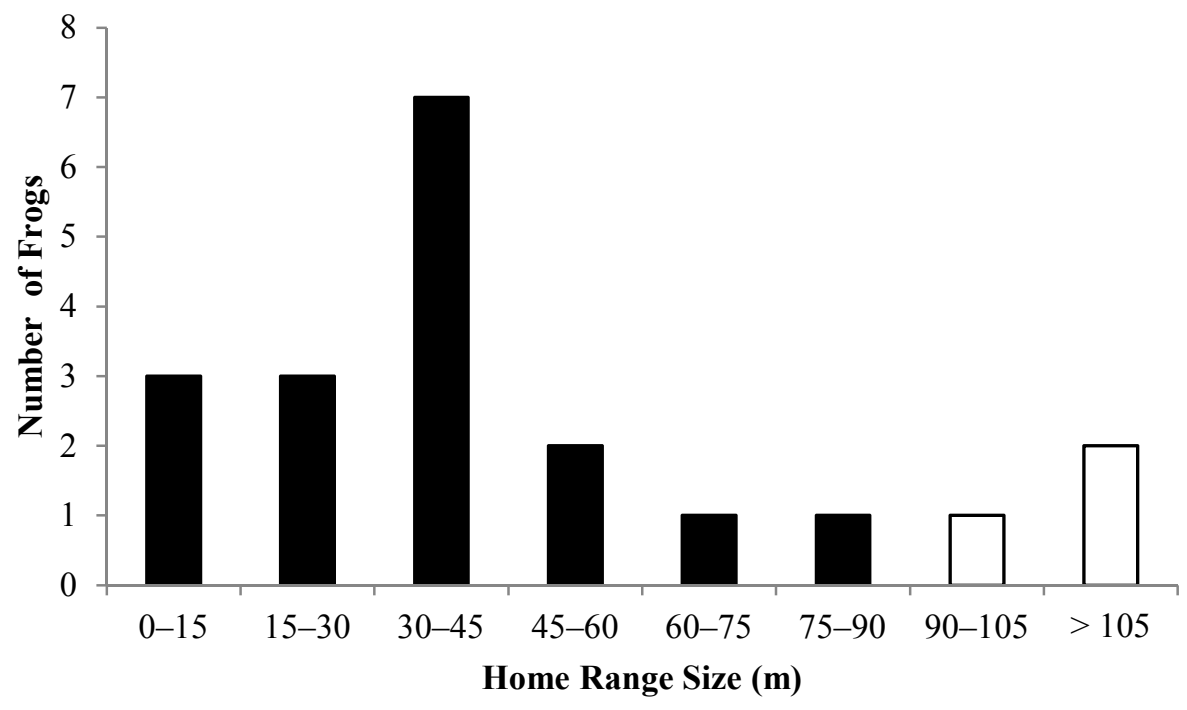

FIGURE 7. Instream home range sizes of transmittered California Red-Legged Frogs $(n=20)$ throughout Waddell Creek from July-November 2012 (prior to breeding movements). Black bars represent frogs with shallow habitats at upper extent of home ranges; white bars represent frogs that moved through shallow habitat within their summer range and used more than one home range during the tracking period.

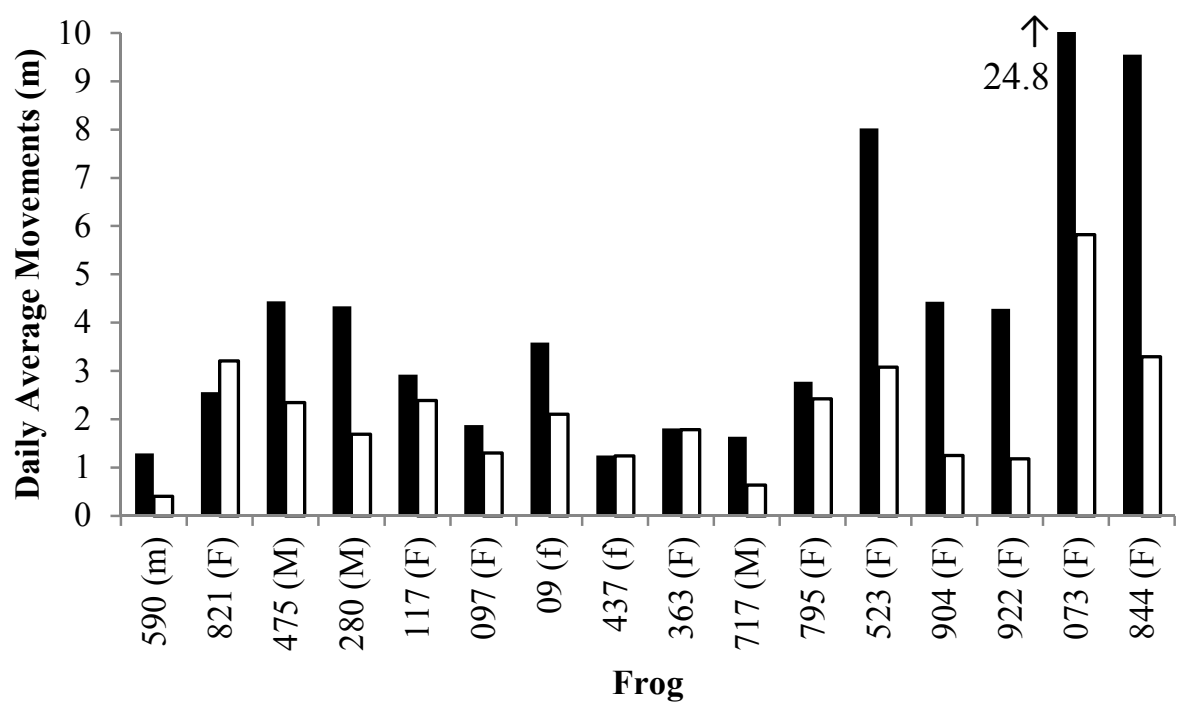

FIGURE 8. Instream daily movements of transmittered California Red-Legged Frogs $(\mathrm{n}=16)$ along Waddell Creek from July-November 2012. Black bars represent daily movements from July through August; white bars represent daily movements from September through November. Frog 073 had a summertime movement of $24.8 \mathrm{~m}$. Frogs are arranged from downstream (left) to upstream (right). 
a)

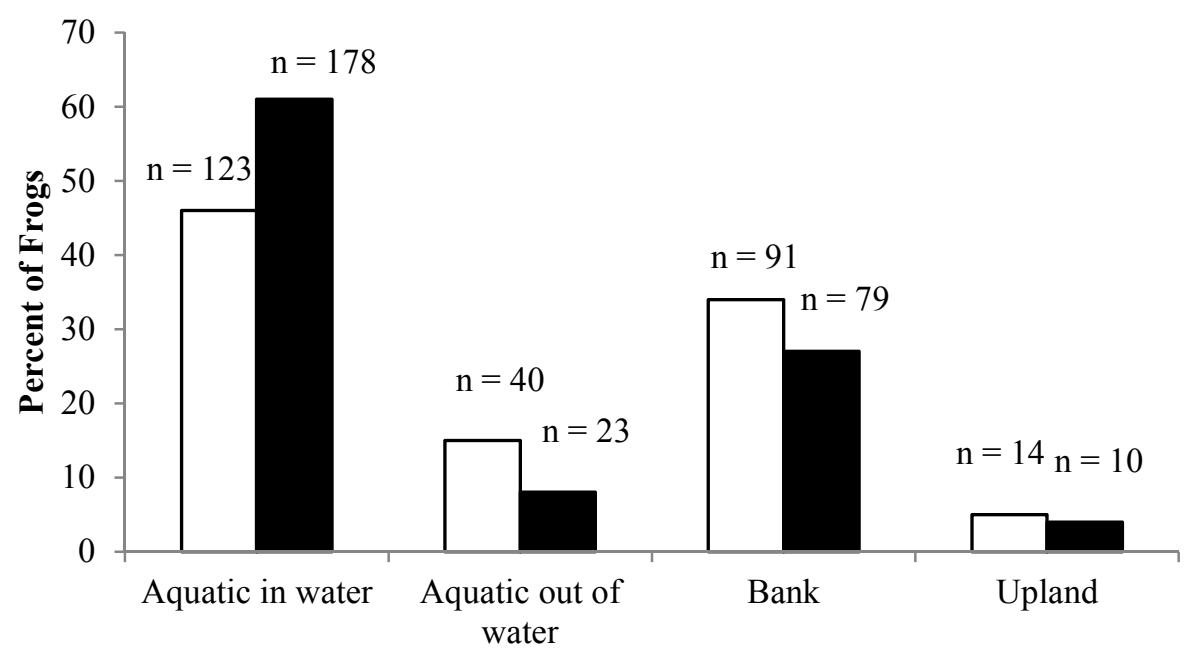

Frog Positions

b)

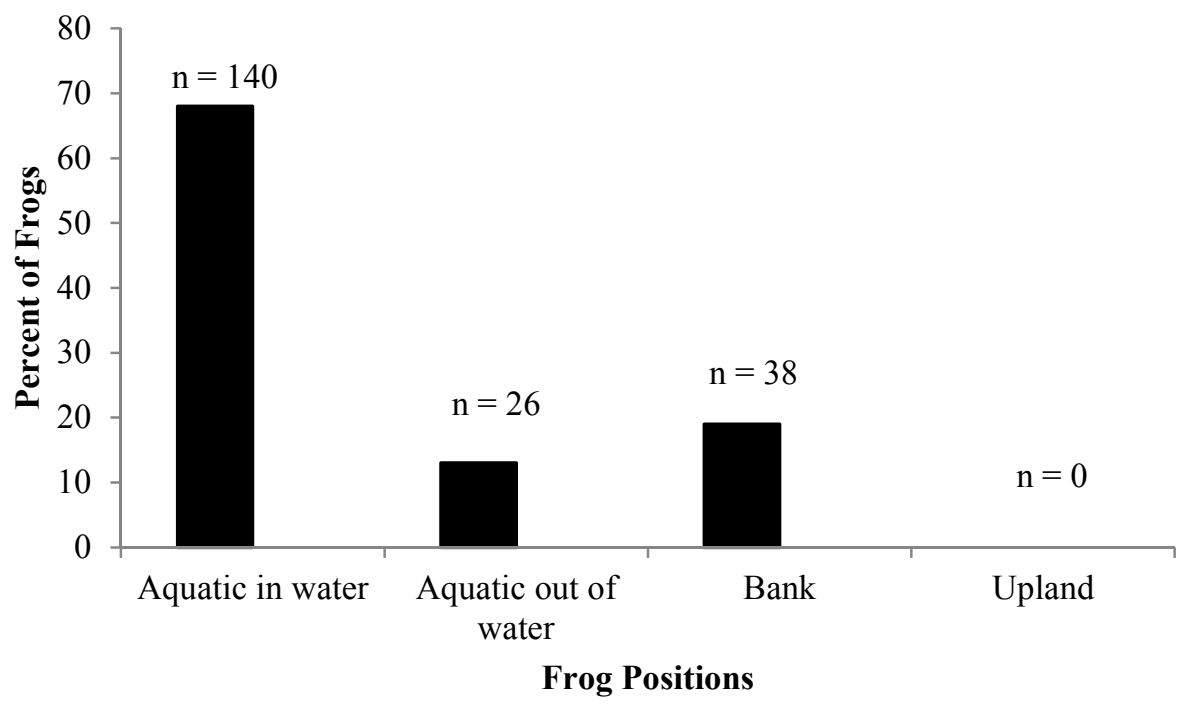

FIGURE 9. Daytime (white bars) and nighttime (black bars) positions of (a) transmittered and (b) nontransmittered visually-located frogs during the non-rainy season from July-early November 2012. Aquatic out of water refers to frogs perched on structures within the stream. 


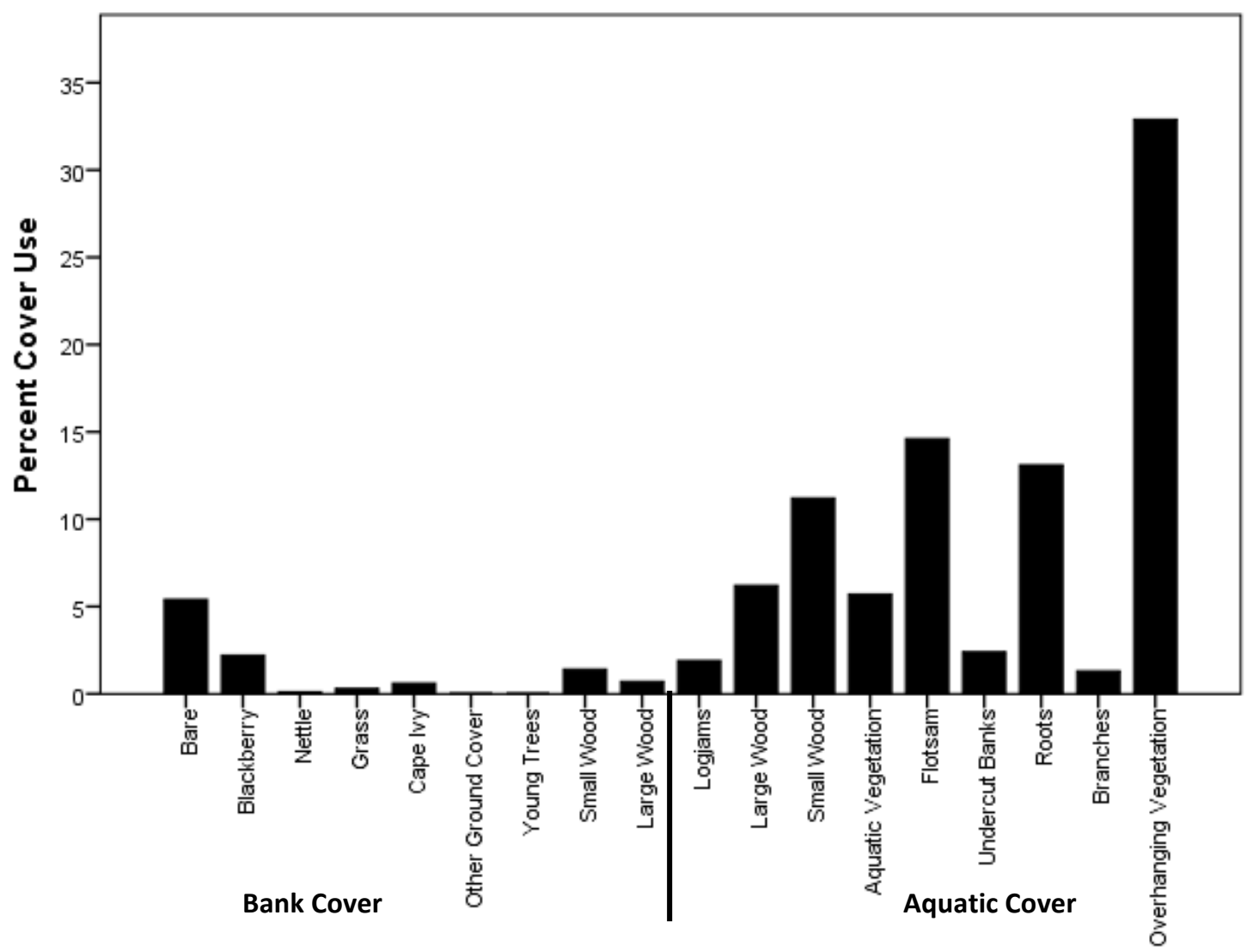

FIGURE 10. Cover-types of nighttime aquatic and bank locations of all non-transmittered California RedLegged Frogs (including repeat encounters and non-captures; $\mathrm{n}=204$ ) along Waddell Creek and lagoon from July-November 2012. No aquatic frogs were located in open water away from cover.

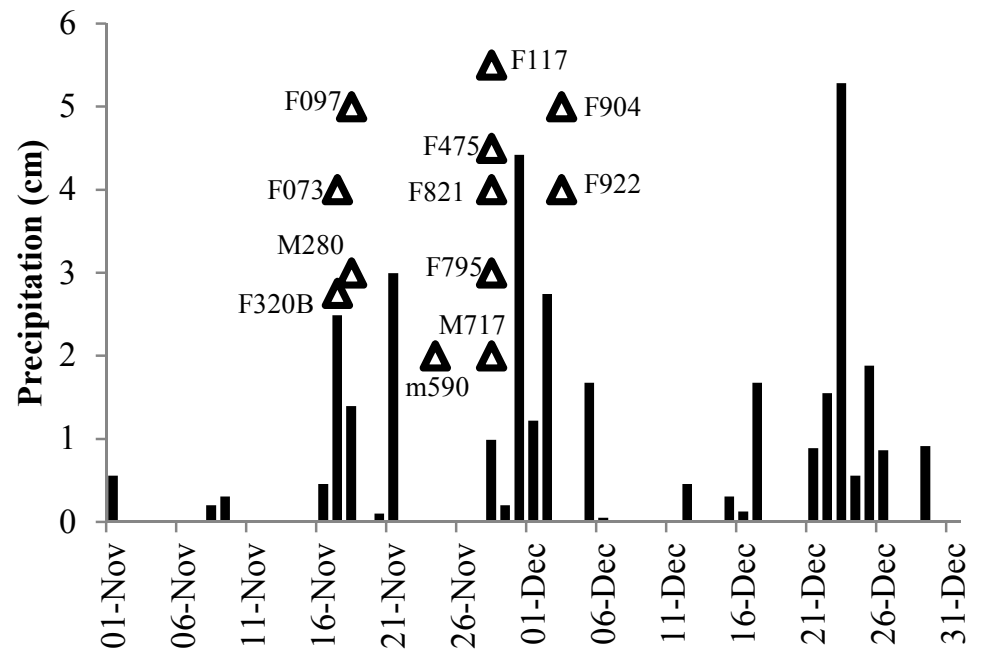

Date

FIGURE 11. Breeding migration timing of transmittered frogs along Waddell Creek during precipitation events (bars; NOAA Record of Climatological Observations 2013) in November and December 2012. Triangles with frog identifier indicate dates of breeding migration initiation. 
a)

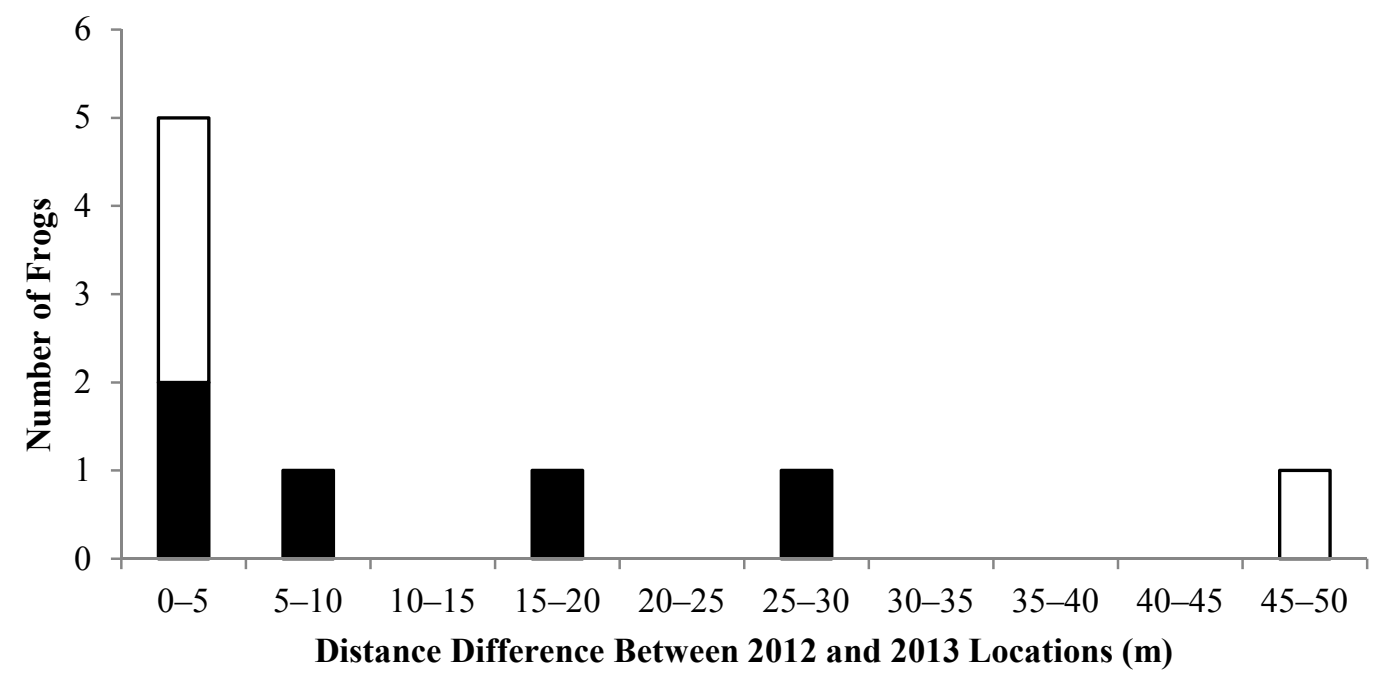

b)

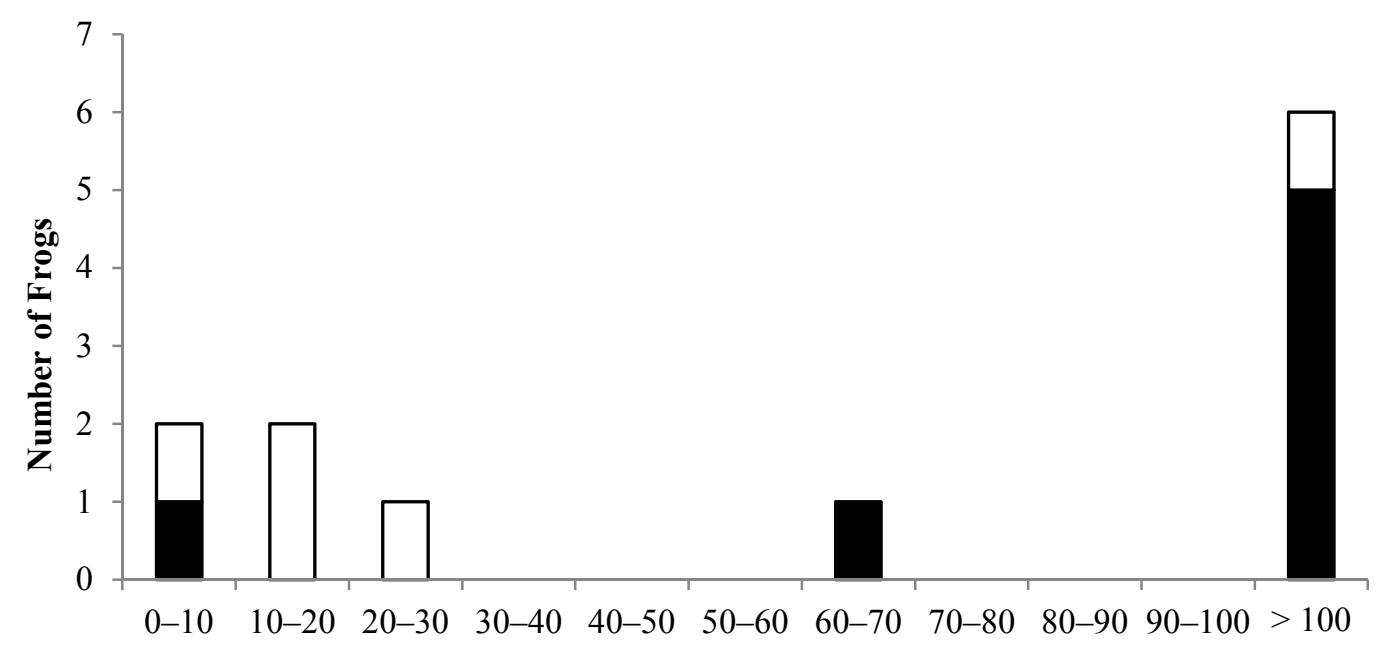

Distance Difference Between 2012 and 2013 Locations (m)

FIGURE 12. Distance differences of (a) transmittered and (b) non-transmittered California Red-Legged Frogs to precise locations along Waddell Creek between 2012 and 2013, confirmed by subsequent recaptures of individuals in summer of 2013. Black bars represent frogs captured in 2013 downstream of 2012 locations; white bars represent frogs captured upstream. Five non-transmittered frogs were captured in 2013 over $100 \mathrm{~m}$ downstream $(199,567,701,866,1759 \mathrm{~m}$; black bar) of their 2012 locations and one frog was captured upstream ( $236 \mathrm{~m}$; white bar). 
TABLES 
TABLE 1. Percent available bank ( $\leq 0.8 \mathrm{~m}$ from shore) and aquatic cover from the transect along Waddell Creek upstream of the lagoon. Values were used to compare frog habitat use in 2012. Eleven frogs were captured downstream of stream marker 46.

\begin{tabular}{|c|c|c|c|c|c|c|c|c|c|c|c|c|c|c|c|c|c|c|c|c|c|c|}
\hline \multirow[b]{2}{*}{$\begin{array}{c}\text { Reach } \\
\#\end{array}$} & \multirow[b]{2}{*}{ Location } & \multirow[b]{2}{*}{$\begin{array}{c}\text { Stream } \\
\text { Length } \\
(\mathrm{m})\end{array}$} & \multirow[b]{2}{*}{$\begin{array}{l}\text { Available } \\
\text { Number } \\
\text { Points } \\
\text { Sampled }\end{array}$} & \multirow[b]{2}{*}{$\begin{array}{c}\text { Number } \\
\text { of Frogs } \\
\text { Caught } \\
\text { in } 2012\end{array}$} & \multicolumn{9}{|c|}{ Bank Cover } & \multicolumn{9}{|c|}{ Aquatic Cover } \\
\hline & & & & & $\begin{array}{l}\stackrel{\varpi}{0} \\
\text { है }\end{array}$ & 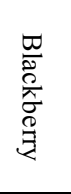 & $\frac{Z}{\stackrel{Z}{O}}$ & 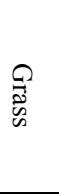 & 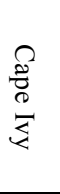 & 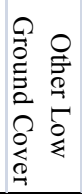 & 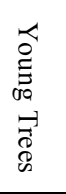 & 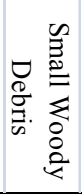 & 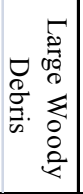 & 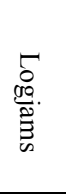 & 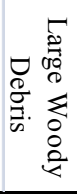 & 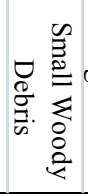 & 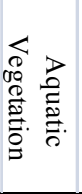 & 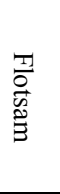 & 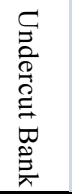 & 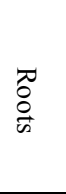 & 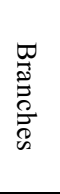 & 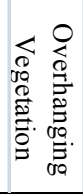 \\
\hline & SM 46 to 124 (Entire Stream) & 2377 & 238 & 53 & 26.6 & 7.7 & 1.5 & 1.6 & 2.3 & 2.0 & 1.8 & 4.7 & 1.5 & 0.3 & 3.5 & 8.0 & 14.3 & 0.2 & 4.0 & 4.0 & 1.9 & 14.1 \\
\hline $1 *$ & SM 46 to 54 (Transition Zone) & 244 & 24 & 7 & 11.1 & 12.9 & 0.2 & 0.0 & 2.2 & 0.0 & 2.4 & 5.1 & 1.9 & 0.0 & 9.4 & 8.8 & \begin{tabular}{|l|}
25.1 \\
\end{tabular} & 0.4 & 1.0 & 0.5 & 4.2 & 14.8 \\
\hline $2 *$ & SM 54 to 60 & 186 & 18 & 11 & 20.4 & 7.7 & 0.4 & 1.5 & 8.1 & 0.2 & 0.3 & 3.9 & 1.2 & 0.1 & 6.2 & 8.2 & 6.3 & 0.6 & 3.8 & 2.4 & 5.9 & 22.8 \\
\hline 3 & SM 60 to 64 & 122 & 12 & 1 & 28.2 & 10.0 & 2.4 & 2.2 & 3.3 & 3.6 & 0.5 & 2.2 & 0.2 & 0.0 & 1.9 & 10.7 & 6.0 & 0.0 & 10.9 & 3.6 & 0.5 & 13.8 \\
\hline $4^{*}$ & SM 64 to 67 & 91 & 9 & 11 & 21.8 & 5.9 & 0.9 & 3.3 & 6.2 & 0.0 & 0.6 & 3.3 & 2.0 & 4.0 & 0.9 & 21.2 & 15.7 & 0.6 & 4.8 & 4.8 & 1.0 & 3.0 \\
\hline 5 & SM 67 to 78 & 335 & 33 & 1 & 33.4 & 5.9 & 1.8 & 0.7 & 2.5 & 1.7 & 1.9 & 7.5 & 5.4 & 0.0 & 2.9 & 11.7 & 0.0 & 0.4 & 4.7 & 5.7 & 1.6 & 12.2 \\
\hline 6 & SM 78 to 97 & 579 & 60 & 21 & 28.9 & 8.6 & 1.4 & 2.0 & 2.2 & 1.7 & 2.4 & 4.4 & 0.9 & 0.0 & 3.1 & 4.2 & 14.1 & 0.1 & 5.0 & 5.0 & 1.3 & 14.7 \\
\hline 7 & SM 97 to 124 & 823 & 81 & 1 & 30.5 & 5.9 & 2.2 & 1.9 & 0.0 & 3.5 & 1.9 & 4.6 & 1.5 & 0.0 & 1.5 & 7.4 & 16.7 & 0.0 & 3.1 & 4.4 & 0.9 & 14.0 \\
\hline
\end{tabular}

* Observed aquatic and bank microhabitat frequencies in Reach $1\left(X^{2}[14, \mathrm{n}=146]=32.509, \mathrm{p}=0.003\right), \operatorname{Reach} 2\left(X^{2}[14, \mathrm{n}=135]=87.555, \mathrm{p}<0.05\right)$, and Reach $4\left(X^{2}[16, \mathrm{n}=131]=75.375, \mathrm{p}<0.001\right)$ differed significantly from aquatic and bankside cover expected throughout the entire stream. Boxes indicate habitat values substantially different from entire stream. 
TABLE 2. Percent available upland cover (at and beyond the top of the bank) from the transect along Waddell Creek.

\begin{tabular}{|c|c|c|c|c|c|c|c|c|c|c|c|c|c|}
\hline \multirow[b]{2}{*}{$\begin{array}{c}\text { Reach } \\
\#\end{array}$} & \multirow[b]{2}{*}{ Location } & \multirow[b]{2}{*}{$\begin{array}{c}\text { Stream } \\
\text { Length } \\
\text { (m) }\end{array}$} & \multirow[b]{2}{*}{$\begin{array}{l}\text { Available } \\
\text { Number } \\
\text { Points } \\
\text { Sampled }\end{array}$} & \multirow[b]{2}{*}{$\begin{array}{l}\text { Number } \\
\text { of Frogs } \\
\text { Caught } \\
\text { in } 2012\end{array}$} & \multicolumn{9}{|c|}{ Upland Ground Cover } \\
\hline & & & & & 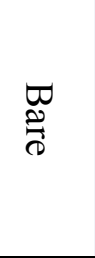 & 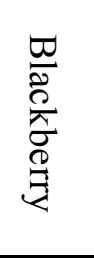 & 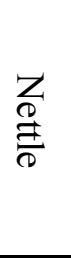 & $\mathbb{Q}_{\substack{0 \\
\infty}}^{\infty}$ & 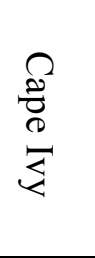 & 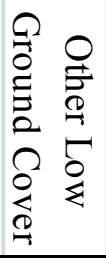 & 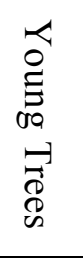 & 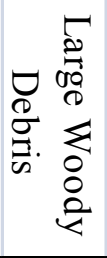 & 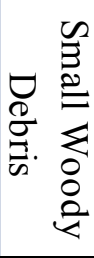 \\
\hline & SM 46 to 124 (Entire Stream) & 2377 & 238 & 53 & 23.8 & 30.8 & 4.0 & 4.2 & 17.6 & 6.9 & 4.9 & 1.9 & 5.9 \\
\hline $1 *$ & SM 46 to 54 (Transition Zone) & 244 & 24 & 7 & 1.8 & 54.7 & 0.0 & 0.6 & 38.4 & 2.2 & $\mathbf{0 . 0}$ & 0.2 & 2.1 \\
\hline $2 *$ & SM 54 to 60 & 186 & 18 & 11 & 26.1 & 21.6 & 1.6 & 4.9 & 31.7 & 3.1 & 4.0 & 1.3 & 5.7 \\
\hline $3 *$ & SM 60 to 64 & 122 & 12 & 1 & 20.2 & 31.6 & 3.8 & 0.4 & 33.5 & 2.3 & 2.1 & 0.2 & 5.9 \\
\hline $4 *$ & SM 64 to 67 & 91 & 9 & 11 & 23.7 & 20.2 & 7.6 & 6.7 & 26.5 & 3.0 & 2.2 & 2.8 & 7.3 \\
\hline 5 & SM 67 to 78 & 335 & 33 & 1 & 25.0 & 25.3 & 6.5 & 4.1 & 23.9 & 5.2 & 0.5 & 2.5 & 7.0 \\
\hline 6 & SM 78 to 97 & 579 & 60 & 21 & 20.2 & 32.9 & 4.5 & 4.1 & 21.1 & 6.5 & 5.3 & 1.6 & 3.8 \\
\hline 7 & SM 97 to 124 & 823 & 81 & 1 & 32.6 & 27.3 & 4.0 & 5.5 & 0.0 & 11.1 & 8.7 & 2.6 & 8.2 \\
\hline
\end{tabular}

* Observed upland microhabitat frequencies in Reach $1\left(X^{2}[6, \mathrm{n}=101]=60.634, \mathrm{p}<0.001\right)$, Reach $2\left(X^{2}[8, \mathrm{n}=101]=15.775, \mathrm{p}=0.046\right)$, Reach 3 $\left(X^{2}[6, \mathrm{n}=100]=16.270, \mathrm{p}=0.012\right)$, and Reach $4\left(X^{2}[9, \mathrm{n}=99]=18.068, \mathrm{p}=0.034\right)$ differed significantly from upland cover expected throughout the entire stream. Boxes indicate habitat values substantially different from entire stream. 
TABLE 3. Additional habitat characteristics available in (a) aquatic and bank (to the top of the bank) and (b) upland (at and beyond the top of the bank) habitat throughout Waddell Creek. Shown below are means with standard deviations in parentheses. Cover Quality and Basking Quality $(1=$ very poor; $2=$ poor; $3=$ fair; $4=$ good; $5=$ very good $)$, and Basking Potential $(1=15-30$ min.; $2=30 \mathrm{~min}-2 \mathrm{~h} ; 3=4+\mathrm{h})$ are ratings based on field observations. Escape Water Depth is the depth of water $0.6 \mathrm{~m}$ out from shore, the distance a frog can cover when jumping from an inclined position. Boxes indicate habitat values substantially different from entire stream.

a)

\begin{tabular}{|c|c|c|c|c|c|c|c|c|}
\hline \multirow[b]{2}{*}{ Reach \# } & \multirow[b]{2}{*}{ Location } & \multicolumn{2}{|c|}{ Aquatic } & \multicolumn{5}{|c|}{ Bank Below Bank Crest } \\
\hline & & $\begin{array}{c}\text { Escape Water } \\
\text { Depth }(\mathrm{m}) \\
\end{array}$ & $\begin{array}{l}\text { Aquatic Cover } \\
\text { Quality Rating } \\
\end{array}$ & $\begin{array}{c}\text { Bank Slope } \\
\left({ }^{\circ}\right) \\
\end{array}$ & \% Canopy & $\begin{array}{l}\text { Hiding Cover } \\
\text { Quality Rating }\end{array}$ & $\begin{array}{c}\text { Basking Quality } \\
\text { Rating } \\
\end{array}$ & $\begin{array}{c}\text { Basking Potential in } \\
\text { Direct Sun }\end{array}$ \\
\hline & SM 46 to 124 (Entire Stream) & $0.8(0.5)$ & $2.4(1.5)$ & $33.1(7.5)$ & $84.8(33.2)$ & $3.1(1.4)$ & $1.6(0.9)$ & $1.4(0.6)$ \\
\hline 1 & SM 46 to 54 (Transition Zone) & $1.5(0.5)$ & $3.0(1.6)$ & $40.5(4.5)$ & $60.6(38.3)$ & $4.3(1.0)$ & $1.7(0.7)$ & $1.8(0.4)$ \\
\hline 2 & SM 54 to 60 & $1.0(0.6)$ & $3.3(1.7)$ & $31.4(6.0)$ & $81.2(33.3)$ & $3.4(1.4)$ & $1.6(1.0)$ & $1.5(0.5)$ \\
\hline 3 & SM 60 to 64 & $0.4(0.1)$ & $2.1(1.4)$ & $32.9(10.5)$ & $88.3(29.2)$ & $2.8(1.4)$ & $1.1(0.4)$ & $1.1(0.4)$ \\
\hline 4 & SM 64 to 67 & $0.6(0.5)$ & $2.6(1.8)$ & $25.8(7.5)$ & $87.0(25.6)$ & $3.6(1.7)$ & $1.7(0.9)$ & $1.6(0.5)$ \\
\hline 5 & SM 67 to 78 & $0.6(0.5)$ & $2.5(1.5)$ & $28.5(6.0)$ & $97.7(23.6)$ & $3.0(1.4)$ & $1.4(0.9)$ & $1.3(0.6)$ \\
\hline 6 & SM 78 to 97 & $0.7(0.5)$ & $2.3(1.4)$ & $34.2(6.0)$ & $91.3(28.2)$ & $3.1(1.3)$ & $1.7(1.0)$ & $1.5(0.6)$ \\
\hline 7 & SM 97 to 124 & $0.7(0.4)$ & $2.3(1.4)$ & $33.3(9.0)$ & $82.1(35.5)$ & $2.7(1.3)$ & $1.7(0.8)$ & $1.3(0.5)$ \\
\hline
\end{tabular}
b)

\begin{tabular}{|l|l|l|}
\hline & & \multicolumn{2}{|c}{ Upland Above Bank Crest } \\
\hline & & \\
Reach \# & Location & Upland Slope ( $\left.{ }^{\circ}\right) \quad$ \% Canopy \\
\hline \hline
\end{tabular}

\begin{tabular}{|c|c|c|c|}
\hline & SM 46 to 124 (Entire Stream) & $26.7(13.5)$ & $81.3(30.8)$ \\
\hline & & & \\
\hline 1 & SM 46 to 54 (Transition Zone) & $28.8(10.5)$ & $71.5(30.8)$ \\
\hline 2 & SM 54 to 60 & $30.2(1.5)$ & $70.4(36.6)$ \\
\hline 3 & SM 60 to 64 & $20.8(9.0)$ & $71.7(27.8)$ \\
\hline 4 & SM 64 to 67 & $\mathbf{1 4 . 0}(\mathbf{1 5 . 0})$ & $\mathbf{6 2 . 6 ( 2 8 . 2 )}$ \\
\hline 5 & SM 67 to 78 & $23.6(12.0)$ & $86.5(28.8)$ \\
\hline 6 & SM 78 to 97 & $27.3(13.5)$ & $83.1(28.7)$ \\
\hline 7 & SM 97 to 124 & $28.0(15.0)$ & $86.7(30.6)$ \\
\hline
\end{tabular}


TABLE 4. Summary of percent use during daytime of aquatic and bank (to the top of the bank) cover-types within $0.8 \mathrm{~m}$ radius of each transmittered frog between July-early November 2012. For each frog, the most used microhabitat feature is bolded and boxed; the second most used microhabitat feature is bolded and underlined; the third most used microhabitat feature is underlined. Cover Quality and Basking Quality $(1=$ very poor; $2=$ poor; 3 = fair; 4 = good; $5=$ very good) are ratings based on field observations. Standard deviations for Cover and Basking Ratings are shown in parentheses. One frog with fewer than five observations was excluded from the table.

\begin{tabular}{|c|c|c|c|c|c|c|c|c|c|c|c|c|c|c|c|c|c|c|c|c|c|c|}
\hline \multirow[b]{2}{*}{ Frog } & \multirow[b]{2}{*}{$\begin{array}{l}\text { Home } \\
\text { Range }\end{array}$} & \multirow[b]{2}{*}{$\begin{array}{c}\text { Number of } \\
\text { Observations }\end{array}$} & \multicolumn{9}{|c|}{ Bank Cover } & \multicolumn{9}{|c|}{ Aquatic Cover } & \multirow[b]{2}{*}{$\begin{array}{c}\text { Mean } \\
\text { Cover } \\
\text { Quality } \\
\text { Rating }\end{array}$} & \multirow[b]{2}{*}{$\begin{array}{c}\text { Mean } \\
\text { Basking } \\
\text { Quality } \\
\text { Rating }\end{array}$} \\
\hline & & & $\begin{array}{l}\mathscr{W} \\
\text { हैं }\end{array}$ & $\begin{array}{l}\frac{\varpi}{20} \\
\frac{0}{2} \\
\frac{\bar{\pi}}{0} \\
\frac{0}{2}\end{array}$ & $\frac{z}{\frac{Z}{0}}$ & 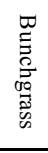 & 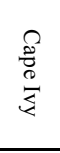 & 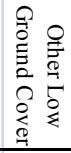 & 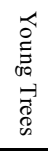 & 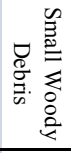 & 竞 & 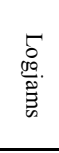 & 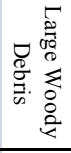 & 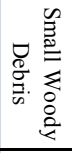 & 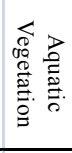 & 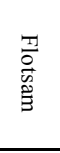 & 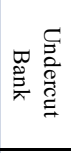 & $\begin{array}{l}\pi \\
\vdots \\
\vdots \\
\infty\end{array}$ & 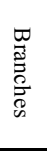 & 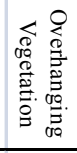 & & \\
\hline $\mathrm{m} 590$ & 5550 & 12 & 4.5 & 3.5 & 1.0 & 0.0 & 28.0 & 0.0 & 0.0 & 1.0 & 0.0 & 0.0 & 0.0 & 4.0 & 5.5 & 6.0 & 21.0 & 16.0 & 0.0 & 9.5 & 5.0 & 2.4 \\
\hline F 821 & 5555 & 13 & $\underline{14.6}$ & 0.0 & 0.0 & 0.0 & 0.0 & 6.2 & 0.0 & 0.0 & 0.0 & 0.0 & 4.6 & $\underline{19.6}$ & 8.5 & 8.1 & 0.0 & 0.0 & 5.8 & 32.6 & 4.3 & 3.2 \\
\hline M475 & 5840 & 19 & 0.0 & 4.3 & 0.0 & 0.0 & 13.5 & 0.0 & 0.0 & 0.0 & 0.0 & 0.0 & 0.0 & 5.3 & 2.6 & $\underline{18.5}$ & 3.3 & 5.0 & 12.9 & 34.6 & 4.7 & 2.1 \\
\hline M280 & 5865 & 17 & 9.3 & 13.2 & 0.0 & 0.0 & $\underline{13.9}$ & 0.0 & 2.8 & 3.2 & 0.0 & 0.0 & 0.0 & $\underline{18.9}$ & 0.0 & 11.7 & 0.0 & 19.9 & 1.4 & 5.7 & 4.5 & 2.3 \\
\hline F117 & 5910 & 20 & 1.4 & 2.9 & 4.6 & 0.0 & 2.6 & 0.0 & 0.0 & 0.0 & 0.0 & 0.0 & 4.9 & 21.7 & 0.6 & 15.4 & 2.5 & 1.7 & 7.2 & 34.5 & 5.0 & 2.5 \\
\hline F97 & 5950 & 19 & 2.3 & 3.4 & 0.0 & 0.0 & 1.7 & 1.1 & 5.6 & 4.0 & 0.0 & 0.0 & 0.0 & 5.6 & 0.0 & $\underline{20.9}$ & 15.8 & 5.1 & 6.8 & 27.7 & 4.7 & 2.1 \\
\hline f9 & 6544 & 14 & 3.8 & 13.6 & 3.0 & 0.0 & 20.8 & 3.8 & 0.8 & 0.0 & 0.0 & 8.7 & 1.1 & 6.0 & 7.9 & $\underline{15.8}$ & 0.0 & $\underline{14.7}$ & 0.0 & 0.0 & 4.8 & 2.9 \\
\hline f 437 & 6545 & 25 & 5.1 & 5.9 & 1.4 & 3.7 & 5.7 & 2.0 & 1.6 & 0.0 & 0.4 & 4.9 & $\underline{10.8}$ & 17.3 & 31.0 & 6.5 & 0.0 & 3.3 & 0.0 & 0.4 & 4.9 & 2.8 \\
\hline $\mathrm{F} 363$ & 6550 & 18 & $\underline{15.1}$ & 0.9 & 0.0 & 0.5 & 4.2 & 0.0 & 0.0 & 5.2 & 0.0 & 15.3 & 15.3 & 20.7 & 6.1 & 7.5 & 3.6 & 4.7 & 0.0 & 0.9 & 4.9 & 2.4 \\
\hline M717 & 7555 & 21 & 23.3 & 4.0 & 1.2 & 2.2 & 2.2 & 0.0 & 6.8 & $\underline{18.3}$ & 2.2 & 0.0 & 9.3 & 13.4 & 0.3 & 1.9 & 6.2 & 6.5 & 1.9 & 0.3 & 4.2 & 1.8 \\
\hline $\mathrm{F} 320 \mathrm{~B}$ & 7876 & 7 & 3.3 & 0.0 & 3.3 & 0.0 & 6.7 & 0.0 & 0.0 & 7.5 & 7.5 & 0.0 & 0.0 & 6.7 & 29.2 & 2.5 & 0.0 & $\underline{12.5}$ & 0.0 & $\underline{20.8}$ & 4.2 & 2.4 \\
\hline $\mathrm{F} 255 \mathrm{~B} / 820$ & $81 \mathrm{~A} 09$ & 5 & 0.0 & 0.0 & 0.0 & 0.0 & 40.0 & 0.0 & 5.0 & 0.0 & 0.0 & 0.0 & 0.0 & $\underline{32.5}$ & 5.0 & $\underline{12.5}$ & 0.0 & 0.0 & 0.0 & 5.0 & 4.2 & 2.3 \\
\hline F795 & $81 \mathrm{~B} 60$ & 20 & $\underline{18.2}$ & 44.8 & 0.9 & 5.5 & 1.2 & 5.2 & 0.0 & 1.5 & 0.0 & 0.0 & 1.5 & 3.6 & 1.8 & 0.9 & 5.5 & $\underline{5.8}$ & 0.0 & 3.6 & 4.2 & 2.5 \\
\hline M255A & 8285 & 7 & $\underline{15.8}$ & 2.5 & 0.0 & 3.3 & 0.0 & 0.0 & 0.0 & 0.0 & 25.8 & 0.0 & 0.0 & 4.2 & 10.0 & 4.2 & 12.6 & $\underline{13.3}$ & 0.0 & 8.3 & 4.2 & 2.0 \\
\hline F523 & 8290 & 20 & $\underline{12.8}$ & 7.8 & 0.0 & 3.2 & 0.0 & 1.4 & 0.0 & 2.1 & 0.0 & 0.0 & 5.0 & 8.5 & 0.0 & $\underline{14.5}$ & \begin{tabular}{|l|}
24.5 \\
\end{tabular} & 9.2 & 0.0 & 11.0 & 4.2 & 1.8 \\
\hline F904 & 8487 & 20 & 6.1 & 8.8 & 0.0 & 4.3 & 4.3 & 0.6 & 0.0 & 2.1 & 0.0 & 0.0 & 2.7 & 0.3 & 29.0 & 1.8 & 15.0 & $\underline{17.7}$ & 0.6 & 6.7 & 4.2 & 3.3 \\
\hline F922 & 8825 & 7 & 43.6 & 2.6 & 3.8 & 0.0 & 0.0 & 0.0 & 0.0 & 15.4 & 0.0 & 0.0 & 10.3 & 0.0 & 0.0 & 0.0 & 9.0 & 0.0 & 0.0 & $\underline{15.3}$ & 4.2 & 2.7 \\
\hline F73 & $9089-9520$ & 12 & $\underline{10.5}$ & 46.6 & 1.4 & 0.0 & 0.0 & 0.0 & 0.7 & 0.0 & 0.0 & 0.0 & 0.0 & 0.0 & 0.0 & 2.0 & 31.7 & 7.1 & 0.0 & 0.0 & 4.2 & 2.3 \\
\hline \multirow[t]{3}{*}{ F844 } & $9243-9645$ & 17 & 7.8 & $\underline{25.6}$ & 0.5 & 0.0 & 2.7 & 0.0 & 0.0 & 0.9 & 0.0 & 0.0 & 0.0 & 4.6 & 6.4 & 4.6 & 26.5 & 5.5 & 3.2 & $\underline{11.7}$ & 4.2 & 2.1 \\
\hline & & Mean: & 10.4 & 10.0 & 1.1 & 1.2 & 7.8 & 1.1 & 1.2 & 3.2 & 1.9 & 1.5 & 3.4 & 10.2 & 7.6 & 8.2 & 9.3 & 7.8 & 2.1 & 12.0 & $4.7(0.7)$ & $2.5(1.2)$ \\
\hline & Ava & ailability Mean: & 26.6 & 7.7 & 1.5 & 1.6 & 2.3 & 2.0 & 1.8 & 4.7 & 1.5 & 0.3 & 3.5 & 8.0 & 14.3 & 0.2 & 4.0 & 4.0 & 1.9 & 14.1 & 2.8 & 1.6 \\
\hline
\end{tabular}


TABLE 5. Summary of percent use during nighttime of aquatic and bank (to the top of the bank) cover-types within $0.8 \mathrm{~m}$ radius of each transmittered frog between July-early November 2012. For each frog, the most used microhabitat feature is bolded and boxed; the second most used microhabitat feature is bolded and underlined; the third most used microhabitat feature is underlined. Cover Quality $(1=$ very poor; $2=$ poor; $3=$ fair; $4=$ good; $5=$ very good) are ratings based on field observations. Standard deviation for Cover Rating is shown in parentheses. Two frogs with fewer than five observations were excluded from the table.

\begin{tabular}{|c|c|c|c|c|c|c|c|c|c|c|c|c|c|c|c|c|c|c|c|c|c|}
\hline \multirow[b]{2}{*}{ Frog } & \multirow[b]{2}{*}{$\begin{array}{l}\text { Home } \\
\text { Range }\end{array}$} & \multirow[b]{2}{*}{$\begin{array}{c}\text { Number of } \\
\text { Observations }\end{array}$} & \multicolumn{9}{|c|}{ Bank Cover } & \multicolumn{9}{|c|}{ Aquatic Cover } & \multirow[b]{2}{*}{$\begin{array}{c}\text { Mean } \\
\text { Cover } \\
\text { Quality } \\
\text { Rating }\end{array}$} \\
\hline & & & 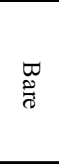 & $\begin{array}{l}\frac{\square}{20} \\
\frac{0}{\hat{\sigma}} \\
\frac{0}{\theta} \\
\ddot{z}\end{array}$ & $\begin{array}{l}\frac{Z}{q} \\
\stackrel{O}{\sigma}\end{array}$ & 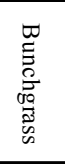 & 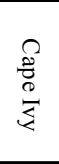 & 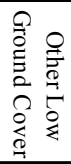 & 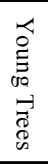 & 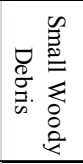 & 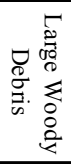 & 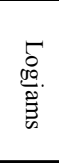 & 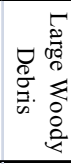 & 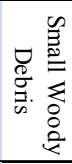 & 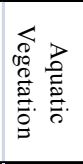 & 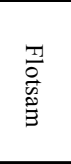 & 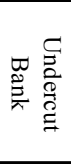 & $\begin{array}{l}\pi \\
0 \\
\dot{0}\end{array}$ & 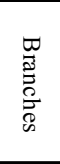 & 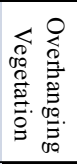 & \\
\hline $\mathrm{m} 590$ & 5550 & 17 & 3.0 & 0.0 & 0.0 & 0.0 & 3.7 & 0.0 & 0.0 & 0.0 & 0.0 & 0.0 & 3.3 & $\underline{20.3}$ & 1.3 & $\underline{14.0}$ & 5.0 & 8.3 & 1.3 & 39.8 & 4.9 \\
\hline F821 & 5555 & 18 & $\underline{13.8}$ & 0.0 & 0.0 & 0.0 & 3.1 & 0.0 & 0.0 & 0.0 & 0.0 & 0.0 & 3.8 & $\underline{11.4}$ & 1.4 & $\underline{9.3}$ & 3.1 & 0.0 & 3.1 & 51.0 & 4.1 \\
\hline M475 & 5840 & 20 & $\overline{5.2}$ & 0.6 & 0.0 & 1.7 & $\underline{12.5}$ & 0.0 & 0.0 & 0.0 & 0.0 & 0.0 & 0.0 & $\overline{6.9}$ & 8.8 & $\underline{22.9}$ & 0.0 & 2.1 & 11.0 & 28.3 & 4.6 \\
\hline M280 & 5865 & 20 & 3.0 & 4.7 & 0.0 & 0.0 & $\overline{0.0}$ & 0.0 & 0.0 & 0.0 & 0.0 & 0.0 & 1.5 & 12.5 & 0.0 & $\overline{19.9}$ & 0.3 & $\underline{15.6}$ & 6.1 & 36.4 & 3.9 \\
\hline F117 & 5910 & 23 & 11.5 & 3.0 & 0.0 & 5.3 & 2.0 & 0.0 & 0.3 & 0.0 & 0.0 & 0.0 & 1.5 & $\underline{17.5}$ & 0.0 & 25.8 & 4.0 & 8.0 & 1.8 & $\underline{19.3}$ & 4.0 \\
\hline F97 & 5950 & 18 & 3.5 & $\underline{11.6}$ & 2.0 & 0.0 & 9.9 & 0.5 & 1.5 & 3.7 & 0.0 & 0.0 & 0.0 & $\overline{9.1}$ & 0.5 & 12.3 & 2.9 & 9.9 & 5.2 & 27.4 & 4.8 \\
\hline f9 & 6544 & 19 & 4.8 & 7.9 & 4.0 & 1.3 & 9.3 & 0.0 & 2.4 & 0.5 & 1.6 & $\underline{13.2}$ & 0.3 & 9.5 & 6.6 & 34.9 & 0.0 & 2.6 & 0.0 & 1.1 & 4.8 \\
\hline f 437 & 6545 & 22 & 7.2 & 5.5 & 0.7 & $\underline{12.5}$ & $\underline{12.0}$ & 0.0 & 0.5 & 0.0 & 2.4 & 1.4 & 2.4 & $\overline{4.3}$ & 32.2 & 3.8 & 0.0 & 11.5 & 0.2 & 3.4 & 5.0 \\
\hline F363 & 6550 & 22 & 1.3 & 0.9 & 0.4 & $\overline{0.4}$ & 2.2 & 0.0 & 0.0 & 0.0 & 0.0 & $\underline{17.6}$ & 6.2 & 13.6 & 21.1 & $\underline{18.7}$ & 7.0 & 9.7 & 0.0 & 0.9 & 4.8 \\
\hline M717 & 7555 & 18 & 40.1 & 4.3 & 0.0 & 0.0 & 9.1 & 0.0 & 3.3 & 5.1 & 1.5 & 0.0 & 2.3 & 3.0 & 0.0 & 1.5 & 5.1 & $\underline{11.4}$ & 5.6 & 7.7 & 4.0 \\
\hline $\mathrm{F} 320 \mathrm{~B}$ & 7876 & 9 & 0.0 & 0.0 & 0.0 & 0.0 & 10.0 & 0.0 & 0.0 & 0.0 & 0.0 & 0.0 & 1.1 & 10.0 & 35.6 & 4.4 & 0.0 & $\underline{25.0}$ & 0.0 & 13.9 & 4.6 \\
\hline F795 & $81 \mathrm{~B} 60$ & 25 & $\underline{24.5}$ & 29.1 & 0.4 & 0.8 & 0.2 & 2.5 & 0.0 & 1.1 & 0.0 & 0.0 & 0.0 & 3.0 & 0.0 & 3.8 & 7.4 & 6.8 & 4.0 & 16.4 & 4.5 \\
\hline M255A & 8285 & 9 & 9.4 & 0.6 & 0.0 & $\underline{18.2}$ & 0.0 & 0.0 & 0.0 & 0.0 & 0.0 & 0.0 & 5.9 & 9.4 & 7.1 & 7.1 & 0.0 & 0.0 & 0.0 & 42.3 & 4.5 \\
\hline F523 & 8290 & 24 & $\underline{13.8}$ & 22.1 & 1.4 & $\underline{15.3}$ & 4.8 & 2.2 & 0.0 & 4.3 & 0.0 & 0.0 & 2.7 & 5.3 & 0.5 & 7.7 & 7.7 & 1.4 & 0.3 & 10.5 & 4.2 \\
\hline F904 & 8487 & 25 & 6.1 & 1.1 & 1.6 & 6.5 & 3.8 & 0.0 & 6.1 & 1.8 & 0.0 & 0.0 & 2.0 & 0.0 & 36.4 & 2.7 & 7.2 & $\underline{11.3}$ & 3.4 & $\underline{10.0}$ & 4.5 \\
\hline F922 & 8825 & 5 & $\underline{17.1}$ & 19.7 & 1.3 & 0.0 & 32.9 & 1.3 & 6.6 & 0.0 & 0.0 & 0.0 & 0.0 & 0.0 & 3.9 & 4.6 & 6.6 & 4.6 & 1.4 & 0.0 & 4.8 \\
\hline F73 & $9089-9520$ & 14 & $\underline{27.0}$ & 36.0 & 1.1 & 0.0 & 0.0 & 0.0 & 0.6 & 0.6 & 0.0 & 0.0 & 1.7 & $\underline{10.0}$ & 0.0 & 8.1 & 5.6 & 3.1 & 5.6 & 0.6 & 4.0 \\
\hline \multirow[t]{3}{*}{ F844 } & $9243-9645$ & 22 & $\underline{17.8}$ & 40.1 & 1.0 & 0.0 & 1.0 & 0.0 & 0.3 & 5.2 & 0.0 & 0.0 & 1.9 & 3.7 & 0.0 & 4.4 & 8.0 & 10.8 & 0.0 & 5.8 & 4.2 \\
\hline & & Mean:| & 11.6 & 10.4 & 0.8 & 3.4 & 6.5 & 0.4 & 1.2 & 1.2 & 0.3 & 1.8 & 2.0 & 8.3 & 8.6 & 11.4 & 3.9 & 7.9 & 2.7 & 17.5 & $4.5(1.0)$ \\
\hline & & iilability Mean: & 26.6 & 7.7 & 1.5 & 1.6 & 2.3 & 2.0 & 1.8 & 4.7 & 1.5 & 0.3 & 3.5 & 8.0 & 14.3 & 0.2 & 4.0 & 4.0 & 1.9 & 14.1 & 2.8 \\
\hline
\end{tabular}


TABLE 6. Summary of use during daytime of additional habitat characteristics of each transmittered frog between July-early November 2012. Means and medians are shown with standard deviations and interquartile ranges in parentheses. Two frogs with fewer than five observations were excluded from the table.

\begin{tabular}{|c|c|c|c|c|c|c|c|c|c|}
\hline \multirow[b]{2}{*}{ Frog } & \multirow[b]{2}{*}{$\begin{array}{l}\text { Home } \\
\text { Range }\end{array}$} & \multirow[b]{2}{*}{$\begin{array}{c}\text { Number of } \\
\text { Observations }\end{array}$} & \multirow[b]{2}{*}{$\begin{array}{c}\text { Mean Water } \\
\text { Depth for } \\
\text { Escape }(\mathrm{m})\end{array}$} & \multirow[b]{2}{*}{ Mean Slope $\left({ }^{\circ}\right)$} & \multirow[b]{2}{*}{$\begin{array}{c}\text { Mean \% Canopy } \\
\text { Cover } \\
\end{array}$} & \multicolumn{2}{|c|}{ Bank and Upland Positions } & \multicolumn{2}{|c|}{ Aquatic Positions } \\
\hline & & & & & & $\begin{array}{l}\text { Mean Distance } \\
\text { from Stream }(\mathrm{m})\end{array}$ & $\begin{array}{c}\text { Median Distance } \\
\text { from Stream }(\mathrm{m})\end{array}$ & $\begin{array}{c}\text { Mean Distance } \\
\text { from Bank (m) }\end{array}$ & $\begin{array}{c}\text { Median Distance } \\
\text { from Bank (m) }\end{array}$ \\
\hline m 590 & 5550 & 12 & 0.7 & 53.1 & 73.8 & 3.2 & 0.2 & 0.1 & 0.03 \\
\hline F821 & 5555 & 13 & 0.5 & 62.2 & 85.4 & 0.2 & 0.3 & 1.0 & 0.8 \\
\hline M475 & 5840 & 19 & 0.7 & 61.3 & 94.7 & 1.1 & 0.3 & 1.0 & 0.8 \\
\hline M280 & 5865 & 17 & 0.7 & 58.1 & 87.7 & 0.4 & 0.3 & 1.5 & 0.7 \\
\hline F117 & 5910 & 20 & 0.7 & 76.6 & 76.2 & 0.5 & 0.5 & 0.9 & 0.6 \\
\hline F97 & 5950 & 19 & 0.8 & 85.0 & 81.5 & 2.9 & 0.6 & 1.1 & 0.6 \\
\hline f9 & 6544 & 14 & 0.5 & 23.0 & 68.9 & 4.2 & 0.6 & 1.0 & 0.8 \\
\hline $\mathrm{f} 437$ & 6545 & 25 & 0.5 & 31.4 & 63.7 & 5.3 & 0.7 & 1.9 & 1.8 \\
\hline F363 & 6550 & 18 & 0.7 & 55.6 & 58.3 & 0.4 & 0.8 & 1.2 & 0.6 \\
\hline M717 & 7555 & 21 & 0.6 & 36.8 & 88.2 & 4.6 & 0.8 & 0.7 & 0.9 \\
\hline F320B & 7876 & 7 & 0.4 & 39.0 & 66.7 & 10.3 & 0.8 & 0.8 & 0.8 \\
\hline F795 & $81 \mathrm{~B} 60$ & 20 & 0.6 & 52.8 & 91.1 & 1.5 & 0.9 & 0.4 & 0.0 \\
\hline M255A & 8285 & 7 & 0.3 & 33.3 & 98.8 & 0.7 & 1.7 & 0.7 & 0.03 \\
\hline F523 & 8290 & 20 & 0.5 & 52.3 & 95.8 & 4.4 & 2.7 & 0.6 & 0.08 \\
\hline F904 & 8487 & 20 & 0.3 & 57.3 & 76.6 & 2.3 & 3.2 & 0.2 & 0.03 \\
\hline F922 & 8825 & 7 & 0.3 & 43.8 & 94.2 & 3.7 & 3.5 & 0.1 & 0.03 \\
\hline F73 & $9089-9520$ & 12 & 0.3 & 52.2 & 99.0 & 1.5 & 3.7 & 0.1 & 0.03 \\
\hline \multirow[t]{3}{*}{ F844 } & $9243-9645$ & 17 & 0.3 & 54.0 & 95.0 & 5.4 & 3.7 & 0.5 & 0.2 \\
\hline & \multicolumn{2}{|c|}{ Mean or Median*: } & $0.6(0.3)$ & $52.0(26.6)$ & $83.7(36.9)$ & $1.3(3.4)$ & $0.03(0.03-0.03)^{*}$ & $0.6(0.8)$ & $0.06(0.03-0.8)^{*}$ \\
\hline & \multicolumn{2}{|c|}{ Availability Mean: } & $0.8(0.5)$ & $33.1(7.5)$ & $84.4(33.2)$ & NA & NA & NA & $\mathrm{NA}$ \\
\hline
\end{tabular}


TABLE 7. Summary of use during nighttime of additional habitat characteristics of each transmittered frog and totals for all non-transmittered frogs (bottom) between July-early November 2012. Means and medians are shown with standard deviations and interquartile ranges in parentheses. Two frogs with fewer than five observations were excluded from the table.

\begin{tabular}{|c|c|c|c|c|c|c|c|c|}
\hline \multirow[b]{2}{*}{ Frog } & \multirow[b]{2}{*}{$\begin{array}{l}\text { Home } \\
\text { Range }\end{array}$} & \multirow[b]{2}{*}{$\begin{array}{c}\text { Number of } \\
\text { Observations }\end{array}$} & \multirow[b]{2}{*}{$\begin{array}{c}\text { Mean Water } \\
\text { Depth for } \\
\text { Escape }(\mathrm{m})\end{array}$} & \multirow[b]{2}{*}{ Mean Slope $\left(^{\circ}\right)$} & \multicolumn{2}{|c|}{ Bank and Upland Positions } & \multicolumn{2}{|c|}{ Aquatic Positions } \\
\hline & & & & & $\begin{array}{l}\text { Mean Distance } \\
\text { from Stream }(\mathrm{m})\end{array}$ & $\begin{array}{l}\text { Median Distance } \\
\text { from Stream }(\mathrm{m})\end{array}$ & $\begin{array}{l}\text { Mean Distance } \\
\text { from Bank }(\mathrm{m})\end{array}$ & $\begin{array}{c}\text { Median Distance } \\
\text { from Bank (m) }\end{array}$ \\
\hline $\mathrm{m} 590$ & 5550 & 17 & 0.7 & 47.6 & 2.1 & 1.1 & 0.8 & 0.6 \\
\hline F821 & 5555 & 18 & 0.5 & 54.4 & 1.3 & 1.1 & 0.8 & 0.5 \\
\hline M475 & 5840 & 20 & 0.7 & 61.3 & 1.1 & 0.9 & 1.0 & 1.4 \\
\hline M280 & 5865 & 20 & 0.7 & 60.8 & 0.03 & 0.03 & 1.7 & 1.4 \\
\hline F117 & 5910 & 23 & 0.6 & 61.8 & 1.1 & 0.6 & 1.2 & 1.1 \\
\hline F97 & 5950 & 18 & 0.7 & 66.2 & 3.6 & 1.1 & 1.0 & 0.4 \\
\hline f9 & 6544 & 19 & 0.6 & 47.5 & 6.8 & 5.3 & 1.3 & 0.9 \\
\hline f 437 & 6545 & 22 & 0.5 & 40.9 & 4.5 & 1.4 & 2.0 & 2.0 \\
\hline F363 & 6550 & 22 & 0.6 & 63.4 & 1.4 & 1.4 & 0.9 & 0.7 \\
\hline M717 & 7555 & 18 & 0.6 & 36.8 & 6.2 & 4.6 & 0.8 & 0.9 \\
\hline F320B & 7876 & 9 & 0.5 & 60.6 & 13.7 & 13.7 & 1.0 & 0.9 \\
\hline F795 & $81 B 60$ & 25 & 0.6 & 53.8 & 1.9 & 1.3 & 0.4 & 0.06 \\
\hline $\mathrm{M} 255 \mathrm{~A}$ & 8285 & 9 & 0.4 & 42.9 & 0.6 & 0.7 & 1.5 & 1.2 \\
\hline F523 & 8290 & 24 & 0.4 & 41.3 & 2.5 & 0.6 & 0.5 & 0.03 \\
\hline F904 & 8487 & 25 & 0.3 & 35.3 & 3.6 & 2.1 & 0.5 & 0.2 \\
\hline F922 & 8825 & 5 & 0.3 & 51.0 & 4.9 & 4 & 0.3 & 0.3 \\
\hline F73 & $9089-9520$ & 14 & 0.6 & 55.5 & 1.5 & 1.7 & 0.9 & 0.7 \\
\hline \multirow[t]{3}{*}{ F844 } & $9243-9645$ & 22 & 0.4 & 53.4 & 0.6 & 0.3 & 0.6 & 0.3 \\
\hline & \multicolumn{2}{|c|}{ Mean or Median*: } & $0.4(0.3)$ & $50.2(24.3)$ & $1.1(3.3)$ & $0.03(0.03-1.1)^{*}$ & $0.2(0.4)$ & $0.03(0.03-0.3)^{*}$ \\
\hline & \multicolumn{2}{|c|}{ Availability Mean: } & $0.8(0.5)$ & $33.1(7.5)$ & NA & NA & NA & NA \\
\hline \multicolumn{2}{|c|}{ Non-transmittered frogs } & 204 & $0.5(0.3)$ & $57.7(20.6)$ & $0.6(0.8)$ & $0.3(0.03-0.8)^{*}$ & $0.8(1.0)$ & $0.6(0.03-0.03)^{*}$ \\
\hline
\end{tabular}


TABLE 8. Summary of percent use during daytime of upland (beyond the top of the bank), farther than $4.5 \mathrm{~m}$ from stream, cover-types within $0.8 \mathrm{~m}$ radius of each transmittered frog during rain events in late October to mid December 2012. For each frog, the most used microhabitat feature is bolded and boxed; the second most used microhabitat feature is bolded and underlined; the third most used microhabitat feature is underlined.

\begin{tabular}{|c|c|c|c|c|c|c|c|c|c|c|c|}
\hline \multirow[b]{2}{*}{ Frog } & \multirow[b]{2}{*}{$\begin{array}{l}\text { Number of } \\
\text { Observations }\end{array}$} & \multirow[b]{2}{*}{$\begin{array}{c}\text { Mean } \\
\text { Distance } \\
\text { from } \\
\text { Water } \\
\text { (m) }\end{array}$} & \multicolumn{9}{|c|}{ Upland Ground Cover } \\
\hline & & & $\begin{array}{l}\underset{0}{0} \\
\stackrel{0}{0}\end{array}$ & 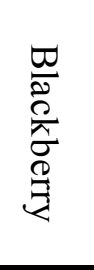 & 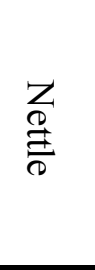 & $\bigcap_{\substack{0 \\
\infty \\
\infty}}$ & 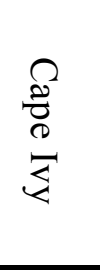 & 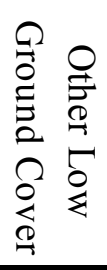 & 苛 & 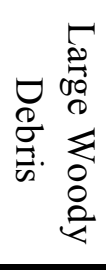 & 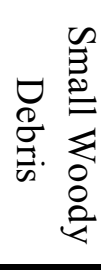 \\
\hline m 590 & 1 & 6.1 & 45.0 & $\underline{35.0}$ & $\underline{10.0}$ & 0.0 & 0.0 & 0.0 & 0.0 & 0.0 & $\underline{10.0}$ \\
\hline F117 & 1 & 4.6 & 0.0 & 60.0 & 0.0 & 0.0 & $\underline{40.0}$ & 0.0 & 0.0 & 0.0 & 0.0 \\
\hline F97 & 2 & 4.6 & $\underline{24.1}$ & 13.8 & 6.9 & 0.0 & 29.4 & 0.0 & 8.6 & 0.0 & $\underline{17.2}$ \\
\hline f 9 & 5 & 14.5 & $\underline{9.0}$ & 4.0 & 8.0 & 0.0 & 64.0 & $\underline{10.0}$ & 2.0 & 0.0 & 3.0 \\
\hline f 437 & 4 & 8.3 & $\underline{15.8}$ & 39.5 & 6.6 & 0.0 & $\underline{19.7}$ & 0.0 & 10.5 & 5.3 & 2.6 \\
\hline M717 & 4 & 13.4 & $\underline{24.7}$ & $\underline{13.6}$ & 0.0 & 8.6 & 8.6 & 7.4 & 1.2 & 4.9 & 31.0 \\
\hline F320B & 1 & 30.5 & $\underline{20.0}$ & 0.0 & $\underline{20.0}$ & 0.0 & 40.0 & 0.0 & $\underline{20.0}$ & 0.0 & 0.0 \\
\hline F795 & 3 & 21.8 & $\underline{20.5}$ & 45.3 & 0.0 & 13.7 & 2.7 & $\underline{17.8}$ & 0.0 & 0.0 & 0.0 \\
\hline F523 & 2 & 15.2 & $\underline{15.0}$ & 45.0 & 5.0 & 0.0 & $\underline{35.0}$ & 0.0 & 0.0 & 0.0 & 0.0 \\
\hline F904 & 2 & 6.9 & $\underline{10.5}$ & 31.6 & 0.0 & 31.6 & 26.3 & 0.0 & 0.0 & 0.0 & 0.0 \\
\hline F922 & 2 & 5.6 & 47.4 & $\underline{21.1}$ & 0.0 & 0.0 & 13.1 & 0.0 & 0.0 & 0.0 & $\underline{18.4}$ \\
\hline F73 & 1 & 5.2 & 55.0 & $\underline{45.0}$ & 0.0 & 0.0 & 0.0 & 0.0 & 0.0 & 0.0 & 0.0 \\
\hline F844 & 2 & 17.5 & $\underline{17.5}$ & 72.5 & $\underline{5.0}$ & 0.0 & $\underline{5.0}$ & 0.0 & 0.0 & 0.0 & 0.0 \\
\hline & & Mean: & 23.4 & 32.8 & 4.7 & 4.1 & 21.8 & 2.7 & 3.3 & 0.8 & 6.3 \\
\hline \multicolumn{3}{|c|}{ Availability Mean: } & 23.8 & 30.8 & 4.0 & 4.2 & 17.6 & 6.9 & 4.9 & 1.9 & 5.9 \\
\hline
\end{tabular}


TABLE 9. Summary of percent use during nighttime of upland (beyond the top of the bank), farther than $4.5 \mathrm{~m}$ from stream, cover-types within $0.8 \mathrm{~m}$ radius of each transmittered frog during rain events in late October to mid December 2012. For each frog, the most used microhabitat feature is bolded and boxed; the second most used microhabitat feature is bolded and underlined; the third most used microhabitat feature is underlined.

\begin{tabular}{|c|c|c|c|c|c|c|c|c|c|c|c|}
\hline \multirow[b]{2}{*}{ Frog } & \multirow[b]{2}{*}{$\begin{array}{l}\text { Number of } \\
\text { Observations }\end{array}$} & \multirow[b]{2}{*}{$\begin{array}{c}\text { Avg. } \\
\text { Distance } \\
\text { from } \\
\text { Water } \\
\text { (m) }\end{array}$} & \multicolumn{9}{|c|}{ Upland Ground Cover } \\
\hline & & & $\begin{array}{l}\underset{0}{0} \\
\stackrel{0}{0}\end{array}$ & 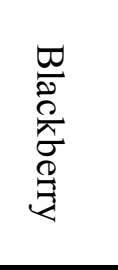 & $\underset{0}{\stackrel{Z}{E}}$ & $\bigcap_{\substack{0 \\
\infty \\
\infty}}$ & 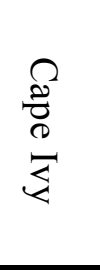 & 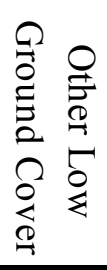 & 苛 & 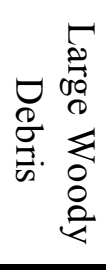 & 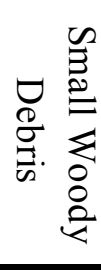 \\
\hline m 590 & 1 & 6.1 & 45.0 & $\underline{35.0}$ & $\underline{10.0}$ & 0.0 & 0.0 & 0.0 & 0.0 & 0.0 & $\underline{10.0}$ \\
\hline F117 & 1 & 4.6 & 0.0 & 60.0 & 0.0 & 0.0 & $\underline{40.0}$ & 0.0 & 0.0 & 0.0 & 0.0 \\
\hline F97 & 1 & 4.6 & 6.3 & $\underline{25.0}$ & $\underline{12.5}$ & 0.0 & 43.8 & 6.3 & 0.0 & 0.0 & 6.1 \\
\hline f 9 & 5 & 10.1 & 3.9 & 5.8 & 10.7 & 4.9 & 62.2 & 0.0 & $\underline{8.7}$ & 1.9 & 1.9 \\
\hline f 437 & 4 & 10.4 & 5.1 & 42.3 & 2.6 & 0.0 & $\underline{24.4}$ & 0.0 & 2.6 & $\underline{17.9}$ & 5.1 \\
\hline M717 & 5 & 17.1 & $\underline{31.3}$ & 7.3 & 0.0 & 0.0 & 37.5 & 0.0 & $\underline{13.5}$ & 4.1 & 6.3 \\
\hline F320B & 1 & 13.7 & 0.0 & 0.0 & 0.0 & 0.0 & 90.0 & 0.0 & 10.0 & 0.0 & 0.0 \\
\hline F795 & 2 & 6.9 & $\underline{10.0}$ & 82.5 & $\underline{5.0}$ & 0.0 & 2.5 & 0.0 & 0.0 & 0.0 & 0.0 \\
\hline F523 & 2 & 5.2 & $\underline{10.5}$ & 47.4 & 5.3 & 0.0 & $\underline{36.8}$ & 0.0 & 0.0 & 0.0 & 0.0 \\
\hline F904 & 2 & 6.9 & 5.0 & 5.0 & $\underline{22.5}$ & $\underline{30.0}$ & 37.5 & 0.0 & 0.0 & 0.0 & 0.0 \\
\hline F922 & 2 & 6.4 & $\underline{32.5}$ & $\underline{22.5}$ & 2.5 & 0.0 & 37.5 & 5.0 & 0.0 & 0.0 & 0.0 \\
\hline F73 & 1 & 2.4 & 0.0 & 100.0 & 0.0 & 0.0 & 0.0 & 0.0 & 0.0 & 0.0 & 0.0 \\
\hline F844 & 2 & 16.8 & $\underline{11.8}$ & 58.8 & $\underline{11.8}$ & 0.0 & 5.9 & 0.0 & 5.9 & 0.0 & 5.8 \\
\hline & & Mean: & 12.4 & 37.8 & 6.4 & 2.7 & 32.2 & 0.9 & 3.1 & 1.8 & 2.7 \\
\hline \multicolumn{3}{|c|}{ Availability Mean: } & 23.8 & 30.8 & 4.0 & 4.2 & 17.6 & 6.9 & 4.9 & 1.9 & 5.9 \\
\hline
\end{tabular}

